\title{
Copper/graphene composites: a review
}

\author{
Paloma Hidalgo-Manrique ${ }^{1, *}$, Xianzhang Lei ${ }^{2}$, Ruoyu $\mathrm{Xu}^{2}$, Mingyu Zhou ${ }^{2}$, Ian A. Kinloch ${ }^{1}$, and \\ Robert J. Young ${ }^{1, \star}$ (D) \\ ${ }^{1}$ National Graphene Institute and School of Materials, University of Manchester, Oxford Road, Manchester M13 9PL, UK \\ ${ }^{2}$ Global Energy Interconnection Research Institute Europe GmbH, Berlin, Germany
}

Received: 9 January 2019

Accepted: 21 May 2019

Published online:

11 June 2019

(C) The Author(s) 2019

\begin{abstract}
Recent research upon the incorporation of graphene into copper matrix composites is reviewed in detail. An extensive account is given of the large number of processing methods that can be employed to prepare copper/graphene composites along with a description of the microstructures that may be produced. Processing routes that have been employed are described including powder methods, electrochemical processing, chemical vapour deposition, layer-by-layer processing, liquid metal infiltration among a number of others. The mechanical properties of the composites are described in detail along with an account of the structural factors that control mechanical behaviour. The mechanics and mechanisms of deformation are discussed, and the effect of factors such as the graphene content and the type of graphene used, along with processing conditions for the fabrication of the composites, is described. The functional properties of copper/graphene composites are also reviewed including their electrical and thermal properties, and tribological and corrosion behaviour. In each case, the effect of the graphene type and content, and processing conditions are also described. Finally, possible future applications of copper/graphene composites are discussed.
\end{abstract}

\section{Introduction}

Carbon nanotubes (CNTs) and graphene have exceptional mechanical and other physical properties, are so considered to be excellent nanofillers in composite materials, offering enormous potential for a wideranging variety of applications [1]. Until recently, CNTs were the dominant carbon nanofillers used in metal matrix composites (MMCs) with extensive experiments demonstrating that CNTs can provide a high degree of reinforcement of both mechanical and functional properties [2]. Compared with CNTs, graphene is considered easier to disperse into the matrices, as well as potentially being more cost-effective [3]. Moreover, graphene has similar intrinsic properties, but a larger surface area than CNTs, which may result in better transfer of its properties to the composite. Therefore, graphene represents a viable alternative to CNTs in MMCs for structural and functional applications, with existing work demonstrating already the vast potential of graphene-reinforced MMCs, including improved tensile strength, Young's modulus,

Address correspondence to E-mail: paloma.hidalgo-manrique@manchester.ac.uk; robert.young@manchester.ac.uk 
hardness, natural lubrication and electrical and thermal conductivities [1].

Since its first isolation, research on graphene-reinforced composites has mainly focused upon polymermatrix composites [4-7], with to date a relatively few, but expanding, number of studies on metal matrix composites [8-10]. The reasons for this are twofold [11]; firstly, metals are characterised by good mechanical, electrical and thermal properties, so the potential improvement in properties may be less than in the case of polymer-matrix composites. Secondly, the technological difficulties in processing graphenereinforced MMCs are more pronounced than in the case of polymer-matrix composites. In particular, driven mainly by the strong van der Waals forces between aromatic rings, graphene is difficult to disperse uniformly into a metal matrix since it tends to form agglomerates in order to reduce its surface energy during processing [1]. In addition, obtaining an effective interfacial bonding is difficult due to the poor affinity of graphene to metals. In particular, copper $(\mathrm{Cu})$ does not wet graphene and covalent bonding is not possible as no reactions take place between $\mathrm{Cu}$ and graphene, which just leaves weak mechanical adhesion and van der Waals interactions [12]. Thus, the often wrinkled structure of graphene could play an important role in enhancing the mechanical interlocking between the graphene and $\mathrm{Cu}$, which in turn leads to a better load transfer [13]. A final challenge is that graphene can easily become damaged during the harsh fabrication conditions (i.e. high temperature and high pressure) usually employed to produce MMCs, weakening its intrinsic properties [1]. Thus, a key challenge in producing good graphene MMCs is their fabrication, which usually relies on powder metallurgy routes.

Copper and its alloys have been employed widely as structural materials in engineering applications due to their excellent thermal and electrical conductivities and chemical stability [14]. However, they exhibit relatively poor mechanical properties, especially at elevated temperature, that greatly limits their uses. Since the rapid developments in machinery, electronic, transport and other industries highly demand $\mathrm{Cu}$ and $\mathrm{Cu}$ alloys with both excellent conductive properties and good mechanical properties, the enhancement of their mechanical performance is increasingly required. The most effective strategy to achieve superior strength is the introduction of secondary phases in $\mathrm{Cu}$ and its alloys to fabricate $\mathrm{Cu}$ matrix composites
(CMCs) [15-18]. Moreover, the composite approach is essentially the only way to enhance the Young's modulus of metals and alloys. The reinforcements used conventionally in $\mathrm{Cu}$ matrices, such as oxides or carbide particles, have resulted in a considerable improvement of the mechanical and tribological properties, but at the expense of a decline of the electrical and thermal conductivities. However, as the relatively short number of studies on $\mathrm{Cu}$ /graphene composites show, by using graphene as the filler one can improve the mechanical properties of $\mathrm{Cu}$, while maintaining good thermal and electrical properties [12, 19-74], thereby obtaining CMCs with good structural-functional integration.

Speciality $\mathrm{Cu}$ alloys that could benefit from graphene additions are the copper-tungsten $(\mathrm{CuW})$ or tungstencopper $(\mathrm{WCu})$ materials. As $\mathrm{Cu}$ and $\mathrm{W}$ are not mutually soluble, these materials are composed of one metal dispersed in a matrix of the other [75-77]. Therefore, they are actually MMCs or pseudo-alloys of $\mathrm{Cu}$ and $\mathrm{W}$ rather than true alloys. They combine the outstanding thermal and electrical conductivities of $\mathrm{Cu}$ with the high arc erosion and low coefficient of thermal expansion of $\mathrm{W}$, the resulting properties depending on the exact composition. Commonly used tungsten-copper mixtures, containing 10-50 $\mathrm{wt} \% \mathrm{Cu}$, have applications in welding electrodes, high voltage electrical contacts and heat sinks. As the continuous development of switches, relays, connectors and circuit breakers demands that contact materials bear ultra-high voltage and larger capability, traditional WCu contacts cannot fully fulfil their requirements anymore [62]. It has been observed that the addition of multi-walled carbon nanotubes (MWCNTs) into WCu significantly enhances the thermal conductivity of the matrix [78]. Moreover, $\mathrm{WCu}$ /graphene composites have been observed to have improved arc erosion resistance [62].

Different microstructures for $\mathrm{Cu}$ /graphene composites have been reported in the literature. The most common microstructures are particulate, where graphene particles are embedded in a $\mathrm{Cu}$ matrix and layered composites, where the $\mathrm{Cu}$ and graphene are arranged in alternating layers. However, more sophisticated configurations such as the bio-inspired, nacre-mimicking composites have also been reported [41, 44, 45, 47, 58, 74].

The aim of this review is to examine the processing-microstructure-properties relationship in the different kinds of $\mathrm{Cu}$ /graphene composites. In particular, the current fabrication techniques will be 
overviewed and the effect of the processing route as well as of the graphene derivative and content on the mechanical, thermal, electrical, tribological and corrosion properties will be addressed. Finally, in the light of the properties obtained, an assessment of the potential applications of these CMCs will follow.

\section{Graphene}

Graphene, a single layer of covalently bonded $\mathrm{sp}^{2}$ hybrised carbon atoms, arranged in a two-dimensional, hexagonal lattice, has attracted significant attention as a nanofiller due to its exceptional electrical $\left(1.5 \times 10^{4} \mathrm{~cm}^{2} / \mathrm{Vs},[79]\right)$, thermal $\left(5 \times 10^{3} \mathrm{~W} /\right.$ $\mathrm{mK},[80])$ and mechanical (1 TPa Young's modulus and $130 \mathrm{GPa}$ tensile strength, [81]) properties. It was first isolated in 2004 by Geim and Novoselov by mechanical exfoliation of graphite crystals using an adhesive tape method [79], and their work was honoured with the 2010 Nobel Prize in Physics. However, while mechanical exfoliation still produces some of the highest quality crystals, the low productivity of this process makes it unsuitable for largescale technological applications. In this respect, many approaches for synthesising graphene in large quantities have been developed, including chemical vapour deposition (CVD) of graphene on metal carbides or metal surfaces [82] and wet chemical synthesis of graphene oxides followed by reduction [5].

The chemical vapour deposition approach involves the growth of graphene on metal carbides or metallic substrates by dissolution of hydrocarbons at high temperature [82]. Dissolved carbon atoms then segregate to the carbide or metal surface to form thin graphitic layers as the substrate temperature cools down. The chemical vapour deposition process allows the synthesis of large area graphene films that are particularly suitable for microelectronic device applications, but inappropriate for reinforcing composite purposes, mainly because due its hydrophobic nature, it is very difficult to disperse on metal matrices.

Graphene in large quantities has been subsequently produced by using ultrasonic and shear energy to break apart graphite into its constituent layers. Success has been found to depend on matching the surface energies of the graphene and the solvent, either through choice of solvent or using surfactants [83]. Alternatively, electrochemical intercalation can be used to peel individual layers of graphite away [84]. Graphene nanoplatelets (GNPs), consisting of 10-30 layers of graphene, are less expensive and easier to produce than mono- or fewlayer graphene [83, 85]. GNPs are typically prepared by intercalation of acid molecules or alkali metals into the graphite gallery spaces, which causes a significant expansion of graphite [84]. Afterwards, expanded graphite can be further exfoliated into GNPs through sonication.

Graphene oxide sheets can be extracted from graphite oxide, which is typically prepared by the oxidation of graphite, mainly by the Hummers method [86]. As a result, graphite oxide is typically functionalized with epoxide and hydroxyl groups on its basal plane and carboxyl groups at its edges [87, 88]. Graphite oxide can be then completely exfoliated to produce aqueous colloidal suspensions of graphene oxide (GO) sheets by sonication [89]. Graphene oxide is frequently used as the precursor for the fabrication of MMCs since the hydroxyl and epoxy functional groups make it much easier to disperse than pristine graphene. Graphene oxide can be chemically or thermally reduced to partly restore the graphene structure to some extent [89]. This gives rise to reduced graphene oxide (RGO), which is also used as the additive in MMCs.

It is worth noting that the oxygen atoms on the surface of graphene in the GO and the RGO not only facilitate the graphene dispersion into the $\mathrm{Cu}$ matrices, but also enhance the $\mathrm{Cu} /$ graphene binding, which is relatively weak [90-97]. However, these oxygen functional groups adversely affect the mechanical and physical properties of graphene. A study on the interaction between $\mathrm{Cu}$ and the pristine, atomic oxygen functionalized and boron- or nitrogendoped graphene by density functional theory calculation [98] revealed that the boron-doping effect is comparable or even better than the chemical bridging effect of oxygen. Moreover, it has been reported that boron-doped graphene exhibits higher electrical conductivity than pristine graphene [99] and its mechanical properties are similar to those of pristine graphene [100]. This provides a promising scheme of introducing boron-doped graphene instead of GO or RGO to prepare CMCs with excellent mechanical and physical properties.

\section{Springer}




\section{Processing}

A variety of processing techniques have been developed over the last 5 years in an effort to optimise the structure and properties of the newly emerging $\mathrm{Cu} /$ graphene composites. Irrespectively of the technique, the main challenges are always the attainment of a homogeneous dispersion of graphene in the matrix, the formation of a strong interfacial bonding and the retention of the structural stability of graphene. Powder metallurgy [12, 27-29, 32, 36, 38, 40, $46,47,49,51-53,55,57,60,63-66,68-70,73,101-104]$ and electrochemical deposition [19-21, 23, 24, 31, $33-35,39,43,45,48,50,54,67,71,72,74,105-114]$ are by far the most extensively applied processing route for such composites. However, other processing techniques employed include CVD [22, 26, 30, 42, 44, 53, 56, 58], cold spraying [115], layer-by-layer assembly [19, 25], metal infiltration [61, 62], preform impregnation [41] and accumulative roll bonding [37].

\section{Powder metallurgy (PM)}

Powder metallurgy is a very versatile process for manufacturing of composites with graphene due to its simplicity, flexibility and near-shape capability [1]. The process basically involves mixing graphene with raw metallic powders to prepare the composite powders followed by their consolidation into a bulk shape. This last step comprises the compaction of the composite process and/or densification processes such as sintering, pressing and/or rolling [1, 2]. The raw metallic powders used tend to be pure $\mathrm{Cu}$ powders or $\mathrm{Cu}$ alloys powders, consisting of atomised $\mathrm{Cu}$ powders mixed with powders of the alloying elements [116].

\section{Mixing}

The composite powders can be prepared by simple mixing techniques including mechanical stirring, magnetic stirring, sonication and vortex mixing $[28,29,32,47,49,51,52,55,57,60,63,65$, $66,68-70,73,103,104]$. However, high-energy processes such as ball milling (BM) or mechanical alloying (MA) have been also employed [12, 27, 28, 36, 38, 40, 53, 60, 61, 64, 101, 102]. Mechanical alloying is the solid-state processing of powder materials which is often used to produce alloys and composites that are difficult to obtain from conventional melting and casting techniques [1]. The process of MA starts with mixing graphene with the metallic powders in the desired proportion and then loading the powder mix into a mill (shaker mill, planetary mill or attritor) along with the grinding medium (generally steel balls) [116]. The mix is milled for the desired length of time, usually in a protective atmosphere to prevent $\mathrm{Cu}$ oxidation. During mixing, the impacted powders undergo repeating fracture, deformation and welding processes, which leads to the intimate mixing of the constituent powder particles on an atomic scale [1]. The total milling energy can be tailored by varying the charge ratio (the ratio of the weight of balls to the powder), ball mill design, milling atmosphere, time, speed and temperature. In certain cases, a process control agent (PCA), such as stearic acid or petroleum ether, is added to the powder mixtures to prevent excessive sticking and agglomeration of $\mathrm{Cu}$ powders during milling $[12,28,36,60]$. The PCA adsorbs on the surface of the powder particles and minimises cold welding between impacted particles, thereby preventing agglomeration [1]. Moreover, mixing techniques such as mechanical stirring, magnetic stirring and sonication and, occasionally, BM are performed in certain organic solvents (e.g. ethanol, acetone, etc.), which hinders the agglomeration of graphene into clusters. The solvents must be then evaporated to obtain dry composite powders before compaction and/or consolidation. For this purpose, vacuumdrying, air-drying and rotary evaporation are commonly used, although other less common techniques such freeze-drying or vacuum infiltration have been also employed.

Mechanical alloying can produce composites with finer microstructures and a better distribution of graphene in the $\mathrm{Cu}$ matrix [1]. However, the processing steps must be handled with care in order to retain the structural integrity of graphene. Yue et al. [60] reported that with increase in BM time the size of the composite powders decreases and the dispersion of graphene improves, but the damage of the graphene intrinsic structure inevitably increases. Figure 1 shows SEM micrographs of $\mathrm{Cu}-0.5 \mathrm{wt} \%$ GO powders after $\mathrm{BM}$ for different times varying from $1 \mathrm{~h}$ to $7 \mathrm{~h}$. It can be seen that the shape of the $\mathrm{Cu} / \mathrm{GO}$ powders undergoes a change from flake-like to more granular morphology with increase in BM time due to the shearing effect of the balls (Fig. 1) [60]. 

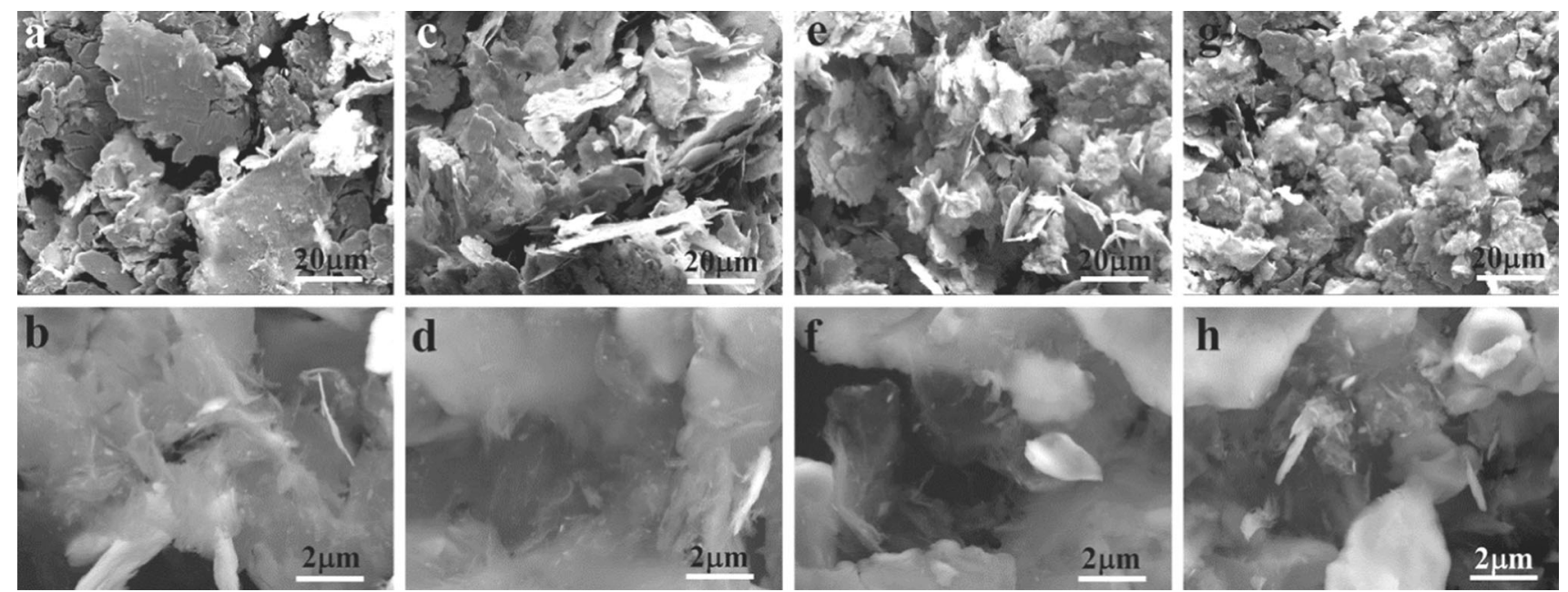

Figure 1 SEM images of Cu- 0.5 wt $\%$ GO powder after ball milling for $\mathbf{a}, \mathbf{b} 1 \mathrm{~h}, \mathbf{c}, \mathbf{d} 3 \mathrm{~h}, \mathbf{e}, \mathbf{f} 5 \mathrm{~h}$ and $\mathbf{g}, \mathbf{h} 7 \mathrm{~h}$. Reproduced with permission from [60].

Figure 2 displays Raman spectra of the composite powders after BM for different times [60]. These spectra show the typical D and G of the GO nanosheets located at around 1349 and $1595 \mathrm{~cm}^{-1}$, respectively. It can be seen that the ratio of $I_{\mathrm{D}} / I_{\mathrm{G}}$ increases from 0.84 to 1.42 with increase in BM time, indicating that the degree of damage of the GO increases with increase in BM time. Additionally, Cui et al. [27] found, for CMCs reinforced with GNPs, that the higher the milling speed, the higher the degree of exfoliation of GNPs. Nevertheless, the $I_{\mathrm{D}} /$ $I_{\mathrm{G}}$ values increased with increase in the milling speed, indicating that the degree of structural damage of graphene also increases with increase in the speed of BM. Thus, the BM conditions need to be balanced to obtain a uniform dispersion of fine graphene particles in $\mathrm{Cu}$ matrix while reducing structural damage to the graphene [60].

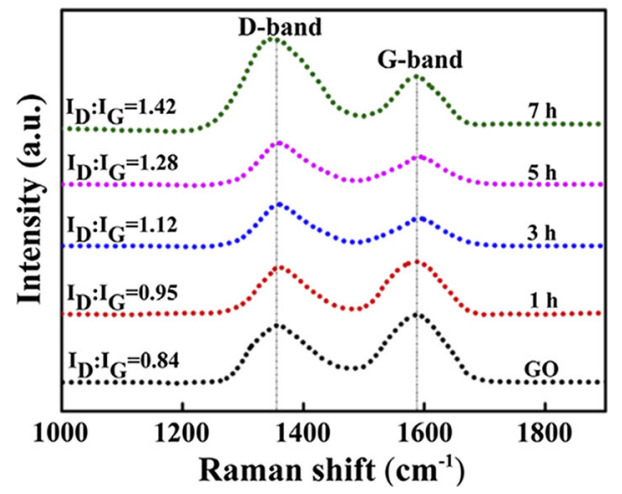

Figure 2 Raman spectra of $\mathrm{Cu}-0.5 \mathrm{wt} \% \mathrm{GO}$ powder after ball milling for different times. Reproduced with permission from [60].
Realising that the most critical issues in processing graphene-reinforced MMCs are the dispersion of graphene and the interfacial bond strength between the graphene and the matrix, many researchers have adopted modified steps in their approach [2]. Gao et al. [47] coated $\mathrm{Cu}$ powders with hexadecyl trimethyl ammonium bromide (CTAB), a cationic surface agent, to obtain a positive surface charge. The results showed that GO, with a negative charge, is adsorbed on the surface of CTAB coated $\mathrm{Cu}$ powder, realising the homogeneous dispersion of graphene in the CMCs [47]. A schematic of the fabrication process of $\mathrm{Cu}$ /graphene composites following this approach is given in Fig. 3.

\section{Consolidation}

Most researchers have used sintering to consolidate the composite powders. In a few works, green compacts, generally prepared using a press or a testing machine, were sintered in a conventional $[38,52,57$, $63,65,73,104]$ or microwave furnace [57]. The major advantage of the microwave sintering over conventional sintering is that it provides rapid heating, resulting in much finer grain sizes. A larger number of researchers have used hot pressing (HP) consolidation of powders or compacts $[12,36,47,52,60,63$, $64,102,103]$. This is a high-pressure consolidation technique working at a temperature high enough to induce sintering. It is conducted by placing either the composite powders or the composite compacts into a suitable die, typically graphite, and applying uniaxial 


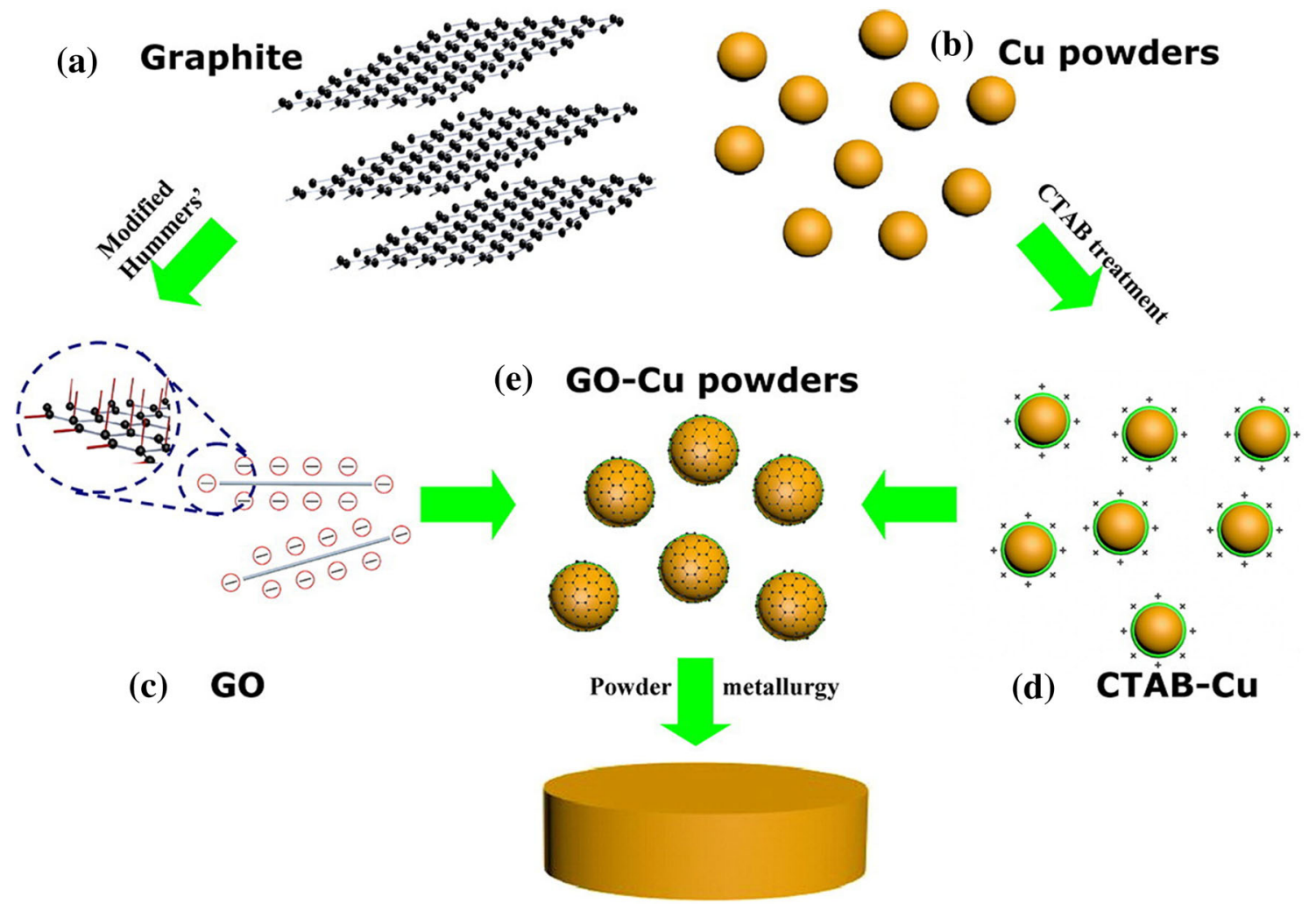

(f) $\mathrm{Gr} / \mathrm{Cu}$ composite

Figure 3 Schematic of the fabrication process of $\mathrm{Cu} /$ graphene composites using hexadecyl trimethyl ammonium bromide (CTAB) modified $\mathrm{Cu}$ powders. Reproduced with permission from [47].

pressure, while the entire system is held at an elevated temperature. So, by hot pressing, consolidation is achieved by the simultaneous application of heat and pressure. Spark plasma sintering (SPS), a comparatively new sintering technique, has also been explored [27, 29, 32, 40, 49, 51, 53, 55, 66, 68-70, 101]. In this process, a pulsed direct current is passed through a graphite die where the powder mixtures or compacts are pressed uniaxially [1]. When a spark discharge appears at the contact point between the particles of a material, a local high-temperature condition is created, resulting in rapid heating and hence increasing the sintering rate [1], so that grain growth, graphene agglomeration and thermal decomposition of graphene can be minimised during consolidation [23]. Efficient densification can be achieved by applying a combination of spark impact pressure, joule heating and electrical field diffusion [32, 117].

Kim et al. [28] rolled composite powders to achieve a better density and distribution of graphene in a $\mathrm{Cu}$ matrix; the powders were balled milled, followed by encapsulation in a pure $\mathrm{Cu}$ tube and degasification, and then subjected to equal speed rolling (ESR) or conventional rolling and to high-ratio differential speed rolling (HRDSR). All the ESR- and HRDSRprocessed $\mathrm{Cu}$ and $\mathrm{Cu}$ composites showed high densities between 98.8 and $99.4 \%$, indicating that almost full densification was obtained after rolling.

\section{Electrochemical deposition}

Traditional processes of PM cannot always effectively prevent agglomeration of graphene in the metal matrix because graphene is prone to segregate from the metal particles due its poor affinity to metal in the absence of any binding sites [23]. Thus, novel dispersion methods, such as electrochemical deposition, are needed. These techniques can be divided into electrodeposition and electroless deposition processes; both of which have been used for $\mathrm{Cu}$ /graphene fabrication. Electrodeposition, also known as electroplating, required the use of an electrochemical cell and a power source in which an applied current flows between the anode and cathode [1, 2]. The 


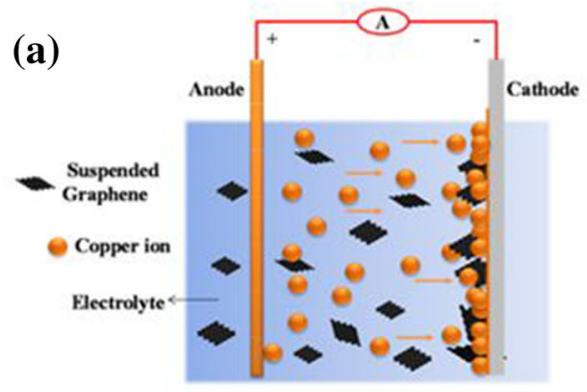

\section{(b) Direct Current Electrodeposition (c) Pulse Reverse Electrodeposition}

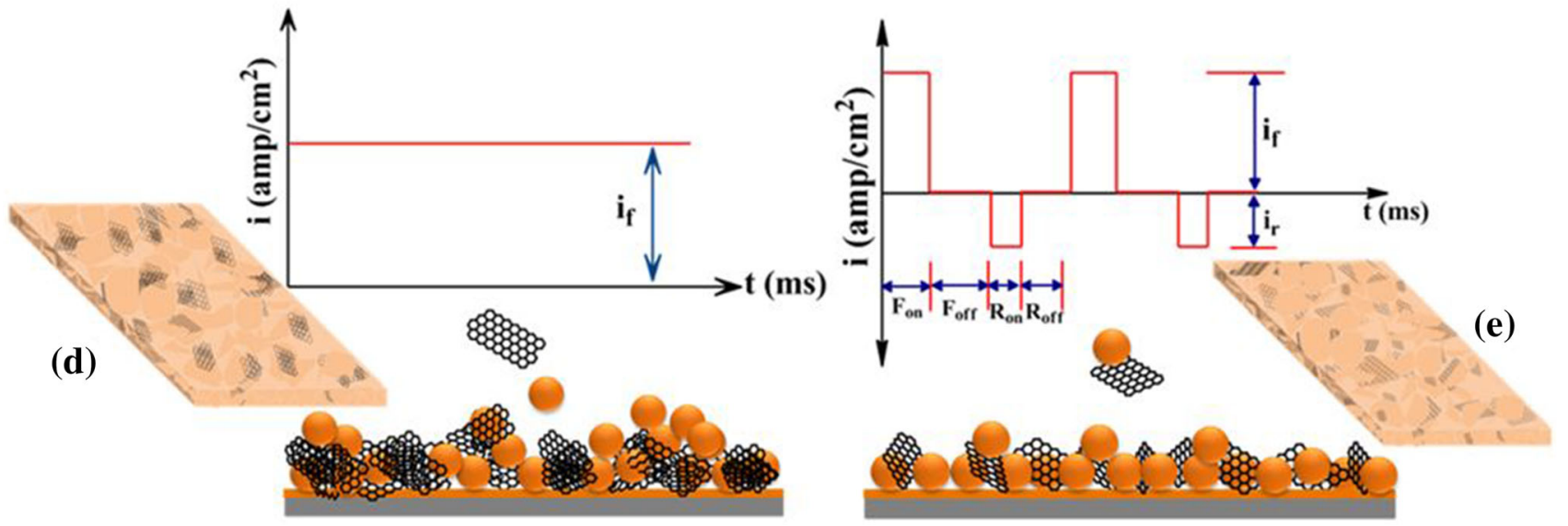

Figure 4 Experimental setup of electrodeposition (a) and schematic representation of the current waveforms and the co-deposition of $\mathrm{Cu}$ and graphene by direct (b) and pulse reverse (c) current. Reproduced with permission from [31].

composite film or coating is deposited onto the cathode surface. In contrast, the second technique, known as electroless plating, does not require electricity for the occurrence of reactions in the bath $[1,2]$. This is basically a chemical process, in which thermochemical decomposition of metallic salts takes place in the bath to release metallic ions to form a composite with graphene [1].

\section{Electrodeposition}

The electrodeposition technique is an easy, cost-effective and scalable method to fabricate $\mathrm{Cu}$ /graphene composite coatings [72, 112-114] and foils or films [19-21, 24, 31, 33, 48]. In addition, electrodeposition being a low temperature process preserves the properties of graphene during the preparation of the composites, unlike in the conventional sintering processes, which may damage graphene because they may involve temperatures higher than its decomposition temperature $\left(>600{ }^{\circ} \mathrm{C}\right)$ [31]. Electrodeposition takes place from a dispersion of graphene in an electrolytic bath consisting of copper sulphate as a source of $\mathrm{Cu}^{2+}$ ions, the graphene content in the $\mathrm{Cu}$ /graphene composites depending on the amount of dispersed graphene in the bath. To disperse graphene sheets uniformly into the electrolyte is one of the main challenges to synthesise graphene enhanced nanocomposites by electrodeposition [72]. Stirring $[24,31,33,48,114]$ can be used to keep graphene in suspension during electrodeposition. Additions of anionic or polymeric surfactants have also been used to improve the wettability of the substrate to be coated and to prevent agglomeration [31, 113, 114]. These additions may, however, introduce heterogeneous impurities, that weaken the interfacial bonding of graphene sheets and matrix, adversely affecting the mechanical and physical properties of the composite coatings. As an alternative, Mai et al. [72] proposed a surfactant-free colloidal solution comprising copper (II)-ethylene diamine tetra acetic acid $\left(\left[\mathrm{Cu}{ }^{\mathrm{II}} \mathrm{EDTA}\right]^{2-}\right)$ complexes and GO sheets to prepare $\mathrm{Cu} / \mathrm{RGO}$ composites. The anionic complexes stably coexist with negatively charged GO sheets due to the 
electrostatic repulsion between them, facilitating the electrochemical reduction and the uniform dispersion of RGO sheets into the $\mathrm{Cu}$ matrix.

Both direct and pulse reverse current have been used by Pavithra et al. [31, 48] for electrodeposition of $\mathrm{Cu}$ /graphene nanocomposite films (Fig. 4). Pulse reverse (PR) is advantageous over direct current (DC) electrodeposition because it allows the optimisation of several key processing parameters including applied current, pulse duration and duty cycle that enables a smooth, highly dense, uniform deposit, while minimising hydrogen embrittlement. This in turn improves the properties of the deposited material. The forward pulse restricts the mass transfer and hence controls the grain size, whereas the reverse pulse minimises the dendritic morphology and helps in the removal of extended graphene and loosely adsorbed $\mathrm{Cu}$ or graphene, in addition to removal of entrapped hydrogen during each pulse. Furthermore, PR electrodeposition facilitates a uniform distribution of graphene sheets into the $\mathrm{Cu}$ matrix, where they spread around the grain boundaries to achieve an improved interface with the $\mathrm{Cu}$ throughout the composite.

In the case of DC electrodeposition, the deposition is rapid at the most active nucleation sites and, due to the continuous application of current, the continuous incorporation of graphene along with the $\mathrm{Cu}$ deposition results in a rough surface with graphene clusters in the matrix.

\section{Electroless deposition}

An electroless plating process consisting in situ chemical or thermal reduction has been used to manufacture graphene-metal nanoparticles (MNPs) hybrids $[29,32,35,50,55,64,66,105-107,110,111]$ or sandwich-like 2D Cu/RGO nanocomposites composed of continuous $\mathrm{Cu}$ layers on both sides of the central RGO [108]. Copper-nanoparticle/graphene composite powders fabricated by this technique were further consolidated by SPS to obtain bulk $\mathrm{Cu}$ /graphene composites [35] or used as such for different applications [105-107, 110, 111]. Graphene decorated with other metallic nanoparticles such as $\mathrm{Ag}$ or $\mathrm{Ni}$ was also fabricated and afterwards successfully introduced as fillers into $\mathrm{Cu}$ matrices by processing techniques such as PM routes or molecular level mixing (MLM) in order decrease the contact angle of $\mathrm{Cu}$ on graphene and thus to improve the wettability between graphene and the $\mathrm{Cu}$ matrix $[29,32,50,55,64,66]$. The fabrication of grapheneMNPs hybrids (Fig. 5) usually consists of the in situ nucleation of MNPs on the graphene sheets by reducing a mixture of $\mathrm{GO}$ and metallic ions. Metal ions prefer to nucleate at the sites of functional groups. For this reason, when GNPs are used as precursor materials, they are sensitised and activated before being decorated with the metallic particles $[50,55,66]$.

Another simple, but usually multi-step electroless plating technique, molecular level mixing (MLM),
Figure 5 Schematic of the preparation of GNPs decorated with Ni nanoparticles. Reproduced with permission from [29].
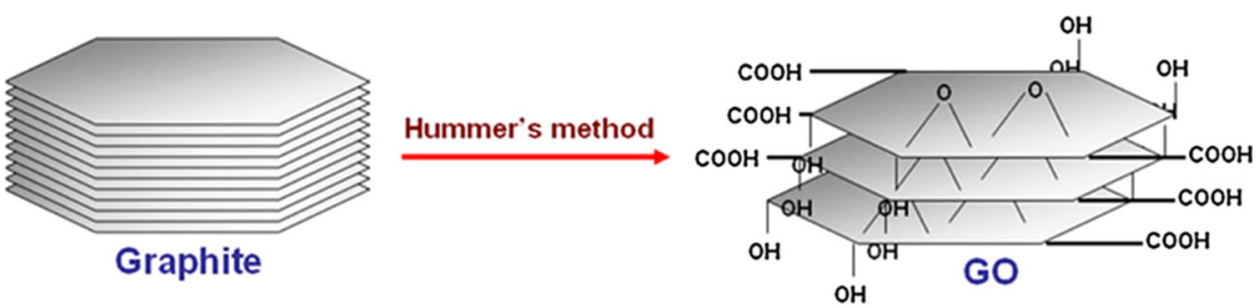

Hummer's method

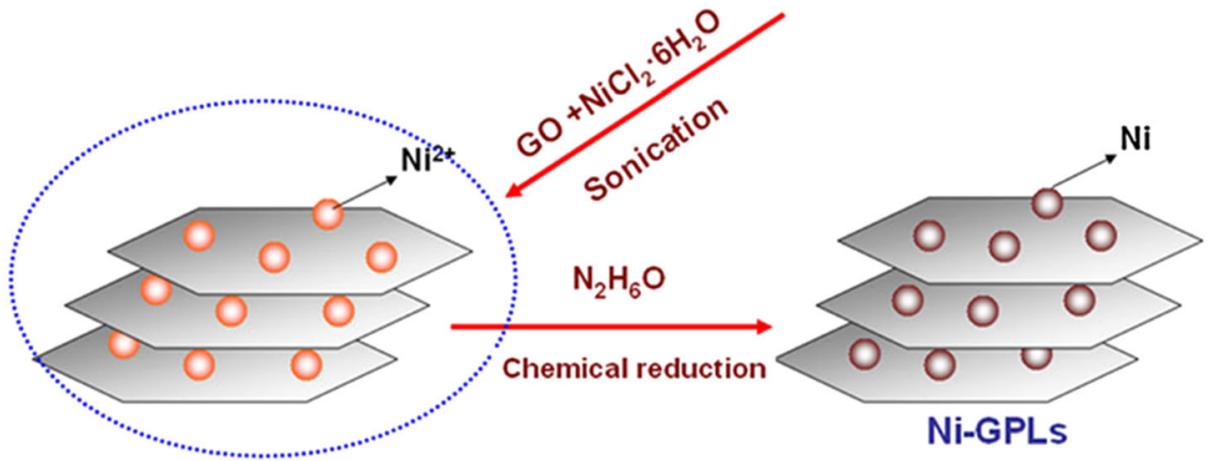



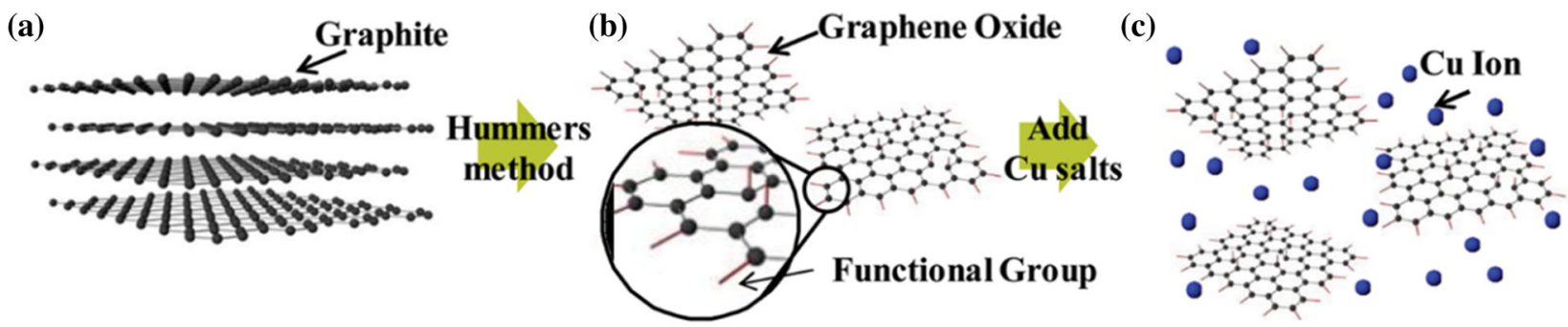

(d)

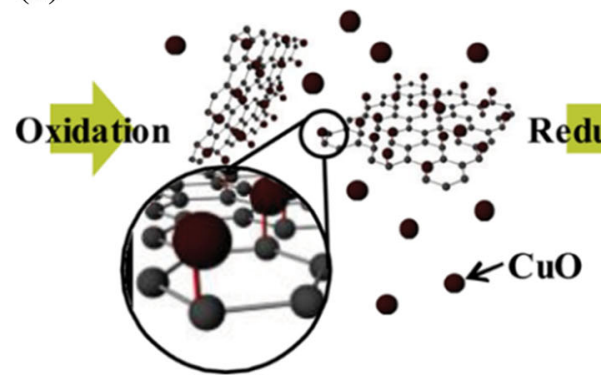

(e)

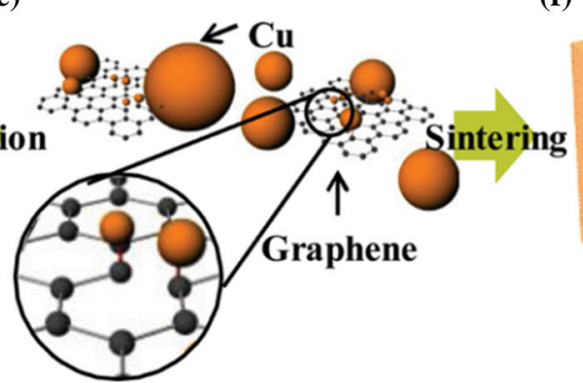

(f)

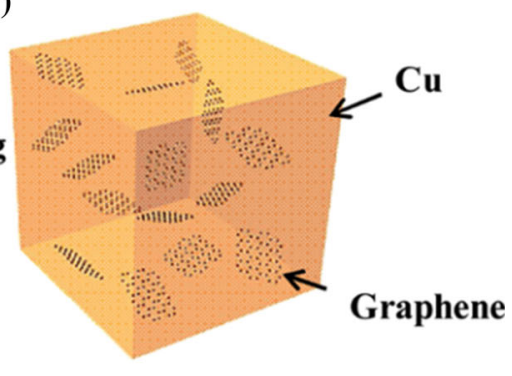

Figure 6 Schematic of fabrication process of $\mathrm{Cu} / \mathrm{RGO}$ nanocomposites by a molecular level mixing method. a Pristine graphite. b Graphene oxide obtained by the Hummers method.

has been used to fabricate $\mathrm{Cu}$ /graphene composite powders which are subsequently consolidated by SPS $[23,34,39,43,50,54,67,74,109]$. A schematic diagram of a fabrication process of $\mathrm{Cu} / \mathrm{RGO}$ nanocomposites by MLM is given in Fig. 6 [23]. Firstly, GO and $\mathrm{Cu}$ ions are homogeneously mixed in deionised water. Chemical bonds are then formed between the functional groups of $\mathrm{GO}$ and the $\mathrm{Cu}$ ions. Finally, $\mathrm{Cu} / \mathrm{GO}$ nanocomposites are thermally reduced in $\mathrm{H}_{2}$, the as-reduced $\mathrm{Cu} / \mathrm{RGO}$ composite powders being subsequently consolidated by SPS. However, additional steps involving the generation of copper oxides $\left(\mathrm{CuO}\right.$ and $\left.\mathrm{Cu}_{2} \mathrm{O}\right)$ as intermediate products are usually required. Graphene-MNPs hybrids or GNPs can be also used as raw material [34, 43, 50, 54, 67]. However, since formation of $\mathrm{Cu}-\mathrm{O}-\mathrm{C}$ chemical bonds (whose origin is in the reaction between the carboxyl or hydroxyl groups and $\mathrm{Cu}$ ) plays a major role in the adsorption of graphene on the $\mathrm{Cu}$ surface, GNPs are usually sensitised and activated by a hydrochloric acid solution of $\mathrm{SnCl}_{2}$ and $\mathrm{PdCl}_{2}$, respectively, beforehand.

Figure 7 displays the evolution of the nanocomposite powders during the MLM and SPS process as proposed by Hwang et al. [23]. Figure 7a shows an atomic force microscopy (AFM) image of GO fabricated by the Hummers method. Figure $7 \mathrm{~b}$ shows that after mixing the GO and $\mathrm{Cu}$ salts, the GO layer was c Dispersion of $\mathrm{Cu}$ salt in $\mathrm{GO}$ solution. $\mathbf{d}$ Oxidation of $\mathrm{Cu}$ ions to $\mathrm{CuO}$ on graphene oxide. e Reduction of $\mathrm{CuO}$ and GO. $\mathbf{f}$ Sintering of the $\mathrm{Cu} / \mathrm{RGO}$ powders. Reproduced with permission from [23].

not agglomerated and was homogeneously mixed with the $\mathrm{Cu}$ ions. After oxidation, GO particles were fully covered with ellipsoidal $\mathrm{CuO}$ particles of about $500 \mathrm{~nm}$ in size (Fig. 7c). The $\mathrm{Cu} / \mathrm{RGO}$ nanocomposite powders obtained by $\mathrm{H}_{2}$ thermal treatment of $\mathrm{Cu} /$ $\mathrm{CuO}$ powders are shown in Fig. $7 \mathrm{~d}$. $\mathrm{CuO}$ particles that were formed on $\mathrm{GO}$ were reduced to form islands with average size of $30 \mathrm{~nm}$, while $\mathrm{CuO}$ particles that were formed without GO were reduced to form large $\mathrm{Cu}$ particles and connected to each other during the thermal treatment. The fine size of $\mathrm{Cu}$ particles on the RGO originated from the difficulty of $\mathrm{Cu}$ diffusion on the surface of RGOs. After consolidation by SPS, the RGO layers were dispersed homogeneously in the $\mathrm{Cu}$ matrix without further agglomeration (Fig. 7e). The Raman spectra in Fig. 7f illustrate the evolution of defects in GO and RGO. The $I_{\mathrm{D}} / I_{\mathrm{G}}$ ratio increased from 0.78 for $\mathrm{GO}$ to 0.81 for $\mathrm{Cu}^{2+} / \mathrm{GO}$, indicating an increase in defects in the GO structure after mixing with $\mathrm{Cu}$ ions. Graphene oxide with $\mathrm{Cu}$ ions could be more defective because the interaction of the $\mathrm{Cu}$ ions with the GO surface could damage the $\mathrm{sp}^{2}$ bonding network of the graphene further. The continuous, conformal coating of $\mathrm{CuO}$ on the GO flakes immediately after the oxidation process blocked the characteristic Raman signals of $\mathrm{GO}$ (i.e. $\mathrm{D}$ and $\mathrm{G}$ bands) from the $\mathrm{CuO} / \mathrm{GO}$ samples. The $I_{\mathrm{D}} / I_{\mathrm{G}}$ ratio of the $\mathrm{Cu} / \mathrm{RGO}$ nanocomposite 

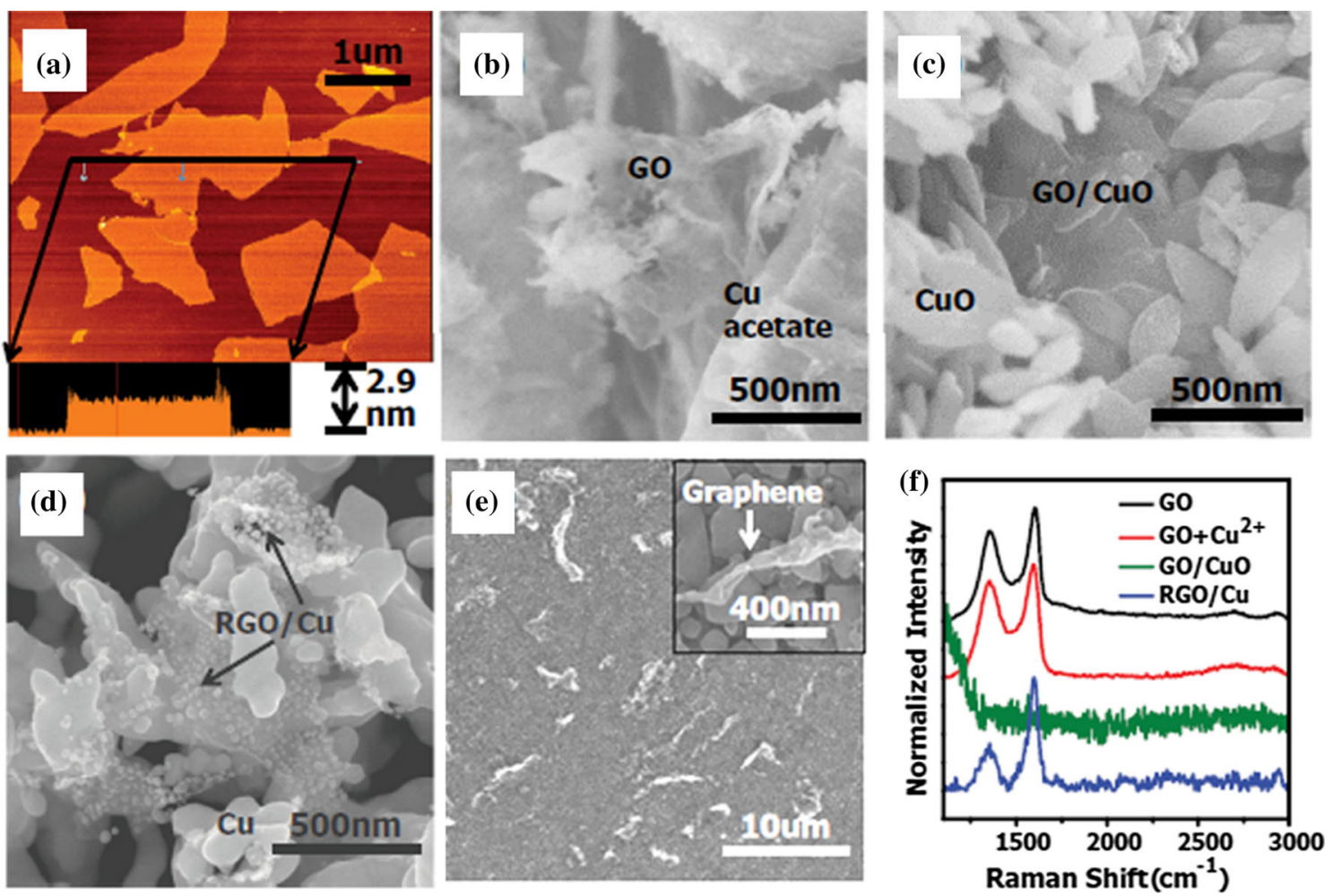

Figure 7 a AFM image of GO prepared using the Hummers method. SEM images of $\mathbf{b} \mathrm{Cu}^{2+}+\mathrm{GO}$ powders, $\mathbf{c} \mathrm{CuO} / \mathrm{GO}$ powders, $\mathbf{d ~ C u} / \mathrm{RGO}$ powders and $\mathbf{e} \mathrm{Cu} / \mathrm{RGO}$ bulk nanocomposite.

powders was markedly lower (i.e. 0.40) because the reduction process removed functional groups and partially recovered the graphene structure.

It is important to note that the reaction products, as well as their morphology, in a MLM process strongly depend on the reaction conditions, with the $\mathrm{pH}$ and the reaction temperature being the most critical factors. Yang et al. [71] carried out experiments at different $\mathrm{pH}$ values of 5.9, 6.6, 12.8 and 13.6, respectively. XRD patterns of the as-collected samples are given in Fig. 8a. It can be seen that the phase f Raman spectra of the GO and different nanocomposite powders. Reproduced with permission from [23].

constitution of the composite powders is $\mathrm{pH}$-sensitive. When the $\mathrm{pH}$ value is lower than 6.6, the diffraction peaks are assigned to the crystal planes of $\mathrm{Cu}_{2}(\mathrm{OH})_{3}$ Ac. However, once the $\mathrm{pH}$ value is increased to 12.8 , the major diffraction peaks match well with $\mathrm{Cu}(\mathrm{OH})_{2}$ and $\mathrm{CuO}$. Figure $8 \mathrm{~b}$, c shows the morphology change of the composite powders at carious $\mathrm{pH}$ values as indicated by SEM analysis. As shown in Fig. $8 \mathrm{~b}, \mathrm{Cu}_{2}(\mathrm{OH})_{3} \mathrm{Ac}$ is in the form of sheets of about $5 \mu \mathrm{m}$ in size. When $\mathrm{pH}$ value is increased to 12.8 and 13.6, the $\mathrm{Cu}_{2}(\mathrm{OH})_{3} \mathrm{Ac}$ sheets transform into
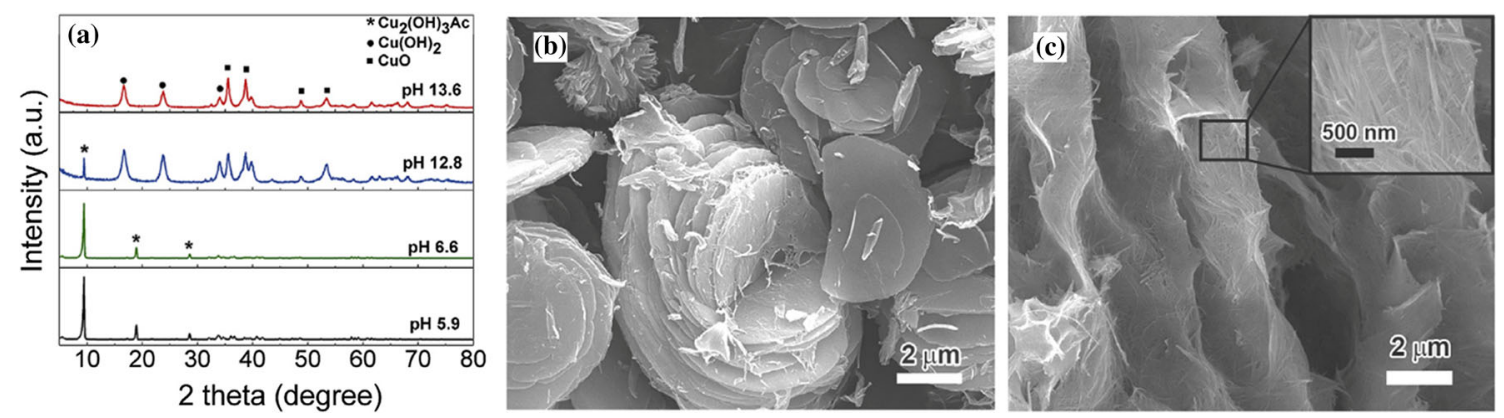

Figure 8 a XRD patterns of composite powders fabricated by MLM at different $\mathrm{pH}$ values. SEM images of the composite powders fabricated at $\mathbf{b} \mathrm{pH} 6.6$ and $\mathbf{c} \mathrm{pH}$ 13.6. Reproduced with permission from [71]. 


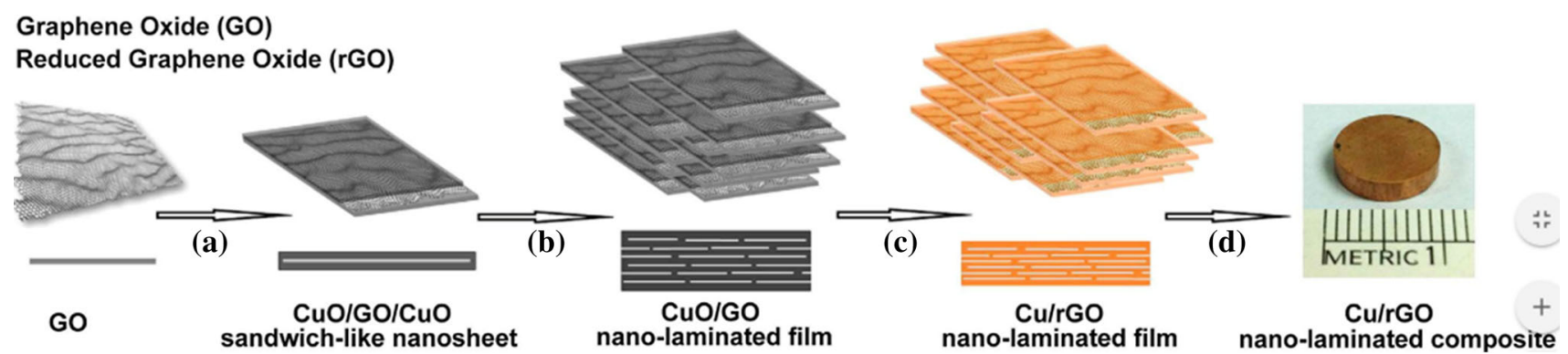

Figure 9 Schematic representation of the fabrication of $\mathrm{Cu} / \mathrm{RGO}$ nano-laminated composites by assembling sandwich-like units. a Deposition of $\mathrm{CuO}$ on both sides of graphene oxide (GO) to form $\mathrm{CuO} / \mathrm{GO} / \mathrm{CuO}$ sandwich-like nanosheet. $\mathbf{b}$ Assembling sandwich-

$\mathrm{Cu}(\mathrm{OH})_{2}$ and $\mathrm{CuO}$ nanofibers (Fig. 8c). The nanofibers are uniformly dispersed on GO sheets with diameters of a few tens of nanometres. Most importantly, the edges of GO sheets can be easily observed and are distributed almost parallel to each other, which can be considered the ideal framework of micro-layered composites with nacre-inspired architecture [74]. Nacre is a natural inorganic/organic composite material that gains its toughness from a microstructure that consists of sheets of calcium carbonate separated by layers of elastic biopolymers.

A modified MLM process, comprising the selfassembly, reduction and consolidation of $\mathrm{CuO} / \mathrm{GO} /$ $\mathrm{CuO}$ or $2 \mathrm{D} \mathrm{Cu} / \mathrm{CuO}$ sandwich-like nanosheets, has been employed to fabricate multilayer $\mathrm{Cu}$ /graphene composites with a nacre-inspired architecture $[45,71,74]$. This process leads simultaneously to a uniform dispersion and high alignment of graphene in the metal matrices. An example of such processing technique is shown schematically in Fig. 9 [45]. First, GO is synthesised from natural graphite flakes by a modified Hummers method. In order to assist the dispersion of $\mathrm{GO}$ in aqueous media and direct the deposition of $\mathrm{CuO}$ on the surface of GO, surfactant sodium dodecyl sulphate (SDS) was chosen to adsorb electrostatically and self-assemble onto the surface of the GO. $\mathrm{Cu}$ cations were bound to the surfactant assembled onto the $\mathrm{GO}$, forming $\mathrm{CuO} / \mathrm{GO} / \mathrm{CuO}$ sandwich-like nanosheets in alkaline solution with the decomposition of the added urea in at elevated temperature. $\mathrm{CuO}$ was deposited on both sides of the GO (Fig. 9a) and prevented them from restacking. Subsequently, the bottom-up assembly of $\mathrm{CuO} / \mathrm{GO} /$ $\mathrm{CuO}$ sandwich-like nanosheets was carried out by vacuum filtering the parent solution (Fig. 9b). Afterwards, by reducing the assembled $\mathrm{CuO} / \mathrm{GO} / \mathrm{CuO}$ like nanosheet via vacuum filtration. c Reduction of $\mathrm{CuO} / \mathrm{GO}$ in $\mathrm{H}_{2} /$ Ar mixed atmosphere. d Stacking the $\mathrm{Cu} / \mathrm{RGO}$ films followed by hot pressing to obtain bulk composites. Reproduced with permission from [45].

films (Fig. 9c), $\mathrm{Cu} / \mathrm{RGO} / \mathrm{Cu}$ films were achieved. Finally, these films were stacked and consolidated by HP to produce bulk nano-laminated composites (Fig. 9d).

\section{Chemical vapour deposition (CVD)}

Most of the techniques commonly used to fabricate bulk $\mathrm{Cu}$ /graphene composites, including PM and MLM routes, consist of dispersing and combining 2D graphene on the surface of metal powders. This technique often fails to produce good dispersions of graphene into the matrix or good interfacial bonding and may even, as in the case of the BM technique, lead to the damage of the graphene structure. Hence, novel methods based on covering the $\mathrm{Cu}$ powders with graphene, mainly by CVD, followed by compaction and/or consolidation are being developed to fabricate bulk composites. These methods solve the above-mentioned disadvantages of other processing techniques and, in addition, can lead to a more ideal structure of graphene within the metal matrix.

Babul et al. [42] fabricated $\mathrm{Cu} / 3 \mathrm{D}$-graphene composites through the following steps: (1) fluidisation under gases containing hydrocarbons in a working chamber, (2) high-temperature decomposition of hydrocarbons that act as the carbon source and (3) nucleation and growth of carbon structures on the surface of the $\mathrm{Cu}$ powders. Afterwards, the composite powders obtained were consolidated by HP. However, the synthesis of graphene onto the $\mathrm{Cu}$ powders generally takes place by CVD. For example, graphene was synthesised on the surface of micronsized copper powder by CVD using ethylene as a carbon source in the temperature range from 700 to $940{ }^{\circ} \mathrm{C}[22,26]$. The composite powders synthesised 
Figure 10 Copper powder particles treated in the presence of ethylene at a $890{ }^{\circ} \mathrm{C}$ and b $940{ }^{\circ} \mathrm{C}$. Reproduced with permission from [22].
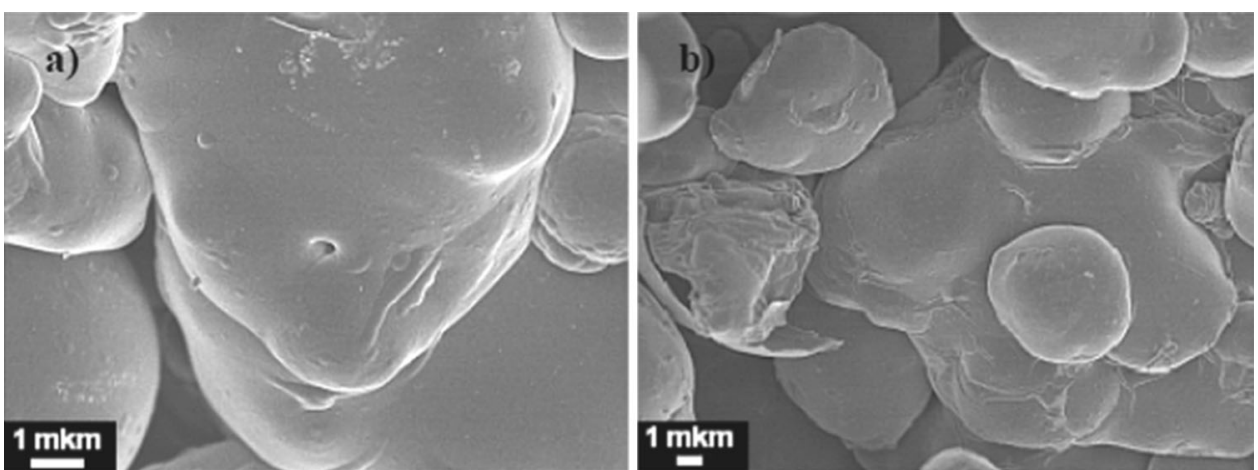

were then mixed with a certain amount of plain $\mathrm{Cu}$ particles, and, in order to obtain compact materials, the mixture was subjected to hot rolling in two stages to a total thickness reduction of $70 \%$. The bulk composites exhibited a grain size around $7 \mu \mathrm{m}$ elongated in the rolling direction with fine carbon layers located around the boundaries. SEM images of the $\mathrm{Cu}$ powder treated at 890 and $940{ }^{\circ} \mathrm{C}$ in the presence of ethylene are presented in Fig. 10. As seen from the images, the $\mathrm{Cu}$ particles are covered by a smooth layer of carbon.

Graphene has also been grown on the surface of the $\mathrm{Cu}$ powders by in situ CVD $[44,56,58]$. This way, $\mathrm{Cu}$ / 3D-graphene composites were fabricated through an approach involving $\mathrm{BM}$ of $\mathrm{Cu}$ powders with poly(methyl methacrylate) (PMMA) as a solid carbon source, in situ growth of graphene on the $\mathrm{Cu}$ powders by heating under $\mathrm{Ar}$ and $\mathrm{H}_{2}$ atmosphere and consolidation of the composite powders [56]. During the BM process, PMMA powders are transformed into extremely small particles and dispersed on the $\mathrm{Cu}$ powders. In addition, nacre-inspired $\mathrm{Cu}$ matrix nano-laminated composites were fabricated by a similar process comprising in situ growth of graphene on flaky metal powders after BM followed by self-assembly assembling and consolidation of the $\mathrm{Cu}$ flakes cladded with in situ grown graphene [44, 58] (Fig. 11).

\section{Layer-by-layer assembly}

This is a time-consuming, although very versatile method has been employed to produce different kinds and scales of multilayer $\mathrm{Cu}$ /graphene composite films. For example, it was used to fabricate
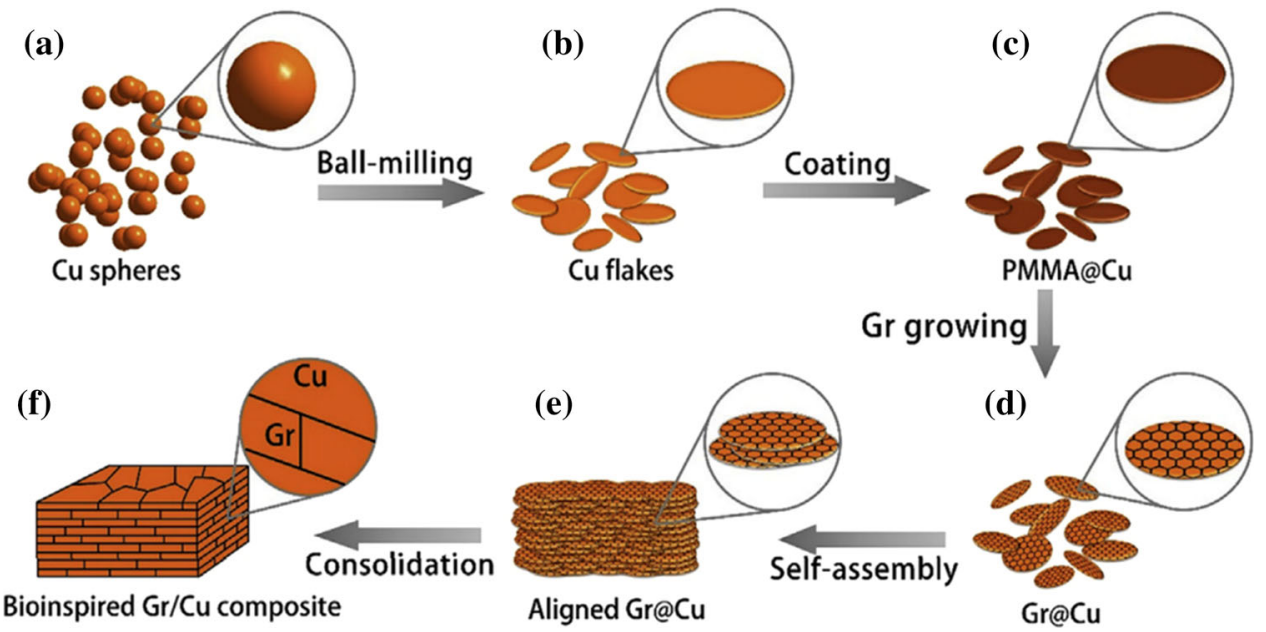

Figure 11 Schematic illustration of fabrication of $\mathrm{Cu} /$ graphene composite with nacre-inspired structure. Spherical $\mathrm{Cu}$ powder a was first transformed into $\mathrm{Cu}$ flake $\mathbf{b}$ by a ball-milling process. c The as-obtained $\mathrm{Cu}$ flakes were soaked in an anisole solution of PMMA and then dried in vacuum, forming a uniform PMMA film on the surface. $\mathbf{d}$ The PMMA-coating was used as carbon source for in situ growing graphene at elevated temperature. e The $\mathrm{Cu} /$ graphene composite powders were self-assembled into green compact by gravity because of its large aspect ratio. $\mathbf{f}$ A nacreinspired composite was finally obtained by a hot-pressing and a hot-rolling process. Reproduced with permission from [58]. 


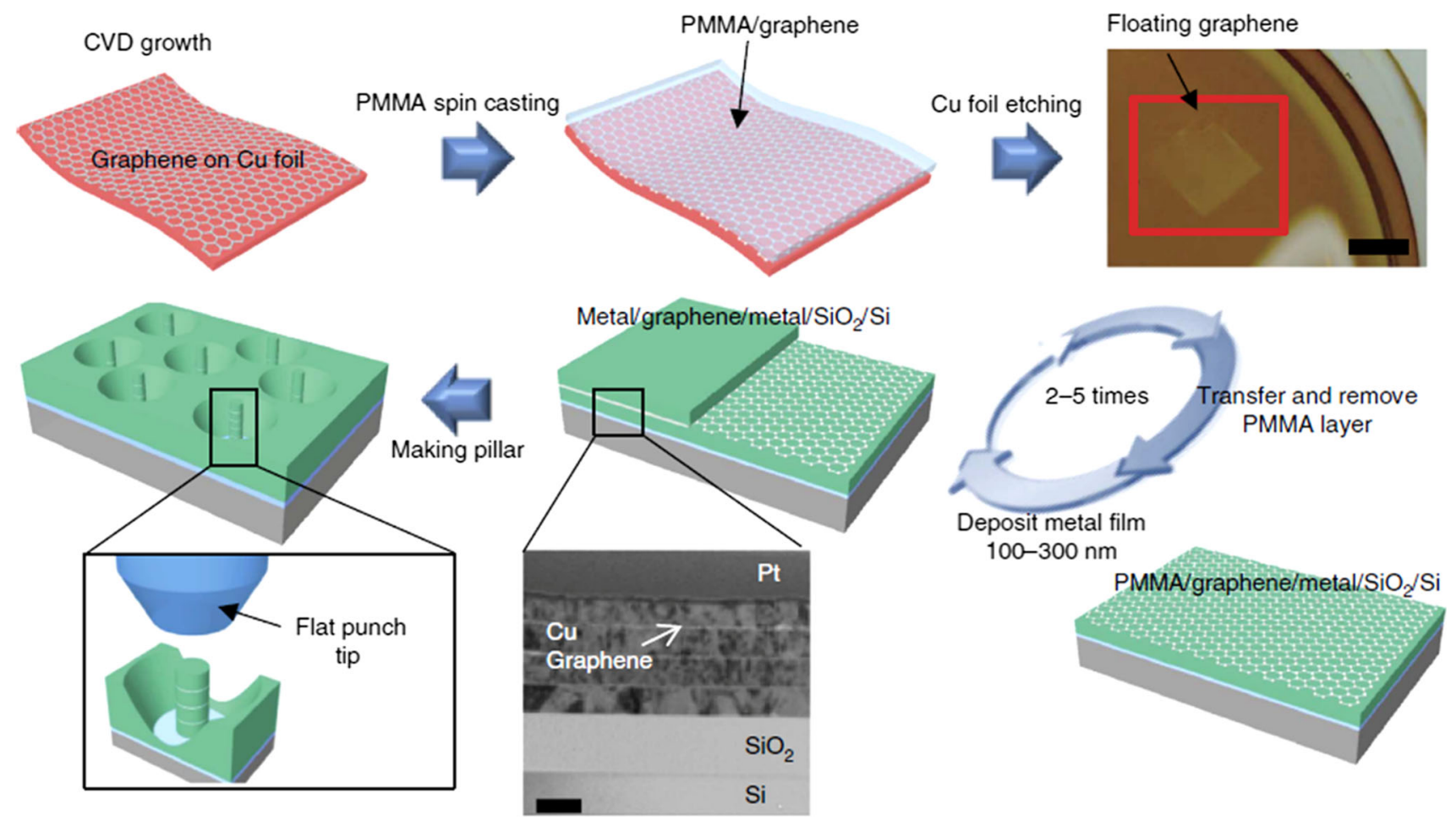

Figure 12 Schematic of a metal-graphene multilayer system synthesis. Graphene is first grown using CVD and transferred onto the evaporated metal thin film on an oxidised Si substrate via a PMMA support layer. The PMMA layer is then removed, and the next metal film layer is evaporated. The mechanical properties of

nanolayered composites consisting of alternating layers of $\mathrm{Cu}$ and monolayer graphene with 70-200 $\mathrm{nm}$ repeat layer spacing following the steps schematically shown in Fig. 12 [25]. First, singleatomic-layer graphene was grown on a $25-\mu \mathrm{m}$-thick foil by a previously reported chemical vapour deposition (CVD) method [118]. The graphene was then transferred onto a deposited $\mathrm{Cu}$ layer to fabricate the metal-graphene multilayer structures. A supporting polymer (PMMA) was spin-coated onto the graphene on the $\mathrm{Cu}$ foil to prevent damage to the graphene during transfer. The $\mathrm{Cu}$ foil was etched by an aqueous solution (ammonium persulphate), thereby detaching the graphene from the $\mathrm{Cu}$ foil. The PMMA with attached graphene was floated in the aqueous solution and cleaned several times with distilled water. The graphene films were transferred by scooping the PMMA/graphene films with a $\mathrm{Cu}$-deposited $\mathrm{Si} / \mathrm{SiO}_{2}$ substrate. Finally, the substrate was heated to $80{ }^{\circ} \mathrm{C}$ for $5 \mathrm{~min}$ and then cleaned with acetone to remove the PMMA. This process was repeatedly performed to fabricate the alternating layers of graphene and $\mathrm{Cu}$. the resulting $\mathrm{Cu}$-graphene nanolayered composites produced by repeating the metal deposition and graphene transfer process were studied by compressing nanopillars etched by FIB. The scale bar for the floating graphene is $10 \mathrm{~nm}$ and that for the TEM is $20 \mathrm{~nm}$. Reproduced with permission from [25].

A multilayer film composite has also been prepared comprising several layers of $\mathrm{Cu}$ /graphene deposited on a $\mathrm{Cu}$ substrate [19]. GO was syphoned from a suspension in isopropyl alcohol and deposited on the $\mathrm{Cu}$ substrate using a 3-mm-diameter glass tube. The GO particulate deposition was repeated several times to achieve a uniform dispersion on the surface after the evaporation of the solvent. In the next step, a $\mathrm{Cu}$ film was deposited on the top of the GO particulates by laser physical vapour deposition (LPVD). The thickness of the resulting film with GO dispersion was found to be between 0.8 and $0.85 \mu \mathrm{m}$. The substrate with the $\mathrm{Cu}$ film and GO dispersion was subjected to flowing hydrogen atmosphere at $400{ }^{\circ} \mathrm{C}$ for $4 \mathrm{~h}$ to reduce GO to graphene. This procedure was repeated to deposit six layers of $\mathrm{Cu}$ film containing the dispersion of graphene on the $\mathrm{Cu}$ substrate with a final thickness of $\sim 5 \mu \mathrm{m}$.

\section{Metal infiltration}

Melt infiltration is a liquid metallurgy process involving the infiltration of molten metal into a 


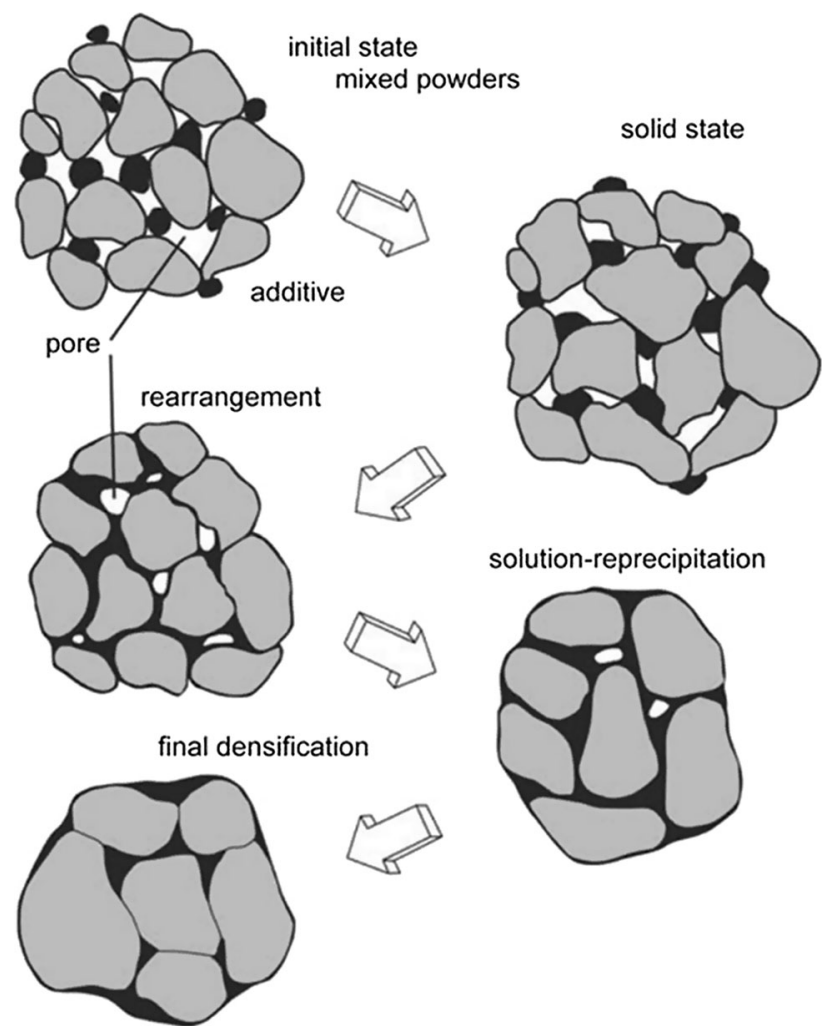

Figure 13 A schematic of the microstructure changes during liquid phase sintering starting with mixed powders and pores between the particles. During heating the particles sinter, but when a melt forms and spreads the solid grains rearrange. Subsequent densification is accompanied by coarsening. For many products, there is pore annihilation as diffusion in the liquid accelerates grain shape changes that facilitate pore removal. Reproduced with permission from [120].

reinforcing preform, which serves to prepare materials that are not accessible by other preparation methods owing to insolubility (e.g. WCu alloys) $[1,119]$. WCu/graphene composites have been fabricated by liquid phase sintering (LPS) above the $\mathrm{Cu}$ melting point $[61,62]$, which could be considered a variant of pressureless melt infiltration where the $\mathrm{W}$ preform is prepared by BM of graphene with a mixture of almost pure $\mathrm{W}$ and $\mathrm{Cu}$ followed by pressing [119]. In brief, the as-prepared graphene was dispersed in a $\mathrm{C}_{2} \mathrm{H}_{5} \mathrm{OH}$ solution. At the same time, $\mathrm{W}$ and $\mathrm{Cu}$ powders were mixed in ethanol solvent by mechanical stirring. The graphene dispersion solution was then added slowly into the $\mathrm{WCu}$ powder solution and the mixture was agitated for several minutes. Afterwards, the graphene and WCu mixture powders solution was ball milled under a high-purity Ar atmosphere and the resultant mixture was dried

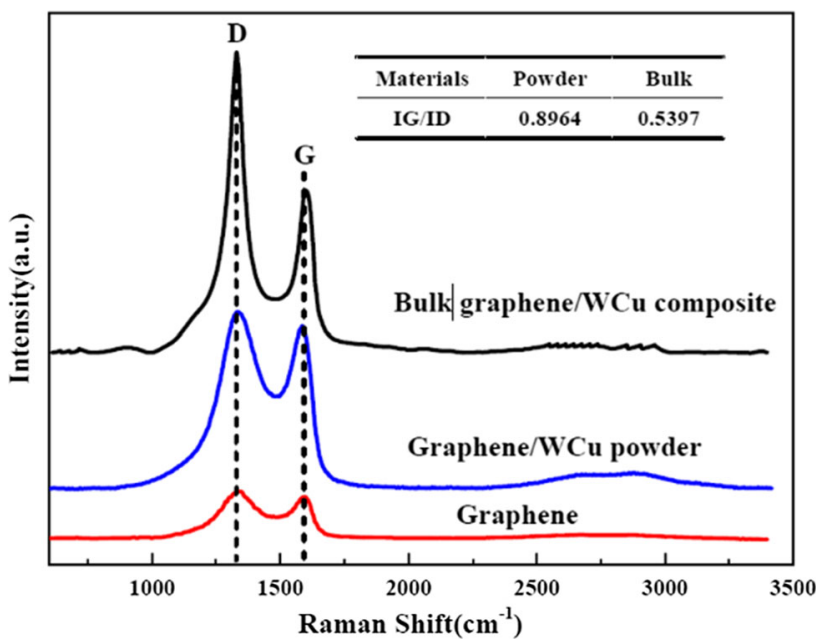

Figure 14 Raman spectra of graphene, $\mathrm{W}_{70} \mathrm{Cu}_{30}-1 \mathrm{wt} \%$ graphene powder and $\mathrm{W}_{70} \mathrm{Cu}_{30}-1 \mathrm{wt} \%$ bulk composite. Reproduced with permission from [61].

in a vacuum oven. The composite powders were then compacted into cylindrical bars with a universal testing machine. These green compacts were sintered at a temperature of $1350{ }^{\circ} \mathrm{C}$, exceeding the $\mathrm{Cu}$ melting point. In these conditions, $\mathrm{W}$ solid grains coexist with $\mathrm{Cu}$ liquid and sintering takes place by particle rearrangement [120], as shown in Fig. 13.

Metal infiltration process has been proved to be very effective at getting dense $\mathrm{WCu}$ alloys with a homogeneous distribution of $\mathrm{W}$ and $\mathrm{Cu}[121,122]$. However, some of the drawbacks of the process include reinforcement damage, a coarse grain size, contact between reinforcement particulate and undesirable interfacial reactions $[1,2,15]$. It was also found that during sintering, the crystal structure of graphene was heavily damaged. Example Raman spectra of $\mathrm{W}_{70} \mathrm{Cu}_{30}-1 \mathrm{wt} \%$ graphene composite powders and sintered composite are shown in Fig. 14 [61]. In the latter, the intensity $I_{\mathrm{G}} / I_{\mathrm{D}}$ ratio decreases dramatically compared to graphene, suggesting that defects or disorder of the graphene structure increased during BM. Unfortunately, after infiltration sintering, the $I_{\mathrm{G}} / I_{\mathrm{D}}$ ratio further decreases.

\section{Other processing methods}

\section{Preform impregnation}

This novel technique was employed by Xiong et al. [41] to fabricate a nature-inspired CMC, where RGO was chosen as "brick" because of its inherent 2D geometry and good mechanical properties and $\mathrm{Cu}$ 
was used as mortar. The entire process consisted of three steps: replication of the ordered porous structure of fir wood with $\mathrm{Cu}$, absorption of RGO into the porous $\mathrm{Cu}$ preform and HP compaction. Fir wood has a highly ordered layer porous structure, in which pores are in rectangular shape with an average size of $\sim 20 \times 30 \mu \mathrm{m}$ and a wall thickness of $1.5 \mu \mathrm{m}$. The authors applied a chemical route comprising copper oxide replication and subsequent reduction to replicate the porous structure of fir wood with $\mathrm{Cu}$.

\section{Cold spraying}

Cold spraying (CS) is a relatively new technique in which the composite powders are accelerated to very high velocities $\left(\sim 500-1200 \mathrm{~ms}^{-1}\right)$ at low temperature and impacted on a substrate [1,2]. During the process, powders are accelerated by injection into a stream of a gas in a converging diverging de-Laval type nozzle. The gas is heated, without using combustion, only to increase the gas and particle velocity [123]. The particles are in solid state when they impact the surface, where they undergo severe plastic deformation. The high kinetic energy upon impact ensures good adhesion of the particles on the substrate. Since the temperature of the process is below the melting point, oxidation and phase transformations can be avoided. Cold spraying in conjunction with ball milling has been shown to be successful in the fabrication of $\mathrm{Cu}$ coatings, where non-agglomerated and uniformly distributed GNPs were embedded [115].

\section{Accumulative roll bonding ( $A R B)$}

Accumulative roll bonding (ARB) is a severe plastic deformation technique consisting of multiple cycles of cutting, stacking and roll bonding [124]. Hence, large strains can be accumulated in the material and significant structural refinement can be achieved [125]. As a result, good mechanical properties at low and high temperatures have been observed for different metals and alloys over their coarse-grained counterparts [125]. In addition, several researchers have also used ARB for the successful fabrication of particle reinforced MMCs [126-129]. So, by manually distributing $\mathrm{SiC}$ or $\mathrm{Al}_{2} \mathrm{O}_{3}$ particles between the two metallic strips prior to each roll-bonding steps, $\mathrm{Al}$ or $\mathrm{Cu}$ matrix composites with excellent distributions of reinforcing particles, good interfacial bonding and no porosity were obtained after several ARB cycles. More recently, Liu et al. [37] adopted a similar approach to fabricate GNPs reinforced CMCs. In this way, pure $\mathrm{Cu}$ was $A R B$ up to eight cycles at $\mathrm{RT}$, a GNPs dispersion being sprayed on the surface of the $\mathrm{Cu}$ strips before each rolling step.

\section{Densification}

Obtaining sufficiently high densification is a common key difficulty of processing particulate MMCs. The absolute density of the composite should reduce with increase in graphene content due to the relative densities of graphene $\left(2.2 \mathrm{~g} / \mathrm{cm}^{3}\right)$ and copper $\left(8.9 \mathrm{~g} / \mathrm{cm}^{3}\right)$. However, graphene also has an effect on their degree of densification or relative densities (ratio of the measured experimental density to the maximum theoretical density). Hence, although $\mathrm{Cu}$ /graphene composites have high relative densities (usually higher than 96\%), they are usually lower than that of the unreinforced matrix and decreases with increase in the graphene content $[12,28,32,38,43,55,57,103]$. This is usually attributed to the presence of graphene agglomerates because they form obstacles in composite consolidation, increasing the distance between $\mathrm{Cu}$ powder particles and thus reducing their sintering ability or restricting the matrix material to flow. Both factors result in the formation of pores or voids in the composites.

In contrast, graphene has been reported to improve the densification behaviour of WCu alloys. Figure 15 shows the variation of theoretical, measured and relative density of $\mathrm{W}_{70} \mathrm{Cu}_{30}$ /graphene composites containing different weight fractions of graphene

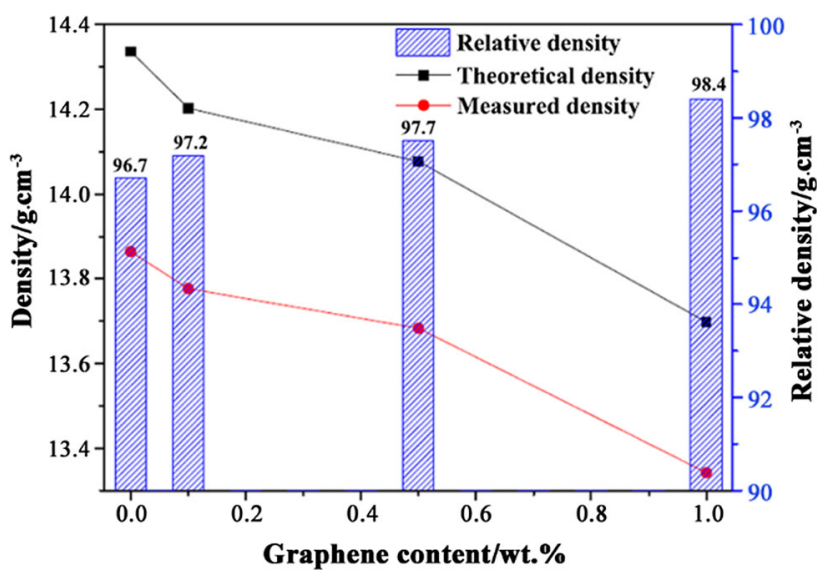

Figure 15 Theoretical, measured and relative density of $\mathrm{W}_{70} \mathrm{Cu}_{30}$ /graphene composites containing different amounts of graphene. Reproduced with permission from [61]. 
[61]. As expected, the theoretical density of the $W_{70-}$ $\mathrm{Cu}_{30}$ /graphene composites decreases with an increasing amount of graphene since the density of graphene is far less than that of $\mathrm{W}\left(19.35 \mathrm{~g} / \mathrm{cm}^{3}\right)$ and $\mathrm{Cu}\left(8.96 \mathrm{~g} / \mathrm{cm}^{3}\right)$. It is clear that the gap between the $\mathrm{W}-\mathrm{W}$ skeleton was not completely filled with molten $\mathrm{Cu}$ during the infiltration-sintering process because the highest relative density is $98.4 \%$ at $1 \mathrm{wt} \%$ graphene loading. Nevertheless, the relative density of $\mathrm{W}_{70} \mathrm{Cu}_{30}$ was improved with the additive amount of graphene, was explained by the authors due to the following two main reasons; firstly, owing to the good wettability of graphene, $\mathrm{W}$ particle rearrangement could be promoted and accelerated to some extent and secondly, graphene has very good wettability on $\mathrm{Cu}$ at high temperature, which will promote greatly the ability of liquid filling the $\mathrm{W}$ skeleton.

\section{Mechanical properties}

\section{Strength and stiffness}

The literature demonstrates that the $\mathrm{Cu}$ /graphene composites exhibit superior hardness, Young's modulus, yield strength and tensile strength at room temperature compared with the corresponding unreinforced matrices. The results are, however, very dependent on the graphene content, the processing route and conditions as well as on the graphene derivative (Table 1). In summary, enhancements as high as $\sim 93 \%$ for hardness [57], 65\% for the Young's modulus [43], 233\% for the yield stress [56] and $\sim 48 \%$ for the tensile strength [35] have been reported.

Regarding the mechanical properties at high temperature, it is found that the hardness of a Cu- $0.5 \mathrm{wt} \%$ graphene composite is approximately twice that of pure $\mathrm{Cu}$ at temperatures ranging from RT to $600{ }^{\circ} \mathrm{C}$ (Fig. 16) [52]. It is worth noting that the hardness of a $\mathrm{Cu}-0.5 \mathrm{wt} \%$ graphite composite prepared with the same process was almost the same than that of the $\mathrm{Cu}$ /graphene composite between RT and $450{ }^{\circ} \mathrm{C}$. However, the hardness of the $\mathrm{Cu}$ /graphite composite decreases faster than that of the $\mathrm{Cu}$ /graphene composite above $450{ }^{\circ} \mathrm{C}$ and is close to that of pure $\mathrm{Cu}$ at $600{ }^{\circ} \mathrm{C}$ [52]. In addition, the temperature dependence of the axial Young's modulus in CMCs reinforced with graphene sheets and CNTs was studied via molecular dynamics (MD) simulations by Barshirvand and Montazeri [13]. It was predicted that both nanofillers can successfully enhance Young's modulus of the $\mathrm{Cu}$ matrix based on the load-carrying capability mechanism; this enhancement increases with increase in temperature from -272 to $227^{\circ} \mathrm{C}$. However, in agreement with previous results for polymer-based nanocomposites, graphene sheets were predicted to perform significantly better than CNTs under identical conditions. In particular, Young's modulus was predicted to be $42.8 \%$ greater than the base-line $\mathrm{Cu}$ at $-272{ }^{\circ} \mathrm{C}, 58.9 \%$ at $27{ }^{\circ} \mathrm{C}$ and $104.1 \%$ at $227{ }^{\circ} \mathrm{C}$.

The strengthening and stiffening effects of graphene are greatly dependent on the efficiency of the load transfer from the matrix to the filler [1], which is, in turn, governed by the dispersion of graphene into the matrix (i.e. degree of agglomeration), the interfacial bonding and the formation of interfacial products, the presence of structural defects in graphene, the number of carbon layers in graphene, the presence of defects in the final product (e.g. porosity or intercalants [130]) and the orientation of graphene in relation to the loading direction. Furthermore, metallurgical factors such as grain refinement, dispersion strengthening and dislocation generation also contribute to the strengthening effect of $\mathrm{Cu}$ /graphene composites [1]. Two different micromechanical models, namely shear-lag and Halpin-Tsai models, originally developed for conventional fibre-reinforced composites, have been used to predict the enhancement of the Young's modulus and yield strength of $\mathrm{Cu}$ /graphene composites [12, 32, 54].

\section{Load transfer}

The simplest model that can be used to predict the mechanical properties of MMCs is the rule of mixtures (ROM), in which the desired property can be estimated from the weighted average of the individual components as follows [7, 15]:

$\beta_{\mathrm{c}}=\beta_{\mathrm{m}} V_{\mathrm{m}}+\beta_{\mathrm{r}} V_{\mathrm{r}}$

where $\beta$ is the property of interest (Young's modulus or yield strength), $V$ is the volume fraction, and the subscripts $\mathrm{c}, \mathrm{m}$ and $\mathrm{r}$ refer to the composite, matrix and reinforcement, respectively. Limitations to the ROM have resulted in models which take into account additional phase parameters other than the content.

The Cox shear-lag model, for example, assumes a perfectly bonded interface, so that the applied stress is transferred from the matrix to the fibre through interfacial shear stress [1, 2, 7]. According to the modified shear-lag model [131], the Young's modulus or yield stress of a randomly distributed graphene composite is expressed as [32, 54]: 


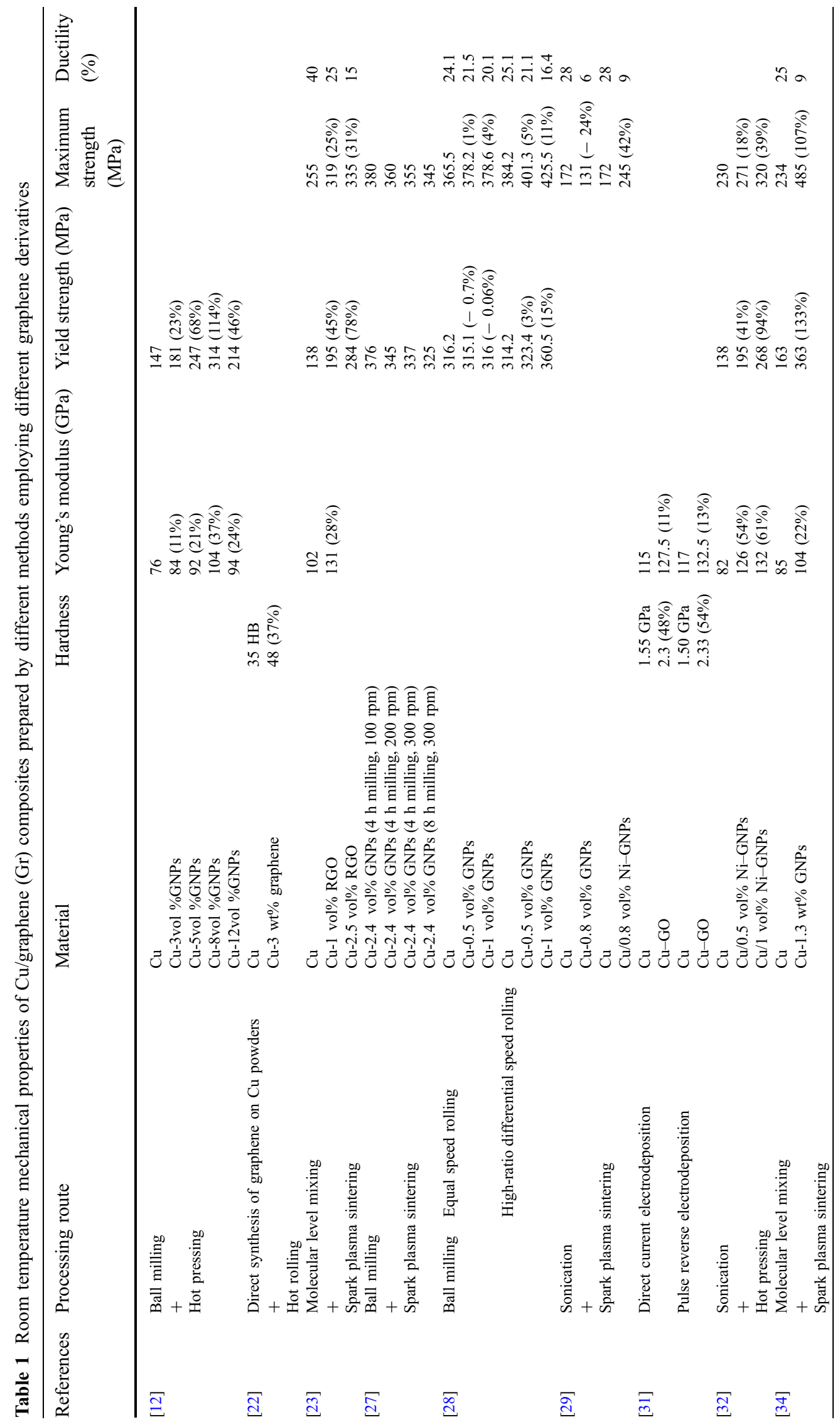




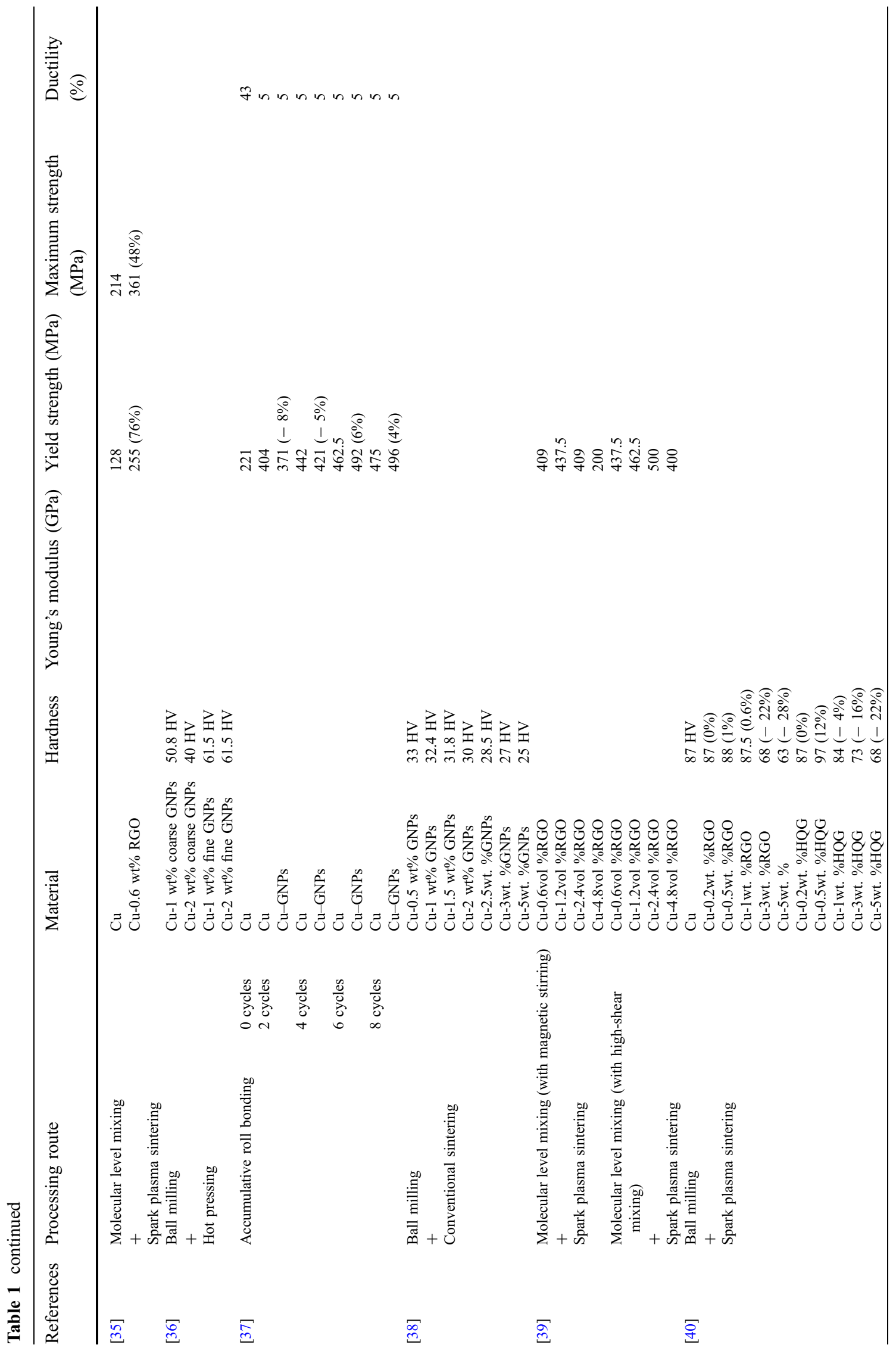




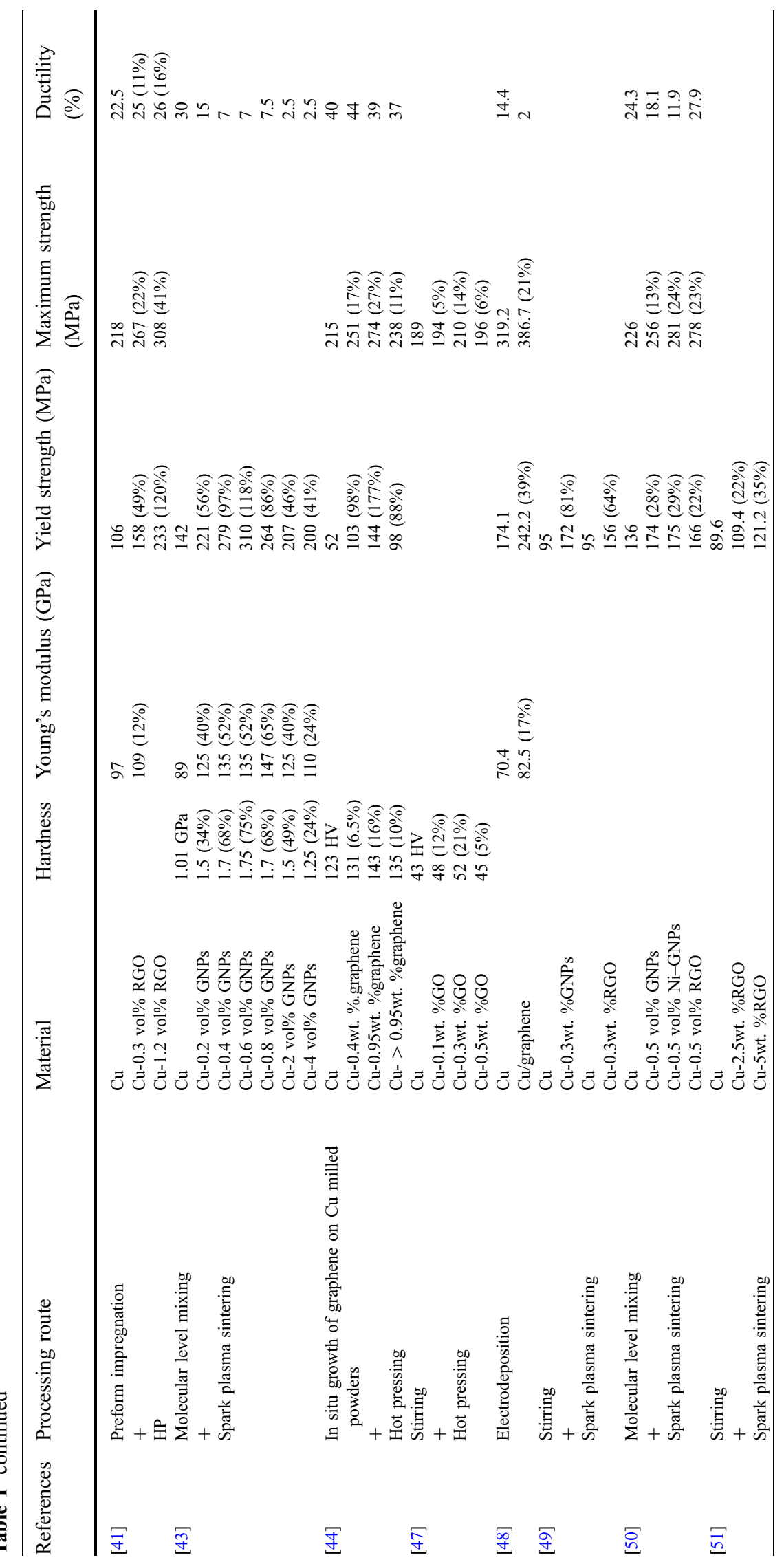




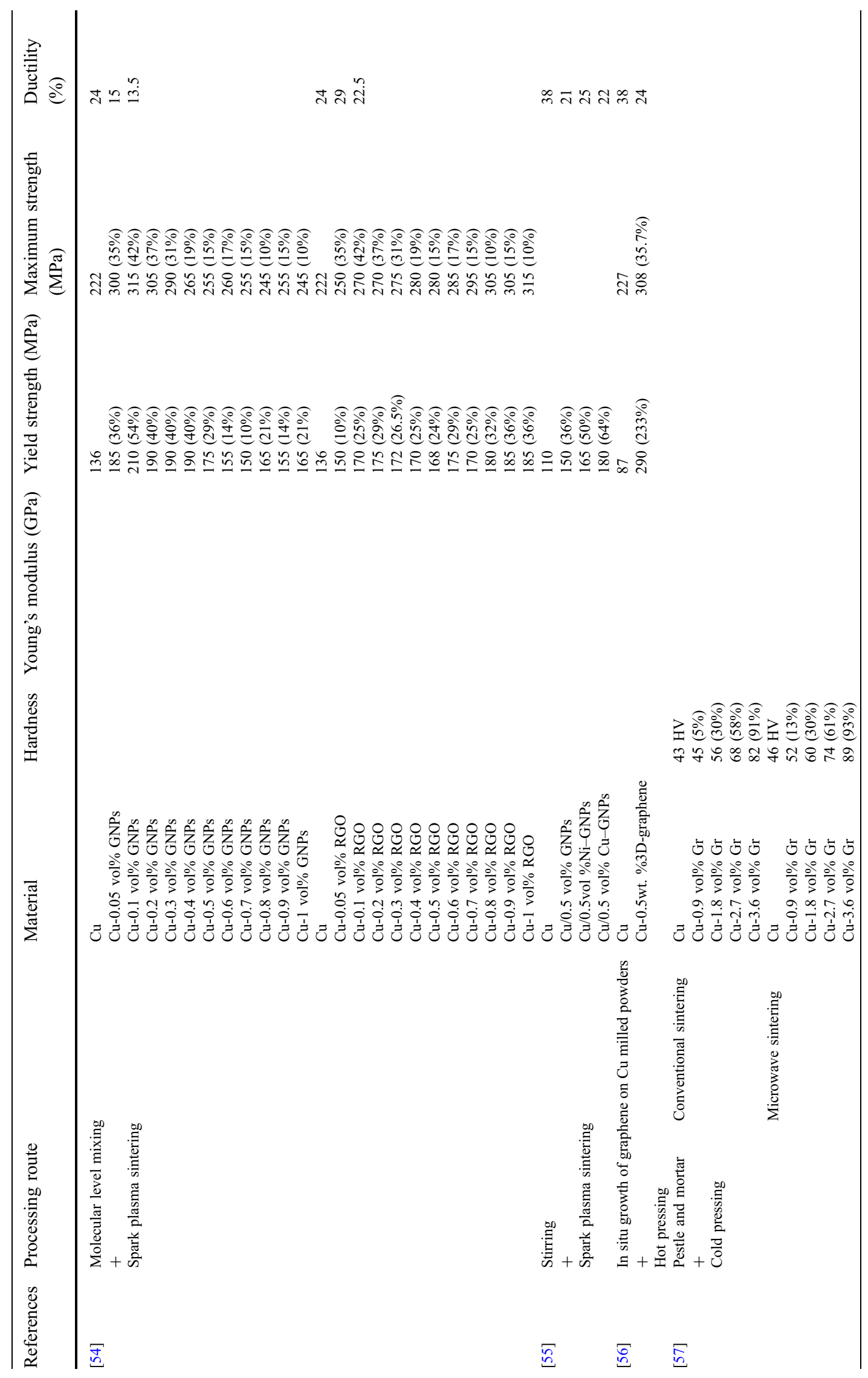




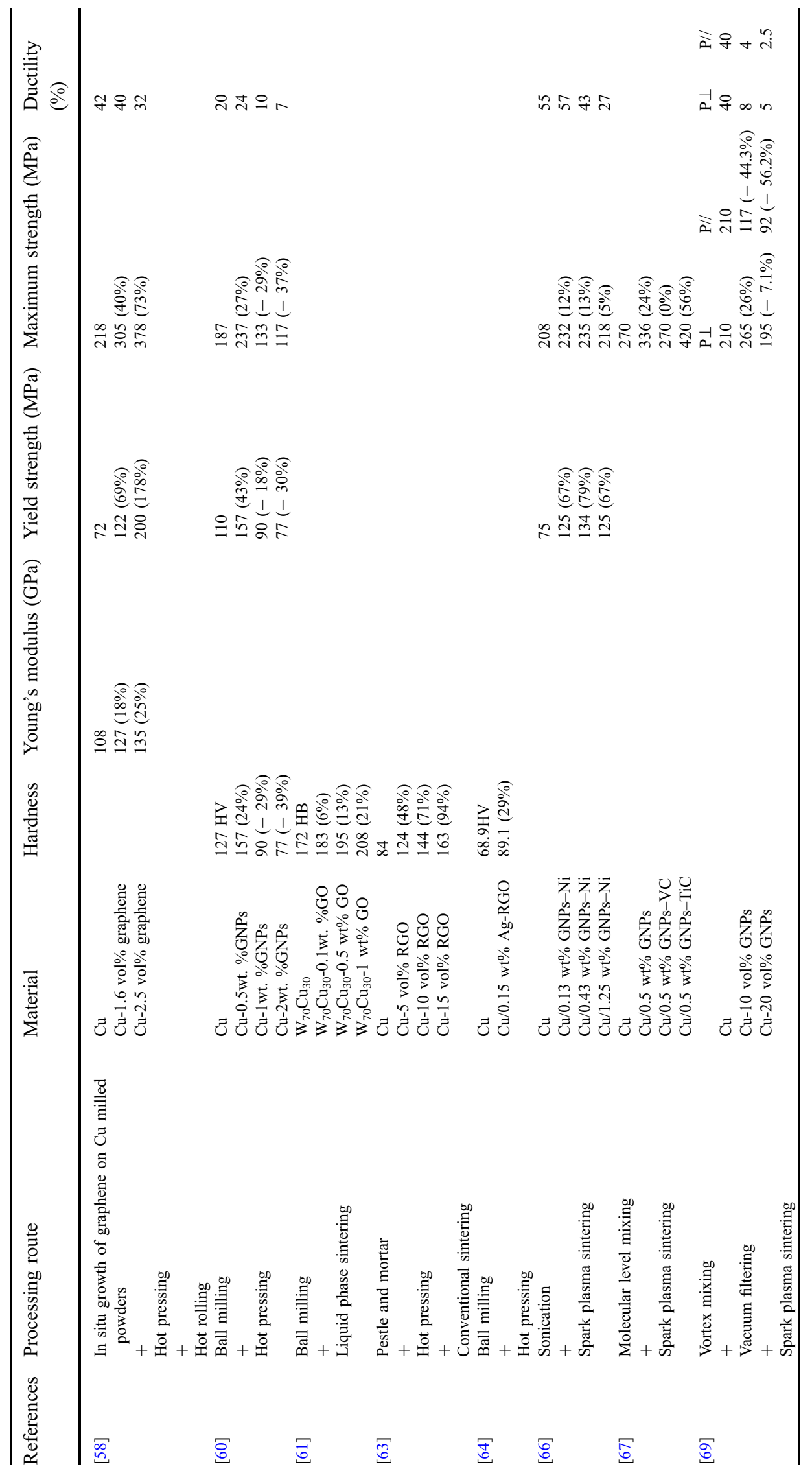




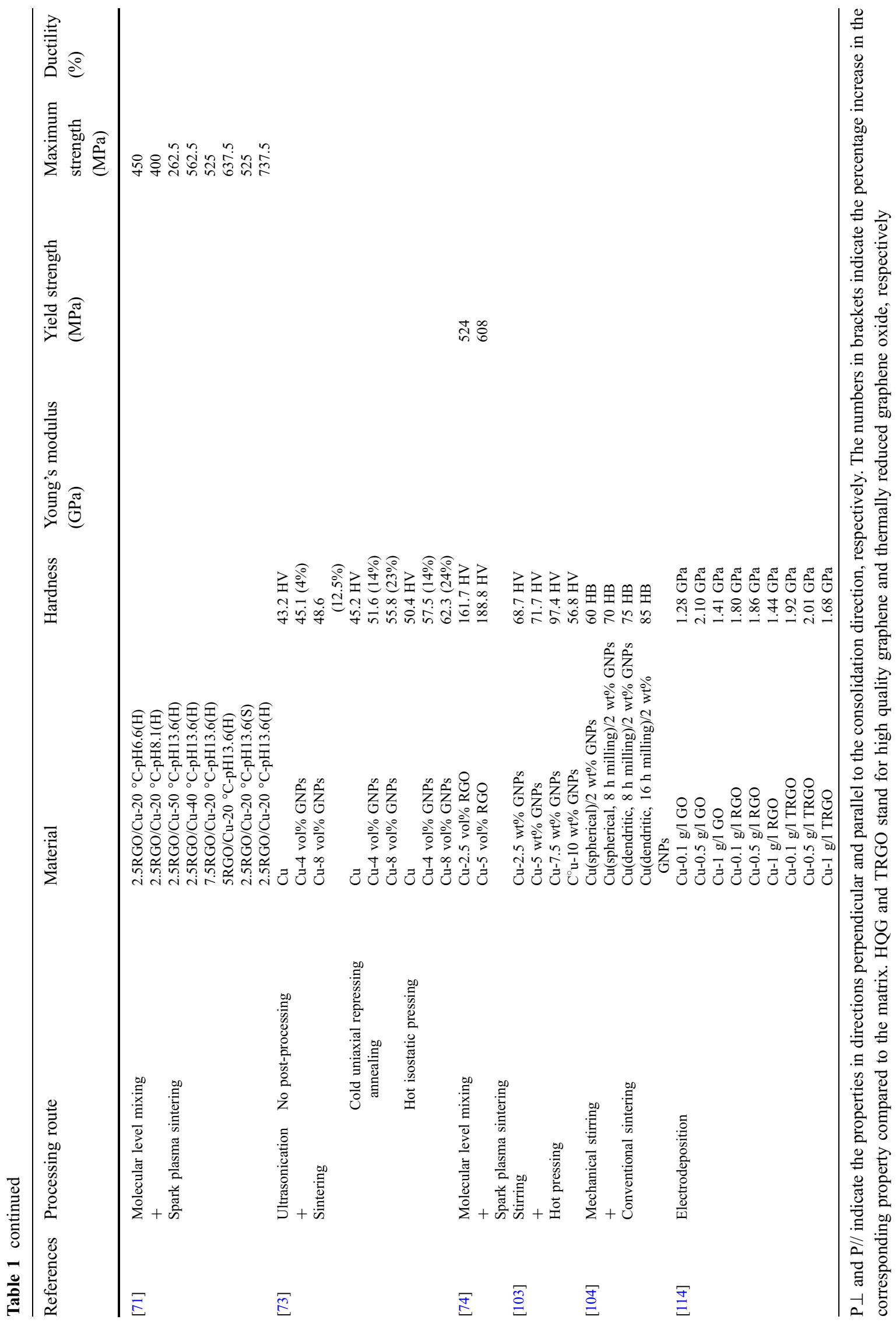




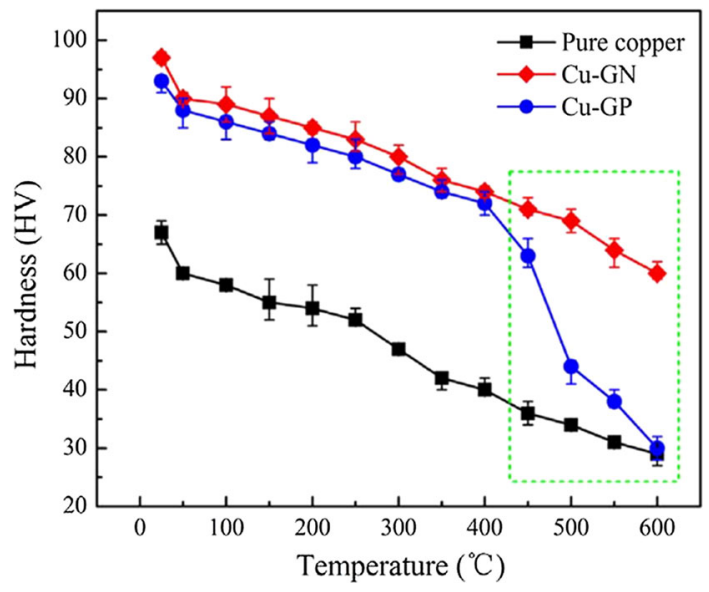

Figure 16 Hardness dependence with temperature for pure $\mathrm{Cu}$, $\mathrm{Cu}-0.5 \mathrm{wt} \%$ graphene $(\mathrm{Cu}-\mathrm{GN})$ and $\mathrm{Cu}-0.5 \mathrm{wt} \%$ graphite $(\mathrm{Cu}-$ GP). Reproduced with permission from [52].

$\beta_{\mathrm{c}}=\beta_{\mathrm{m}}\left(1+p V_{\mathrm{r}}\right)$

where $p$ is the aspect ratio of the graphene reinforcement.

The Halpin-Tsai model, however, considers not only the reinforcement aspect ratio, but also its spatial distribution [132]. Considering a random or a unidirectional distribution of graphene into the matrix, the Halpin-Tsai model is expressed by the following empirical equations [12]:

$\beta_{\text {random }}=\beta_{\mathrm{m}}\left[\frac{3}{8} \times \frac{1+2 / 3 \eta_{\mathrm{L}} p V_{\mathrm{r}}}{1-\eta_{\mathrm{L}} V_{\mathrm{r}}}+\frac{5}{8} \times \frac{1+2 \eta_{\mathrm{T}} V_{\mathrm{r}}}{1-\eta_{\mathrm{T}} V_{\mathrm{r}}}\right]$

$\beta_{\|}=\beta_{\mathrm{m}}\left[\frac{1+2 / 3 \eta_{\mathrm{L}} p V_{\mathrm{r}}}{1-\eta_{\mathrm{L}} V_{\mathrm{r}}}\right]$

where the subscripts random and II refer to the composites with randomly oriented and unidirectionally distributed graphene, respectively, and $\eta_{\mathrm{L}}$ and $\eta_{\mathrm{T}}$ are parameters defined by:

$\eta_{\mathrm{L}}=\frac{\beta_{\mathrm{r}} / \beta_{\mathrm{m}}-1}{\beta_{\mathrm{r}} / \beta_{\mathrm{m}}+2 / 3 p}$

$\eta_{\mathrm{T}}=\frac{\beta_{\mathrm{r}} / \beta_{\mathrm{m}}-1}{\beta_{\mathrm{r}} / \beta_{\mathrm{m}}+2}$

\section{The effect of matrix microstructure}

The incorporation of graphene into $\mathrm{Cu}$ can lead to grain refinement of the matrix phase $[12,22,26,35,37,43,55,61,67,69,73]$. The dependency of yield stress $\left(\sigma_{\mathrm{y}}\right)$ on grain size $(D)$ generally follows the Hall-Petch relationship [133, 134]:
$\sigma_{\mathrm{y}}=\sigma_{0}+K D^{-1 / 2}$

where $\sigma_{0}$ is the friction stress and $K$ is the Hall-Petch slope, which is associated with a measure of the resistance to dislocation motion caused by the presence of grain boundaries.

Grain refinement in $\mathrm{Cu} /$ graphene composites has been ascribed to an acceleration of the BM process by graphene and oxide particles, obtaining much smaller particles [36, 38, 61], and to the pinning effect of graphene or carbides on the grain boundaries during the consolidation processes $[12,35,37,38,41,43$, $53,55,58,61,69,73]$.

Graphene itself can also impede dislocation motion during mechanical tests. Assuming that graphene is not sheared by dislocations, the flow stress would be then controlled by the stress required to bend graphene particles and subsequent form loops around them, as proposed by Orowan [135]. The following expression could be used to calculate the Orowan increment of the yield stress [136]:

$\Delta \sigma_{\mathrm{y}(\text { Orowan })}=\frac{G b}{2 \pi \lambda \sqrt{1-v}} \ln \left(\frac{d_{\mathrm{p}}}{r_{0}}\right)$

where $G$ is the shear modulus of the matrix, $b$ is the magnitude of the Burgers vector, $\lambda$ is the effective planar interparticle spacing, $v$ is the Poisson's ratio of the matrix, $d_{\mathrm{p}}$ is the mean planar diameter of the particles, and $r_{0}$ is the core radius of the dislocations in the matrix.

Generally, the Orowan looping mechanism is more pronounced in MMCs reinforced with particles of low aspect ratio [1]. So, in principle, its contribution to the strengthening of MMCs reinforced with graphene it is expected to be little. Moreover, to play an important role in Orowan strengthening, graphene should be finely dispersed within the grains, because particles in grain boundaries are not expected to effectively impede the movement of dislocations in grain interiors [28]. This is quite challenging because, in MMCs, graphene has a tendency to distribute along the grain boundaries in most of the fabrication routes, [22, 47, 52, 60, 103]. For example, in a composite produced by MLM followed by SPS a small amount of spherical-shape GNPs, RGO or Ni-plated GNPs were observed within the $\mathrm{Cu}$ grain interiors $[50,54]$. However, only after the combination of BM and HRDSR, nanosized graphene particles were densely and uniformly dispersed in the grain 
interiors, attributable to the large shear stress introduced during the rolling process [28].

When uniform dispersions of fine graphene particles are not achieved, graphene can also act, due its two-dimensional geometry, as an effective obstacle for dislocation motion [23, 29, 31, 32, 37, 44, 49, 51, 56, $65,69,103]$. As a result, dislocations are at the grain boundaries, piled up at the interface region under loading causing an enhancement of the yield stress. This has been proved to be the main strengthening mechanism in nanolayered composites consisting of alternating layers of $\mathrm{Cu}$ and monolayer graphene, where graphene acts as an efficient barrier to dislocation propagation and provides a strengthening effect which can reach far beyond the simple ROM prediction [25]. As a result of the gliding dislocations being blocked by the metal-graphene interface, ultrahigh flow stresses were observed for the $\mathrm{Cu} /$ graphene multilayers, these increasing systematically with a reduction in metal layer spacing (Fig. 17a). The flow stresses at 5\% plastic strain for the $\mathrm{Cu} /$ graphene nanopillars were extracted and plotted against the corresponding metal layer spacing (Fig. 17b). The slope of the log-log is -0.402 , which is in close agreement with the Hall-Petch exponent, $\sigma$ $\propto h^{-1 / 2}$, where $h$ is the repeat layer thickness. This finding suggests multiple dislocation pile-up at the interface, consistent with the studies on metal nanolayered composites that demonstrate HallPetch-like behaviour.

Since immobilised dislocations also hinder the movement other dislocations, the enhancement of the yield strength in MMCs has been also related to an increase in dislocation density in the matrix $\left(\Delta \rho_{\text {dis }}\right)$ originated mainly from different thermal contractions $[43,54,55,60,67,103]$, but also from the additional plastic deformation induced by the presence of reinforcing phases during processing [43]. The dependence of the yield stress of composites upon of dislocation density in the matrix can be expressed as [137]:

$\Delta \sigma_{\mathrm{y}(\mathrm{dis})}=a G b \Delta \rho_{\mathrm{dis}}^{-1 / 2}$

where a is a constant.

The significant mismatch of coefficient of thermal expansion (CTE) between the $\mathrm{Cu}$ matrix $\left(\sim 24 \times 10^{-6} \mathrm{~K}^{-1}\right.$ at RT) and graphene $\left(-6 \times 10^{-6} \mathrm{~K}^{-1}\right.$ in-plane at RT) causes a residual plastic strain during processing, thereby generating dislocations at the interface whose density is given by [138]:

$\rho_{\operatorname{dis}(\mathrm{CTE})}=\frac{A V_{\mathrm{r}} \Delta C \Delta T}{1\left(1-V_{\mathrm{r}}\right) d_{\mathrm{p}}}$

where $A$ is a geometrical constant, $\Delta C$ is the value of CTE mismatch between graphene and the $\mathrm{Cu}$ matrix, and $\Delta T$ is the temperature change.

The accumulation of dislocations at the interfaces after yielding, caused by the blocking effect of graphene, leads to an enhancement of the work hardening and thus of the maximum strength and hardness compared with the unreinforced materials [74]. This is because the dislocations pin each other and form tangles so that an increase in stress is required to continue plastic deformation. The presence of geometrical constraints also generates additional dislocations in the matrix during the mechanical tests [51]. Hence, during deformation of a ductile matrix containing a dispersion of hard particles, continued plastic flow necessitates the formation of dislocations in order to avoid the void formation [15]. The density of geometrically necessary dislocations (GNDs) is given by [139]:
Figure 17 Results of nanopillar compression tests on $\mathrm{Cu} /$ graphene nanolayered composites with different metal layer spacings. a True stress-true strain curves. b Flow stress at 5\% plastic strain versus repeat layer spacing. Reproduced with permission from [25].
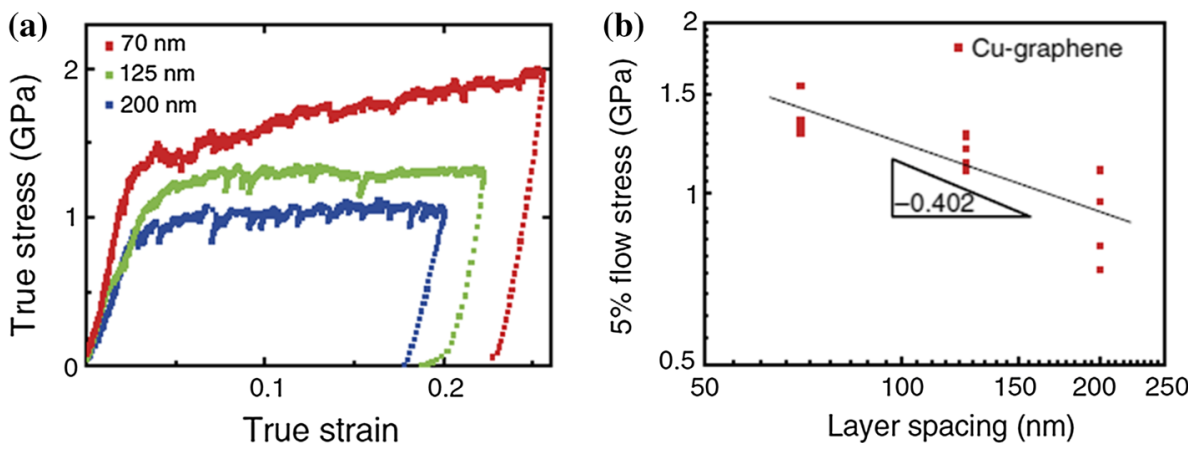
$\rho_{\mathrm{GND}}=4 \gamma / \lambda b$

where $\gamma$ is the shear strain, $\lambda$ is the geometric slip distance, and $b$ is the Burgers vector.

\section{Strengthening efficiency}

The strengthening efficiency $R$, defined as the ratio of the amount of yield strength increase in the composite to that of the matrix by the addition of reinforcing materials, can be expressed as [29, 39, 54, 60]:

$R=\frac{\left(\sigma_{\mathrm{y}, \mathrm{c}}-\sigma_{\mathrm{y}, \mathrm{m}}\right)}{V_{\mathrm{r}} \sigma_{\mathrm{y}, \mathrm{m}}}$

where $\sigma_{\mathrm{y}, \mathrm{c}}$ and $\sigma_{\mathrm{y}, \mathrm{m}}$ are the yield stress of the composite and the matrix, respectively.

The reinforcing phase content of graphene in the available works is presented either in volume fraction or weight fraction. The relation between the volume fraction $\left(V_{\mathrm{r}}\right)$ and weight fraction $\left(W_{\mathrm{r}}\right)$ of the reinforcement of a composite is given by:

$V_{\mathrm{r}}=\frac{W_{\mathrm{r}} / \rho_{\mathrm{r}}}{\left(W_{\mathrm{r}} / \rho_{\mathrm{r}}\right)+\left(1-W_{\mathrm{r}}\right) / \rho_{\mathrm{m}}}=\frac{W_{\mathrm{r}} \rho_{\mathrm{m}}}{W_{\mathrm{r}} \rho_{\mathrm{m}}+\left(1-W_{\mathrm{r}}\right) \rho_{\mathrm{r}}}$

where $\rho_{\mathrm{r}}$ and $\rho_{\mathrm{m}}$ are the density of the graphene reinforcement $\left(2.2 \mathrm{~g} / \mathrm{cm}^{3}\right)$ and $\mathrm{Cu}$ matrix $(8.96 \mathrm{~g} /$ $\left.\mathrm{cm}^{3}\right)$, respectively.

By using Eq. (12), the strengthening effect of various processing routes for $\mathrm{Cu}$ /graphene composites with different graphene derivatives can be compared. Moreover, the level of reinforcement imparted by graphene on pure $\mathrm{Cu}$ is usually calculated as the percentage increase in the yield stress compared to the matrix. However, in terms of the enhancement of mechanical properties upon the addition of graphene, it is also instructive to examine the relationship between the experimental data and the theoretical predictions. It is found that the experimental data generally lie close to the expectations only at very low graphene volume fractions $(<0.1 \%)$ and then fall away, especially above volume fractions of $1 \%$ as is found for both aluminium-matrix [140] and polymer-matrix systems [141]. There are a number of possible reasons why this might be the case:

1. Some of the experimental data for composites reinforced with GO or RGO, whose mechanical properties are, especially for the former, inferior to those of pristine graphene due to the disruption of the structure through oxidation and the presence of $\mathrm{sp}^{3}$ rather than $\mathrm{sp}^{2}$ bonding [142-144]. In addition, defects introduced for example during $\mathrm{BM}$ in the graphene structure result in the loss of their intrinsic properties and thus in the reduction of their load-carrying capability [11, 12].

2. Graphene is not preferentially oriented along the loading direction in the composites and exhibits a wrinkled structure. The value taken to calculate the theoretical values of $\sigma_{\mathrm{y}}, \mathrm{c} / \sigma_{\mathrm{y}, \mathrm{m}}$ actually corresponds to the in-plane yield stress of flat graphene, which is expected to be lower than the out-of-plane yield stress. This means that a randomly oriented distribution disturbs the unidirectional load transfer mechanism, reducing the strength efficiency of graphene since then the mechanical properties of the graphene-based composites are controlled not only by its exceptional in-plane properties, but also by its out-ofplane properties. For the same reason, the inplane strength of graphene is effectively reduced by out-of-plane ripples [145, 146].

3. The composites are filled with multilayer graphene. The above-mentioned in-plane yield stress corresponds not only to flat graphene, but also to monolayer graphene. However, experimental measurements show that the mechanical properties of graphene depend strongly on the number of layers [147]. In particular, they decline with increase the number of layers, evolving from those of graphene to those of graphite, and thus, the load-carrying capability gradually decreases. This has been attributed to the easy shear between the graphene layers [148].

4. The interface between graphene and the matrix may be weak, which leads to a poor stress transfer. Due to the low solubility of carbon in copper only mechanical locking between the two phases occur, the wrinkle structure of graphene plays an important role in enhancing the interlocking effect [13]. It has been confirmed experimentally that no reaction takes place between $\mathrm{Cu}$ and graphene during sintering at even $900{ }^{\circ} \mathrm{C}$ [57]. However, wettability and thus chemical bonding can be promoted by the modification of the $\mathrm{Cu}$ powders or the graphene sheets $[29,32,47,49,64,67]$. 
5. The dispersion of graphene in the composites may be poor, particularly at higher volume fractions, leading to aggregation. A good dispersion yields large contact areas or interfaces between graphene and $\mathrm{Cu}$. Hence, higher loads can be transferred to graphene during deformation. Moreover, graphene aggregates are intrinsically softer and cause preferential formation of cracks under deformation, also resulting in less effective load transfer [29].

6. The composites may contain structural defects, e.g. pores. Porosity causes ineffective distribution of reinforcement within the matrix alloy, and thus, reinforcement does not dominate the matrix alloy properties. Since pores are observed to create stress concentration, porosity overrules the reinforcement performance by developing a nonuniform stress field, which produces an ineffective reinforcing condition [149].

\section{Influence of the graphene content}

Due to the excellent mechanical properties of graphene together with the changes induced in the matrix microstructure, it is expected that both strength and stiffening increase with increase in the graphene content. However, although the available results show that graphene is generally a good reinforcement for $\mathrm{Cu}$, there exists an optimal loading with the mechanical performance deteriorating above this loading. This degradation of the mechanical properties has been mainly related to a poor stress transfer, mainly caused by aggregative trend of graphene and interface debonding. For example,
Chu and Jia [12] prepared $\mathrm{Cu} / \mathrm{GNPs}$ composites by a combination of $\mathrm{BM}$ and $\mathrm{HP}$ processing. Compared to the unreinforced $\mathrm{Cu}$, the $\mathrm{Cu} / \mathrm{GNPs}$ composites showed a remarkable increase in the yield stress and Young's modulus up to $114 \%$ and $37 \%$ at 8 vol\% GNPs content, respectively (Fig. 18a). This extraordinary reinforcement was attributed to the homogeneous dispersion attained by BM for 0-8 vol\% GNPs contents and to grain refinement, the average grain size decreases from $\sim 10 \mu \mathrm{m}$ for the $\mathrm{Cu}$ matrix to $\sim 4 \mu \mathrm{m}$ for the $\mathrm{Cu}-8$ vol\% GNPs composite. However, as seen in Fig. 18a, with further increasing GNPs content up to $12 \mathrm{vol} \%$, the increments of the yield strength and Young's modulus dramatically decrease to $46 \%$ and $24 \%$, respectively. The less effective enhancement in $\mathrm{Cu}-12$ vol\% GNPs composites arises mainly from the GNPs aggregations in the BMed powders. Moreover, the mechanical improvement of the $\mathrm{Cu} /$ GNPs composites was still below the theoretical value. So, as shown in Fig. 18b, it is obvious that the Young's modulus measurements are lower than the predictions made by the Halpin-Tsai model, implying that there is still some room for further enhancement in the mechanical performance of the $\mathrm{Cu}$ /GNPs composites. The gap between the predictions and the experimental results was attributed by the authors to following three reason: the loss of intrinsic properties of GNPs due to the introduction of structural defects during the BM process, an insufficient interfacial bonding due to no-wetting of the GNPs and $\mathrm{Cu}$ and a reduction in the strengthening efficiency of the GNPs due to their random orientation.

$\mathrm{Cu} / \mathrm{GNPs}$ composites were also prepared via MLM and SPS [43]. With the exception of ductility,

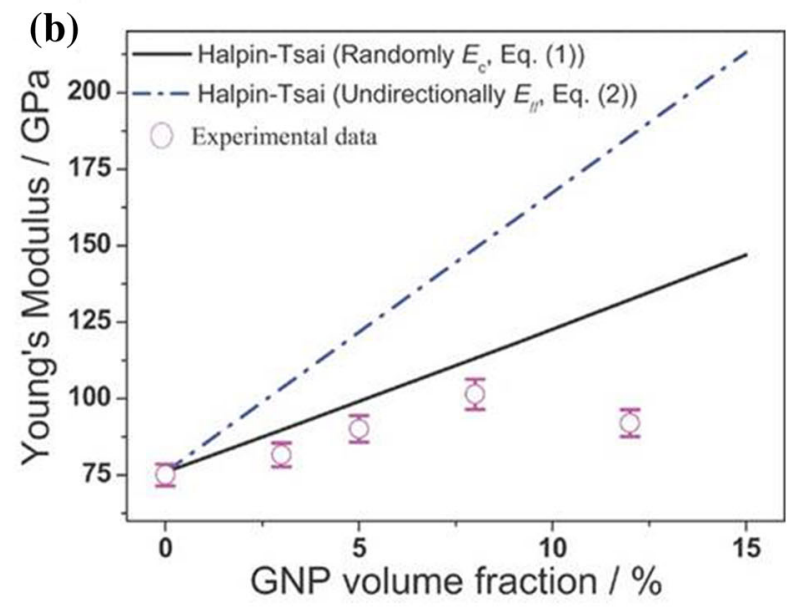

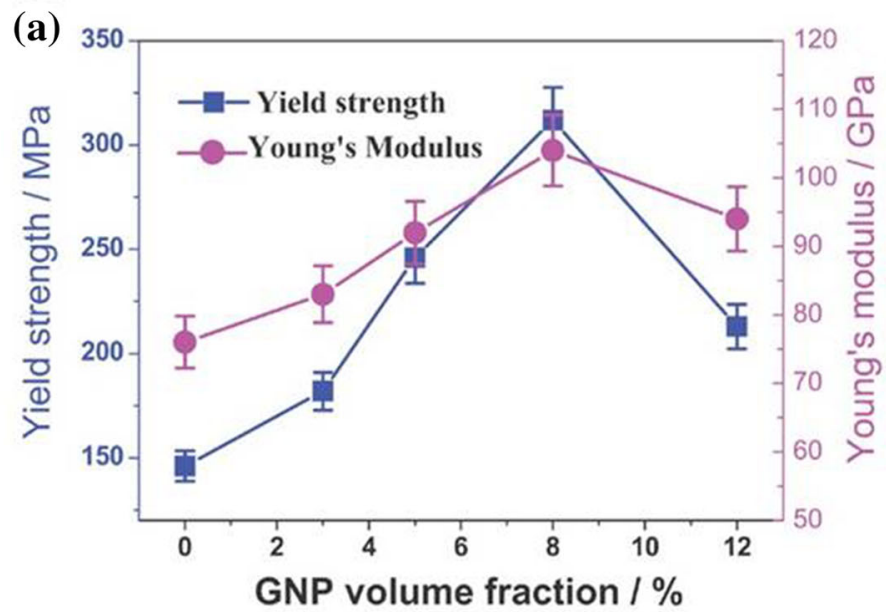

Figure 18 a Yield strength, Young's modulus and b comparison between experimental data and theoretical calculations of Young's moduli for $\mathrm{Cu} / \mathrm{GNPs}$ composites as a function of GNPs volume fraction. Reproduced with permission from [12]. 
(a)

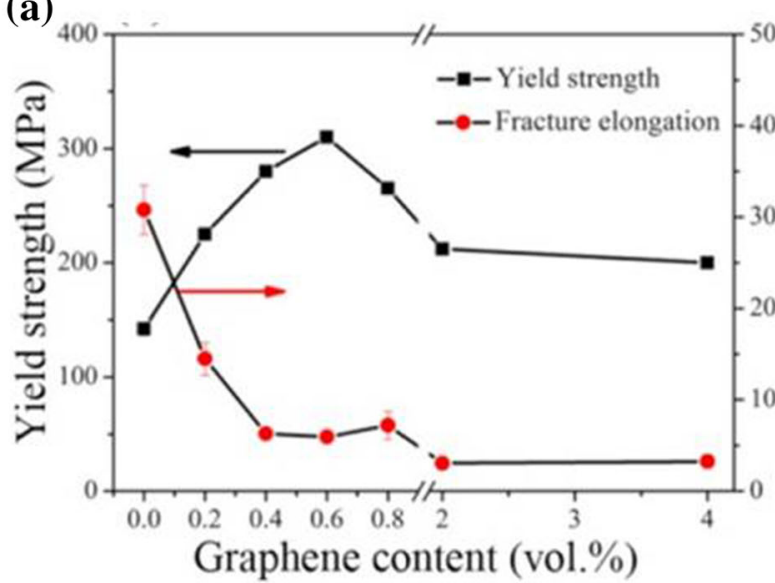

(b)

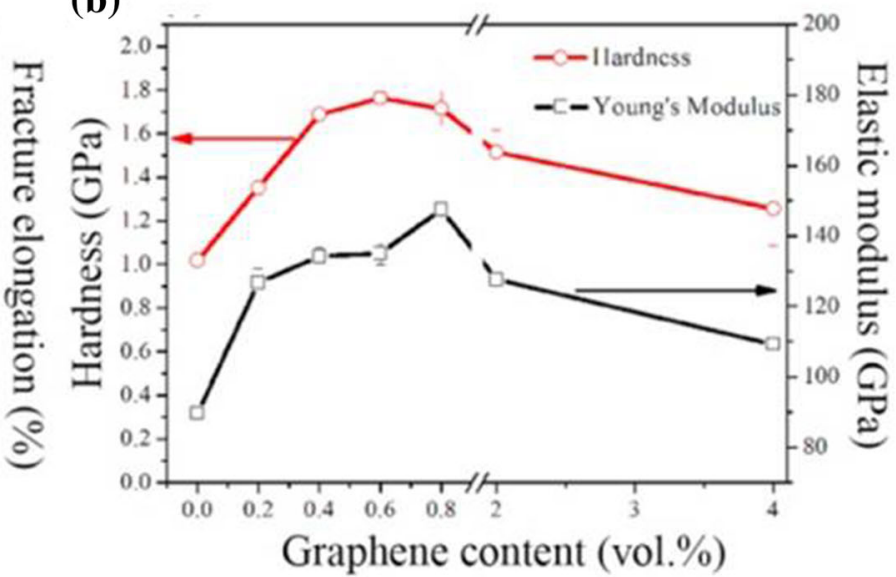

Figure 19 a Yield stress, fracture elongation, $\mathbf{b}$ elastic modulus and hardness of $\mathrm{Cu} / \mathrm{GNPs}$ composites as a function of GNPs content. Reproduced with permission from [43].

the mechanical performance of $\mathrm{Cu}$ was improved evidently by the graphene addition. However, the strengthening effect was first enhanced and then deteriorated by increasing graphene content (Fig. 19). So, for pure $\mathrm{Cu}$, the average yield strength is $142 \mathrm{MPa}$ and fracture elongation is about $30 \%$. With the increase in graphene content, the fracture elongation decreases from 30 to $3.5 \%$ (Fig. 19a). In contrast, the yield strength is first increased to $310 \mathrm{MPa}$, corresponding to an enhancement of $118 \%$, at the graphene content of $0.6 \mathrm{vol} \%$ and then drops to $200 \mathrm{MPa}$ when the graphene content further increases to $4.0 \mathrm{vol} \%$. Similarly, both the elastic modulus and hardness of the composites increase to their maximum values before decrease beginning at the graphene content around 0.6-0.8 vol\% (Fig. 19b). The highest elastic modulus and hardness obtained were 147 and $1.75 \mathrm{GPa}$, the increment compared with pure $\mathrm{Cu}(\mathrm{E} \approx 89 \mathrm{GPa}, \mathrm{H} \approx 1.01 \mathrm{GPa})$ being $65 \%$ and $75 \%$, respectively. The strengthening effect of graphene was attributed to a high dislocation density generated in the vicinity of GNPs due to the large thermal expansion mismatch between GNPs and $\mathrm{Cu}$ and to grain refinement. However, interface debonding was observed to take place in the composites during loading. So, the decline of mechanical performance for GNPs contents greater than $0.6-0.8$ vol\% could be attributed to poor interfacial bonding.

Chen et al. [44] fabricated $\mathrm{Cu} /$ graphene composites through in situ growth of graphene on flaky $\mathrm{Cu}$ powders and HP. Figure 20a shows the stress-strain curves of the composites with different graphene contents and of pure $\mathrm{Cu}$. It is obvious that there is a marked improvement on the mechanical properties of the $\mathrm{Cu}$ /graphene composites, the strengthening effect of in situ grown graphene attributable to load transfer and the role of graphene as an obstacle to the propagation of dislocations during deformation. A yield strength of $144 \mathrm{MPa}$ and a tensile strength of $274 \mathrm{MPa}$ are achieved by the composite with
Figure 20 a Stress-strain curves of pure $\mathrm{Cu}$ and different $\mathrm{Cu}$ /graphene composites.

b Raman spectra of the $\mathrm{Cu} /$ graphene composites. The content of graphene increases when going from graphene/ $\mathrm{Cu}-1$ to graphene/Cu-3. Reproduced with permission from [44].
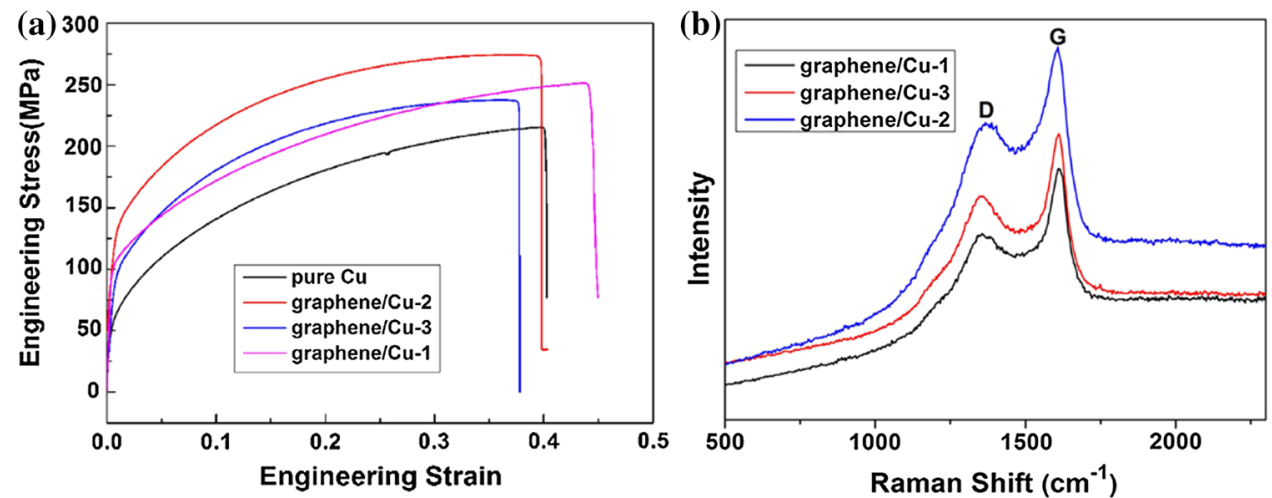
0.95 wt\% graphene (graphene/Cu-2 composite), which are, respectively, a $177 \%$ and $27 \%$ enhancement over pure $\mathrm{Cu}$. However, for a higher graphene content (graphene/Cu-3 composite), the mechanical properties fall to a lower level. The poor enhancement of graphene/Cu-3 was mainly attributed to a worse bonding between the $\mathrm{Cu}$ matrix and graphene. However, the Raman spectra of the composites showed an increased $I_{\mathrm{D}} / I_{\mathrm{G}}$ ratio for such composite (Fig. 20b). So, its poor enhancement in mechanical properties could be also attributed to an increase in defects in the in situ grown graphene obtained.

\section{Influence of the processing conditions}

GNPs and $\mathrm{Cu}$ powders were mixed by BM to produce composite powders using different milling speeds and times. Then, $\mathrm{Cu}-2.4$ vol\% GNPs bulk composites were fabricated by SPS [27]. The compressive yield strength and maximum compressive strength of the composites are shown in Fig. 21a. The yield strength of the composite fabricated at $100 \mathrm{rpm}$ for $4 \mathrm{~h}$ is $376 \mathrm{MPa}$. However, the yield strength of the composites decreased from $376 \mathrm{MPa}$ to $337 \mathrm{MPa}$ as the milling speed increased from $100 \mathrm{rpm}$ to $300 \mathrm{rpm}$. Moreover, for a rotating speed of $300 \mathrm{rpm}$, the yield strength decreased from $337 \mathrm{MPa}$ to $325 \mathrm{MPa}$ by increasing the milling time from $4 \mathrm{~h}$ to $8 \mathrm{~h}$. This was attributed to the increase in the defect concentration, showed by the decrease of the $I_{\mathrm{D}} / I_{\mathrm{G}}$ ratios in the Raman spectra (Fig. 21b) with increase in the milling speed and time.

The combination of BM followed by equal speed rolling (ESR) or high-rate differential speed rolling (HRDSR) was applied to fabricate 0.5 and $1 \mathrm{vol} \%$ $\mathrm{Cu} / \mathrm{GNPs}$ composites [28]. Following the same procedures, two pure $\mathrm{Cu}$ sheets were also fabricated using BMed powders. All the materials exhibited similar grain sizes and grain boundary misorientations, indicating that neither the consolidation process nor the additions of GNPs contributed to grain size reduction. However, the results indicate that HRDSR process increases the efficiency of the addition of GNPs for strengthening and strain hardening.

$\mathrm{Cu} / \mathrm{GNP}$ composites, as well as pure $\mathrm{Cu}$, were fabricated by ARB at room temperature up to 8 cycles [37]. It was observed that the dispersion of GNPs and the interface bonding improves and the matrix grain size decreases with increase in the number of ARB cycles. In agreement, the tensile strength of the $\mathrm{Cu} / \mathrm{GNPs}$ composites increased with increase in the number of cycles. After 6 ARB cycles, the tensile strength of the $\mathrm{Cu} / \mathrm{GNPs}$ composites reached $496 \mathrm{MPa}$, which is higher than that of the annealed $\mathrm{Cu}$ by $275 \mathrm{MPa}$.

$\mathrm{Cu}$ metal matrix composites reinforced with varying amounts $(0.9,1.8,2.7$ and $3.6 \mathrm{vol} \%)$ of graphene particles were fabricated through powder metallurgy route by employing conventional and microwave sintering processes [57]. In both cases, it was found that with the addition of graphene, hardness increases as compared to pure $\mathrm{Cu}$ sample due to the superior mechanical properties of graphene. However, for the same graphene content, microwave sintered samples exhibited higher hardness compared to conventional counterparts. The highest hardness value of $89 \pm 2.4 \mathrm{HV}_{100}$ was observed for the microwaved sintered $\mathrm{Cu}-3.6 \mathrm{vol} \%$ graphene and $82 \pm 2.2 \mathrm{HV}_{100}$ for the conventional sintered one. This difference was attributed to the more rapid heating during microwave sintering resulting in a more refined and homogeneous microstructure.

An Ag-RGO hybrid was employed as reinforcement to prepare $\mathrm{Cu}-0.15 \mathrm{wt} \%$ graphene composites via $\mathrm{BM}$ followed by vacuum hot pressing sintering at $800{ }^{\circ} \mathrm{C}$ using a pressure of $30,40,50$ or $60 \mathrm{MPa}$ [64]. For
Figure 21 a Mechanical properties and $\mathbf{b} I_{\mathrm{D}} / I_{\mathrm{G}}$ ratios of $\mathrm{Cu} / \mathrm{GNPs}$ composites fabricated by a PM route varying the milling speed and time. Reproduced with permission from [27].
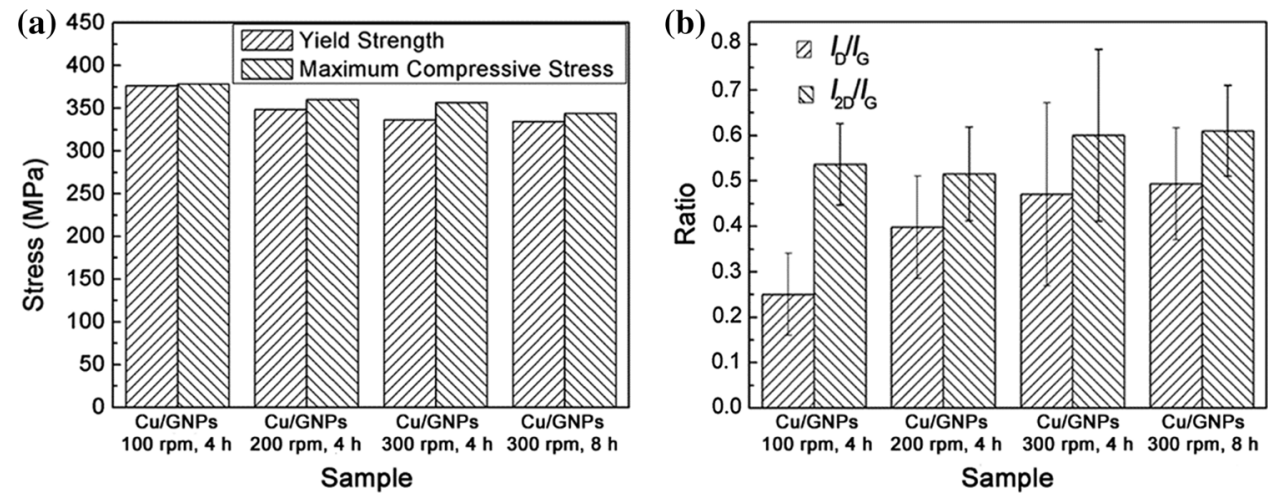
Figure 22 a TEM

micrograph of the interface between $\mathrm{Cu}$ and RGO.

b Micro-hardness of pure $\mathrm{Cu}$ and $\mathrm{Cu}-0.15 \mathrm{wt} \% \mathrm{Ag} / \mathrm{RGO}$

composites sintered at

different pressures.

Reproduced with permission from [64].
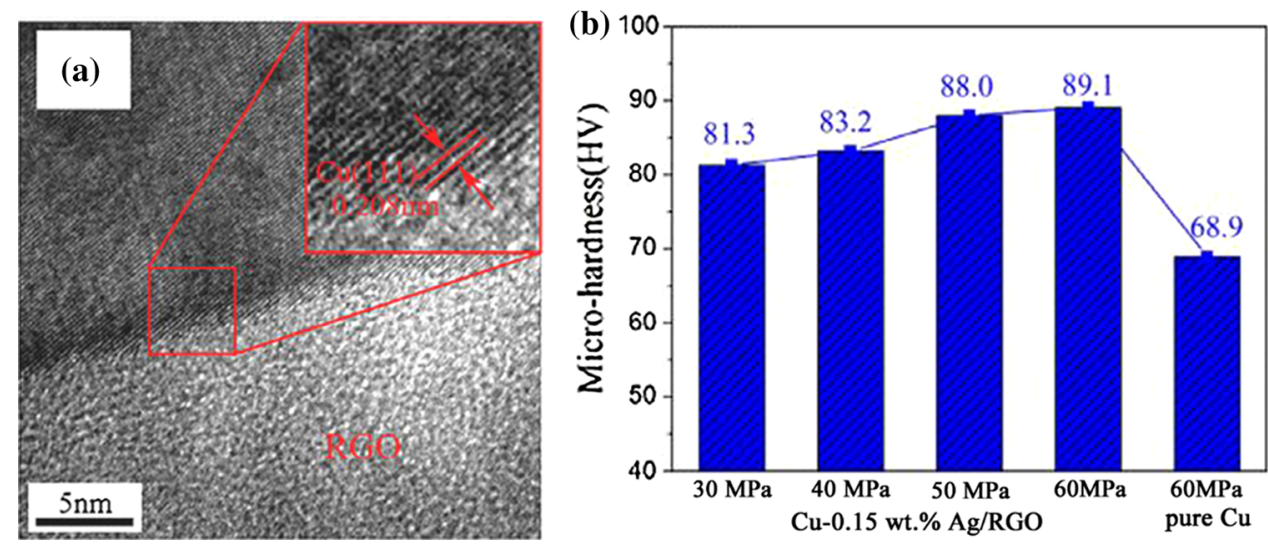

comparison, pure $\mathrm{Cu}$ specimens were also fabricated at $60 \mathrm{MPa}$. Due to the good bonding interface between RGO and $\mathrm{Cu}$ (Fig. 22a), promoted by the Ag NPs, the micro-hardness of the $\mathrm{Cu} / \mathrm{Ag}-\mathrm{RGO}$ was higher than that of pure $\mathrm{Cu}$ and increased with increase in sintering pressure (Fig. 22b). In addition to micro-hardness measurements, nanoindentation [150, 151] can also be employed to follow the effect of the addition of graphene in, for example, metal foils [31].

Cu-2 wt\% GNPs composites were fabricated by Ponraj et al. [104] through mixing the pure $\mathrm{Cu}$ and the GNPs powders using a mechanical stirrer, followed by compaction and conventional sintering. Two different $\mathrm{Cu}$ powders were used: spherical powders with an average size of $45 \mu \mathrm{m}$ and dendritic powders with an average size of $70 \mu \mathrm{m}$. Moreover, they were subjected to $\mathrm{BM}$ for different times before being mixed with GNPs. It was found that, for the same starting $\mathrm{Cu}$ powder morphology, the hardness of the composites increases with increase in the milling time. This was attributed to a higher reduction in the $\mathrm{Cu}$ powder size and to a better dispersion of GNPs into the $\mathrm{Cu}$ matrix. It was also apparent that, for the same milling time, the hardness of the composites fabricated with dendritic $\mathrm{Cu}$ powders was higher than that of the composites fabricated with spherical $\mathrm{Cu}$ powders, suggesting that the morphology of the starting $\mathrm{Cu}$ powders also has an effect on the mechanical properties of the $\mathrm{Cu} / \mathrm{GNPs}$ composites.

$\mathrm{Cu}$ matrix composites with a homogeneous dispersion of RGO sheets were successfully fabricated by a MLM method [109]. The composite powders were reduced in $\mathrm{H}_{2}$ at 350,450 and $550{ }^{\circ} \mathrm{C}$ and then consolidated by SPS. It was found that both the compressive yield stress and hardness increase with decrease in the reduction temperature. This has been related to an increase in the interface strength between graphene and copper caused by a lower degree of reduction in the functional groups in the graphene surface, which are required to form the oxygen-mediated bonding between $\mathrm{Cu}$ and graphene.

\section{Influence of the graphene derivative}

The effect of graphene structural defects on the mechanical behaviour of CMCs was also investigated by Li et al. [40]. Different amounts of RGO or high quality graphene (HQG) were mixed with copper powders by BM followed by SPS. The HQG was obtained from regular RGO by a hot pressing treatment. The hardness of both the $\mathrm{Cu} / \mathrm{RGO}$ and $\mathrm{Cu} / \mathrm{HQG}$ composites was higher than that of pure $\mathrm{Cu}$. However, due to the absence of defects on the surface of the HQG, the hardness of the $\mathrm{Cu} / \mathrm{HQG}$ composites is generally higher than that of the $\mathrm{Cu} / \mathrm{RGO}$ composites.

Zhang and Zhan [54] used two kinds of graphene derivatives, namely GNPs and RGO, to fabricate $\mathrm{Cu}$ matrix composites through a MLM process followed by SPS. Neither $\mathrm{Cu} / \mathrm{GNPs}$ nor $\mathrm{Cu} / \mathrm{RGO}$ composites showed obvious grain refinement compared to pure $\mathrm{Cu}$, and both GNPs and RGO were well bonded with the $\mathrm{Cu}$ matrix after sintering. RGO was more defective than GNPs. However, GNPs showed an obvious aggregative trend when the volume fraction was above $0.5 \%$. Consequently, GNPs showed better strengthening efficiency at content below $0.5 \mathrm{vol} \%$, while RGO performed better when the content increased from 0.5 to $1 \mathrm{vol} \%$ (Fig. 23).

In agreement with these results, the same authors observed in a different work [50] that the tensile strength of a Cu- 0.5 vol\% RGO composite increased by $22 \mathrm{MPa}$ compared with a Cu- 0.5 vol\% GNPs one, 


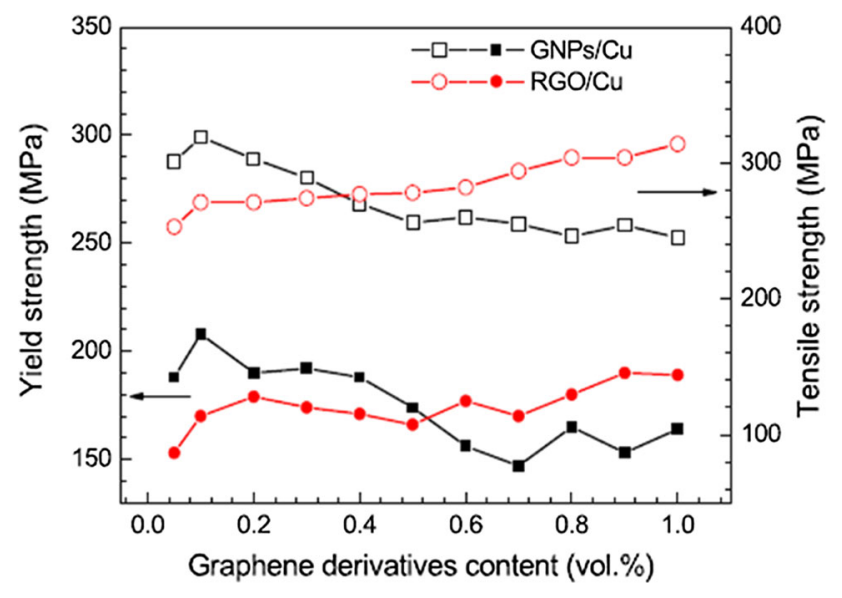

Figure 23 Yield and tensile strength of $\mathrm{Cu} /$ graphene derivatives composites versus graphene derivative volume fraction. Reproduced with permission from [54].

both fabricated by MLM and SPS (Table 1). However, in this case they attributed the difference to the fact that the interface bonding between RGO and $\mathrm{Cu}$ was stronger than that of GNPs with $\mathrm{Cu}$. In fact, a combination of mechanical and metallurgical bonding was observed between GNPs and the $\mathrm{Cu}$ matrix, while the interfacial adhesion between RGO and the copper matrix was oxygen-mediated chemical bonding.

\section{Effect of graphene modification}

$\mathrm{Ni}$ decorated graphene nanoplatelets (Ni-GNPs), consisting of well-dispersed Ni NPs strongly attached on GNPs, were synthesised by chemically reducing $\mathrm{Ni}$ ions on the surface of GNPs, which were then added to a $\mathrm{Cu}$ matrix to synthesise a $\mathrm{Cu}$ $0.8 \mathrm{vol} \% \mathrm{Ni} / \mathrm{GNPs}$ composite by sonication in ethyl alcohol and SPS [29]. For comparison, pure $\mathrm{Cu}$ specimens and a $\mathrm{Cu} / \mathrm{GNPs}$ composite with $0.8 \mathrm{vol} \%$
GNPs were also fabricated under the same processing conditions. The $\mathrm{Cu} / \mathrm{Ni}-\mathrm{GNPs}$ composite exhibited a significant improvement in ultimate tensile strength (UTS), being $42 \%$ higher than that of the monolithic $\mathrm{Cu}$ (Fig. 24a). In contrast, the UTS of the $\mathrm{Cu} / \mathrm{GNPs}$ composite was lower than that of the monolithic $\mathrm{Cu}$ (Fig. 24a). The significant strength enhancement of the first composite was attributed to the unique role of Ni NPs, which generate a good dispersion and strong $\mathrm{Cu}-\mathrm{GNPs}$ bonding. Hence, more stress can be transferred to the GNPs during deformation. Figure 24b, c shows the representative microstructure of the $\mathrm{Cu} / \mathrm{GNPs}$ and $\mathrm{Cu} / \mathrm{Ni}-\mathrm{GNP}$ composites. According to the SEM image of the $\mathrm{Cu} /$ GNP composite (Fig. 24b), the GNPs appear to be poorly dispersed in the $\mathrm{Cu}$ matrix forming aggregates in the surface. The authors claim [29] that the micrograph of the $\mathrm{Cu} / \mathrm{Ni}-\mathrm{GNP}$ composite (Fig. 24c) does not show any GNP aggregates although without any elemental mapping it is not possible to draw clear conclusions.

Zhang and Zhan [55] fabricated Cu-0.5 vol\% GNPs by a PM route. Electroless $\mathrm{Cu}$ and $\mathrm{Ni}$ plating were firstly performed on the surface of the GNPs before mixing with $\mathrm{Cu}$ powders in order to improve their wettability. The yield strength of the composites is higher than that of pure $\mathrm{Cu}$, which was attributed to grain refinement, an increase in dislocation density and better load transfer. The yield strength of the $\mathrm{Cu} / \mathrm{GNPs}-\mathrm{Cu}$ and $\mathrm{Cu} / \mathrm{GNPs}-\mathrm{Ni}$ composites is higher than that of the $\mathrm{Cu} / \mathrm{GNPs}$ composites, attributable to more uniform dispersion of the GNPs in the $\mathrm{Cu}$ matrix and to a better interfacial bonding. However, since the bonding of graphene is higher to $\mathrm{Ni}$ than to $\mathrm{Cu}[90,91,93,94,97]$, the wettability of the GNPs-Ni is better than that of the GNPs-Cu.
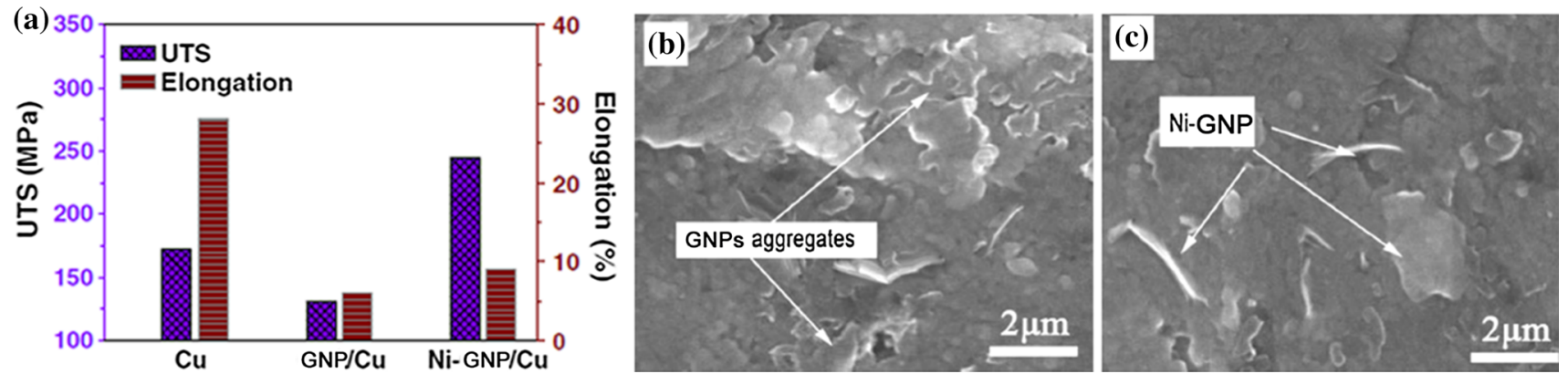

Figure 24 a Ultimate tensile strength (UTS) and elongation for pure $\mathrm{Cu}$ and the $\mathrm{Cu} / \mathrm{GNPs}$ and $\mathrm{Cu} / \mathrm{Ni}-\mathrm{GNPs}$ composites. SEM images of the $\mathbf{b} \mathrm{Cu}-0.8$ vol\% GNPs and $\mathbf{c} \mathrm{Cu}-0.8$ vol\% Ni/GNPs. Reproduced with permission from [29]. 


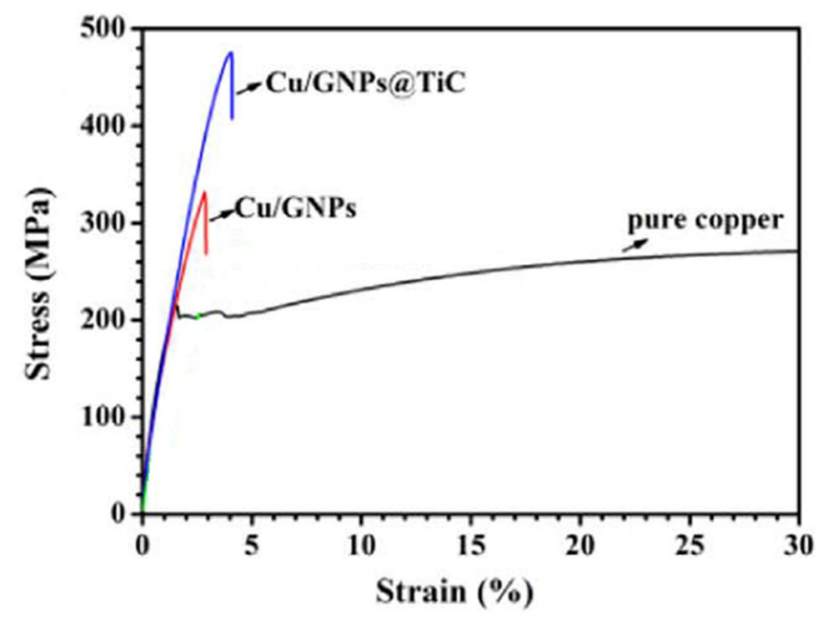

Figure 25 Stress-strain curves for pure $\mathrm{Cu}$ and the $\mathrm{Cu} / \mathrm{GNPs}$ and $\mathrm{Cu} / \mathrm{GNPs}-\mathrm{TiC}$ composites. Reproduced with permission from [67].

Therefore, the $\mathrm{Cu} / \mathrm{GNPs}-\mathrm{Ni}$ composite is stronger than the $\mathrm{Cu} / \mathrm{GNPs}-\mathrm{Cu}$ composite.

Copper matrix composites reinforced with carbidecoated GNPs were investigated in order to understand the role of the carbide interlayers on different properties of the $\mathrm{Cu} / \mathrm{GNPs}$ composites [67]. Figure 25 presents the stress-strain curves of pure $\mathrm{Cu}$ and the $\mathrm{Cu} / 0.5 \mathrm{wt} \%$ GNPs and $\mathrm{Cu} / 0.5 \mathrm{wt} \%$ GNPsTiC composites. The tensile strength of the two composites is higher than that of pure $\mathrm{Cu}$, which was attributed to grain refinement, dislocation strengthening and load transfer. However, for the $\mathrm{Cu} / \mathrm{GNPs}-$ TiC composite, the tensile strength was increased to $470 \pm 7 \mathrm{MPa}$, which is $40 \%$ higher than that of the $\mathrm{Cu} / \mathrm{GNPs}$ composite. This was attributed to an improvement of the interfacial properties and thus to a more efficient load transfer when reinforcing with Ti-coated GNPs than with bare GNPs.

\section{Ductility}

Due to graphene's lack of ductility, the addition of graphene usually results in lower ductility compared with the unreinforced $\mathrm{Cu}$ matrix, especially at higher graphene content (Table 1), where the presence of agglomerates, pores and interfaces, acting as preferred nucleation sites for cracks, is also higher $[23,28,29,35,37,43,54]$. Thus, the strengthening in $\mathrm{Cu} /$ graphene composites generally takes place at the expense of ductility [152]. However, there are a few cases where simultaneous improvements of strength and ductility were reported $[44,50,54,60,66]$. In the case of particulate $\mathrm{Cu} /$ graphene composites, this could be attributed to the presence of an interface that slows crack propagation through a crack-tip-shielding mechanism, taking advantage of graphene's high aspect ratio and large contact area with the matrix. However, this ductility might also arise from the wrinkled structure of graphene, which can be straightened during load transfer from the matrix, so that the ductility of the composite is maintained or even improved. In the case of nacre-inspired $\mathrm{Cu} /$ graphene composites, the increase in ductility may be related to the energy dissipation caused by the process of crack deflection [41], during which an initial crack tilts and twists and is forced to move out of the initial propagation plane when it encounters a rigid reinforcement (Fig. 26c). Typical fracture surface of such composites show a typical stepwise fracture observed parallel to layers and some graphene fragments are also observed on the fractured steps (Fig. 26a, b), indicating that the staggered graphene plays a role in hindering or deviating cracks.
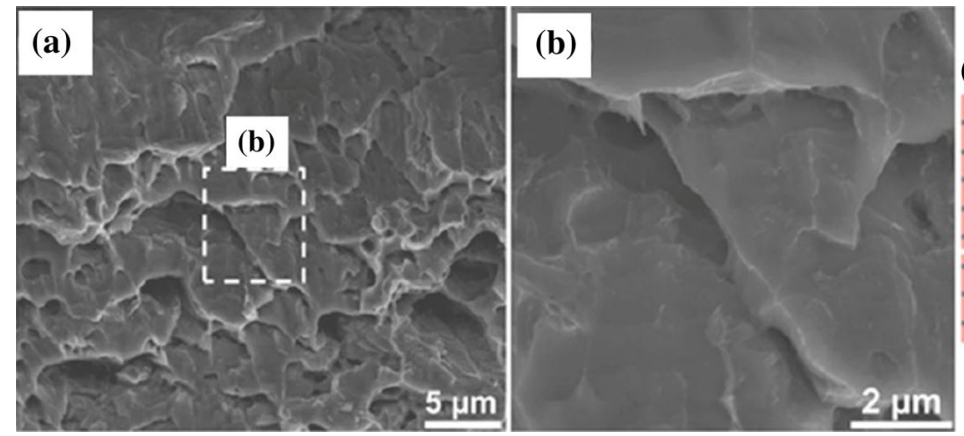

(c)

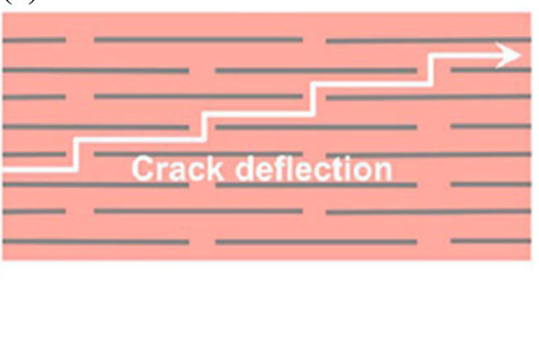

Figure 26 a Stepwise fracture parallel to the layers indicating and effective deflection of crack propagating along the $\mathrm{Cu}-\mathrm{RGO}$ interface in a nacre-inspired $\mathrm{Cu} / \mathrm{RGO}$ composite. $\mathbf{b}$ Enlargement of the box marked in image (a). c Schematic representation of crack deflection. Reproduced with permission of the American Chemical Society from [41]. 


\section{Electrical properties}

\section{Electrical conductivity}

Owing to the excellent electrical conductivity of graphene, it has been used as filler for the enhancement of electrical conductivity of $\mathrm{Cu}$. As a matter of fact, an improvement as high as $20-30 \%$ was observed for electrodeposited particulate composite films [24, 33]. However, the literature reveals that the enhancement of electrical conductivity in $\mathrm{Cu} /$ graphene composites is sometimes quite modest or even negative compared with the unreinforced alloys, the exact enhancements depending on the graphene content, the processing route conditions and the graphene derivative (Table 2). Note that, even in the cases of decreased conductivity, electrical conductivity of most of the $\mathrm{Cu} /$ graphene composites is still more than $70-80 \%$ of that of the reference $\mathrm{Cu}$, which indicates that the graphene additions do not reduce the electrical conductivity of $\mathrm{Cu}$ significantly.

Electrical conductivity $(\kappa)$ in metals is accomplished by the movement of free electrons and can be expressed by [40]:

$\kappa=n|e| \mu_{\mathrm{e}}$

where $n$ is the density of electrons, $e$ is the electron charge, and $\mu_{\mathrm{e}}$ is the mobility of electrons. One factor affecting electron mobility is the presence of obstacles such as grain boundaries, dislocation, graphene and oxide or carbide particles, which determine the mean-free path (MFP) of electrons. Other important factors affecting the electrical conductivity of the $\mathrm{Cu}$ /graphene composites are the interfaces between and the presence of non-conductive open spaces (e.g. pores or voids), where the electrons are scattered during their transmission, and the graphene characteristics. Other factors such as the presence of less conductive phases cannot be neglected. The electrical conductivity of the $\mathrm{Cu}$ /graphene composites is usually expressed in \% IACS. IACS stands for International Annealed Copper Standard, a unit of electrical conductivity for metals and alloys relative to a standard annealed copper conductor whose conductivity is $58 \mathrm{MS} / \mathrm{m}$ at $20^{\circ} \mathrm{C}$ [27].

\section{Influence of graphene content}

The effect of graphene content upon electrical conductivity for $\mathrm{W}_{70} \mathrm{Cu}_{30}$ /graphene composites fabricated by BM and LPS is shown in Fig. 27a [61]. It can be seen from the picture that, unlike hardness, which increases with increase in graphene content, the electrical conductivity tends to increase gradually first and decrease sharply then with increase in the graphene content. The electrical conductivity of the $\mathrm{W}_{70} \mathrm{Cu}_{30}$ alloy was $42 \%$ IACS, while that of the $\mathrm{W}_{70} \mathrm{Cu}$ /graphene composites was $\sim 46 \%$ IACS when the doping amount of graphene was $0.5 \mathrm{wt} \%$, which is attributed to the high electrical conductivity of graphene. However, the electrical conductivity of $1.0 \mathrm{wt} \%$ bulk composites was only $38.3 \%$ IACS, which was reduced by $10 \%$ compared with $\mathrm{W}_{70} \mathrm{Cu}_{30}$ alloys without any additive. For $\mathrm{W}_{70} \mathrm{Cu}_{30}$ composites with $1.0 \mathrm{wt} \%$ graphene addition, tungsten carbides (WC and $\mathrm{W}_{2} \mathrm{C}$ phases) were formed. Figure $27 \mathrm{~b}$, c presents the XRD pattern of the $\mathrm{W}_{70} \mathrm{Cu}_{30}$ alloy doped with different graphene contents both after BM (Fig. 27b) and sintering by LPS (Fig. 27c) [61]. In Fig. 27b, it is clearly seen that all the samples have only the major $\mathrm{W}$ and $\mathrm{Cu}$ peaks after BM. However, it is notable that new peaks are still observed after sintering (Fig. 27c). In particular, for $1 \mathrm{wt} \%$ graphene, tungsten carbides, whose formation may be promoted by the presence of defects in graphene (Fig. 14), can be identified. It is not clear from this study, however, why carbide formation only takes place for $1 \mathrm{wt} \%$ graphene loading. For the electrical conductivity, the presence of carbide is equivalent to adding obstacles to the electron mobility in the WCu alloys. Furthermore, the electrical conductivity of tungsten carbides is much lower than that of pure $\mathrm{W}$ and $\mathrm{Cu}$ as well as they inevitably increase the number of interphases and hence electron scattering. As a result, the $\mathrm{W}_{70} \mathrm{Cu}_{30}$ alloys with $1.0 \mathrm{wt} \%$ graphene addition have lower conductivity in comparison with that of $\mathrm{W}_{70} \mathrm{Cu}_{30}$ alloys without any addition.

$\mathrm{Cu} /$ graphene composites have been prepared by electroless plating of graphene with $\mathrm{Ni}$ particles [66], and it is found that at a content of $0.13 \mathrm{wt} \%$, the electrical conductivity of the composite is comparable to that of pure $\mathrm{Cu}$. However, a dramatic drop of the electrical conductivity occurs at higher EPG contents. This decline has been ascribed to a weakening of the interface bonding with increase in the content of EPG.

Figure 28a shows the electrical conductivity of $\mathrm{Cu}$ / GNPs composites synthesised by BM and HP with varying graphene content [102]. Upon increasing the graphene content, the electrical conductivity first 
Table 2 Electrical conductivity of $\mathrm{Cu} /$ graphene composites prepared by different methods employing different graphene derivatives

\begin{tabular}{|c|c|c|c|c|}
\hline References & Processing route & Material & Relative density (\%) & $\begin{array}{l}\text { Electrical conductivity ( } \% \\
\text { IACS) }\end{array}$ \\
\hline \multirow[t]{2}{*}{ [20] } & \multirow[t]{2}{*}{ Electrodeposition } & $\mathrm{Cu}$ & & 76 \\
\hline & & $\mathrm{Cu} /$ graphene & & $84(10.5 \%)$ \\
\hline \multirow[t]{11}{*}{ [24] } & \multirow[t]{5}{*}{ Electrodeposition } & $\mathrm{Cu}$ & & 81.8 \\
\hline & & $\mathrm{Cu}$-graphene1 & & $97.7(19 \%)$ \\
\hline & & $\mathrm{Cu}$-graphene 2 & & $89.5(9 \%)$ \\
\hline & & $\mathrm{Cu}$-graphene3 & & $87.3(7 \%)$ \\
\hline & & $\begin{array}{l}\mathrm{Cu} \text {-graphene } 4 \\
\text { (The content of graphene decreases } \\
\text { when going from } \mathrm{Cu} \text {-graphene } 1 \\
\text { to } \mathrm{Cu} \text {-graphene4) }\end{array}$ & & $82.3(0.6 \%)$ \\
\hline & With stirring & $\mathrm{Cu}$ & & 81.8 \\
\hline & & $\mathrm{Cu}$-graphene5 & & $92.2(13 \%)$ \\
\hline & & $\mathrm{Cu}$-graphene6 & & $82.4(0.7 \%)$ \\
\hline & & $\mathrm{Cu}$-graphene 7 & & $77.6(-5.1 \%)$ \\
\hline & & $\mathrm{Cu}$-graphene8 & & $74.9(-8.4 \%)$ \\
\hline & & $\begin{array}{l}\text { (The content of graphene decreases } \\
\text { when going from } \mathrm{Cu} \text {-graphene } 5 \\
\text { to } \mathrm{Cu} \text {-graphene } 8 \text { ) }\end{array}$ & & \\
\hline \multirow[t]{4}{*}{ [26] } & \multirow{2}{*}{$\begin{array}{l}\text { Direct synthesis of graphene on } \mathrm{Cu} \\
\text { powders }\end{array}$} & $\mathrm{Cu}$ & & 100 \\
\hline & & $\mathrm{Cu}-3 \mathrm{wt} \%$ graphene & & $95(-5 \%)$ \\
\hline & & & & \\
\hline & \multicolumn{4}{|l|}{ Hot rolling } \\
\hline \multirow[t]{6}{*}{ [27] } & Ball milling & Cu-2.4 vol\% GNPs (4 h milling, & 94.7 & 70.4 \\
\hline & + & $100 \mathrm{rpm})$ & 93.3 & 62.8 \\
\hline & \multirow{4}{*}{ Spark plasma sintering } & Cu-2.4 vol\% GNPs ( $4 \mathrm{~h}$ milling, & 91.7 & 61.4 \\
\hline & & $200 \mathrm{rpm})$ & 91.1 & 58.1 \\
\hline & & $\begin{array}{l}\text { Cu- } 2.4 \text { vol } \% \text { GNPs ( } 4 \mathrm{~h} \text { milling, } \\
300 \mathrm{rpm} \text { ) }\end{array}$ & & \\
\hline & & $\begin{array}{l}\text { Cu- } 2.4 \text { vol } \% \text { GNPs ( } 8 \mathrm{~h} \text { milling, } \\
300 \mathrm{rpm})\end{array}$ & & \\
\hline \multirow[t]{2}{*}{ [31] } & \multirow[t]{2}{*}{ Pulse reverse electrodeposition } & $\mathrm{Cu}$ & & 100 \\
\hline & & $\mathrm{Cu}-\mathrm{GO}$ & & $75(-25 \%)$ \\
\hline \multirow[t]{9}{*}{ [33] } & \multirow[t]{9}{*}{ Electrodeposition } & $\mathrm{Cu}(-0.8 \mathrm{~V}, 10 \mathrm{~min})$ & & 44.8 \\
\hline & & $\mathrm{Cu} / \mathrm{RGO}(-0.8 \mathrm{~V}, 1 \mathrm{~min})$ & & $53.4(19 \%)$ \\
\hline & & $\mathrm{Cu} / \mathrm{RGO}(-0.8 \mathrm{~V}, 5 \mathrm{~min})$ & & $52.6(17 \%)$ \\
\hline & & $\mathrm{Cu} / \mathrm{RGO}(-0.8 \mathrm{~V}, 10 \mathrm{~min})$ & & $57.2(28 \%)$ \\
\hline & & $\mathrm{Cu} / \mathrm{RGO}(-0.8 \mathrm{~V}, 120 \mathrm{~min})$ & & $53.3(19 \%)$ \\
\hline & & $\mathrm{Cu} / \mathrm{RGO}(-1.2 \mathrm{~V}, 20 \mathrm{~min})$ & & $55.3(23 \%)$ \\
\hline & & $\mathrm{Cu} / \mathrm{RGO}(-1.2 \mathrm{~V}, 30 \mathrm{~min})$ & & $49.7(11 \%)$ \\
\hline & & $\mathrm{Cu} / \mathrm{RGO}(-1.2 \mathrm{~V}, 60 \mathrm{~min})$ & & $50.1(12 \%)$ \\
\hline & & $\mathrm{Cu} / \mathrm{RGO}(-0.4 \mathrm{~V}, 180 \mathrm{~min})$ & & $53.4(19 \%)$ \\
\hline \multirow[t]{6}{*}{ [36] } & \multirow{6}{*}{$\begin{array}{l}\text { Ball milling } \\
+ \\
\text { Hot pressing }\end{array}$} & $\mathrm{Cu}$ & & 100 \\
\hline & & Cu- 1 wt $\%$ coarse GNPs & & $65(-35 \%)$ \\
\hline & & $\mathrm{Cu}-2 \mathrm{wt} \%$ coarse GNPs & & $62.3(-38 \%)$ \\
\hline & & $\mathrm{Cu}$ & & 100 \\
\hline & & Cu-1 wt $\%$ fine GNPs & & $77.3(-23 \%)$ \\
\hline & & $\mathrm{Cu}-2 \mathrm{wt} \%$ fine GNPs & & $74.7(-25 \%)$ \\
\hline [38] & Ball milling & $\mathrm{Cu}$ & 98.1 & 93 \\
\hline & + & $\mathrm{Cu}-0.5 \mathrm{wt} \%$ GNPs & 95.3 & $78.6(-15.5 \%)$ \\
\hline & Conventional sintering & $\mathrm{Cu}-1 \mathrm{wt} \%$ GNPs & 94.8 & $77.1(-17.1 \%)$ \\
\hline & & $\mathrm{Cu}-1.5 \mathrm{wt} \%$ GNPs & 94.5 & $76.7(-17.5 \%)$ \\
\hline & & $\mathrm{Cu}-2 \mathrm{wt} \%$ GNPs & 93.8 & $75(-19.4 \%)$ \\
\hline & & $\mathrm{Cu}-2.5 \mathrm{wt} \% \mathrm{GNPs}$ & 93.9 & $72.9(-21.6 \%)$ \\
\hline & & $\mathrm{Cu}-3 \mathrm{wt} \%$ GNPs & 91.7 & $72.1(-22.5 \%)$ \\
\hline & & $\mathrm{Cu}-5 \mathrm{wt} \%$ GNPs & & $61.4(-34 \%)$ \\
\hline [41] & Preform impregnation & $\mathrm{Cu}$ & & 96 \\
\hline & + & $\mathrm{Cu}-0.3$ vol $\%$ RGO & & $95(-1 \%)$ \\
\hline & HP & $\mathrm{Cu}-1.2$ vol\% RGO & & $98(2 \%)$ \\
\hline [43] & Molecular level mixing & $\mathrm{Cu}$ & 97.5 & 92.5 \\
\hline & + & $\mathrm{Cu}-0.2$ vol $\%$ GNPs & 97 & $90(-3 \%)$ \\
\hline & Spark plasma sintering & $\mathrm{Cu}-0.4$ vol\% GNPs & 96.5 & $87.5(-5 \%)$ \\
\hline & & $\mathrm{Cu}-0.6$ vol\% GNPs & 96 & $88(-5 \%)$ \\
\hline & & $\mathrm{Cu}-0.8$ vol $\%$ GNPs & 95.6 & $87(-6 \%)$ \\
\hline & & $\mathrm{Cu}-2$ vol $\%$ GNPs & & $84(-9 \%)$ \\
\hline & & $\mathrm{Cu}-4$ vol $\%$ GNPs & & $79.5(-14 \%)$ \\
\hline
\end{tabular}


Table 2 continued

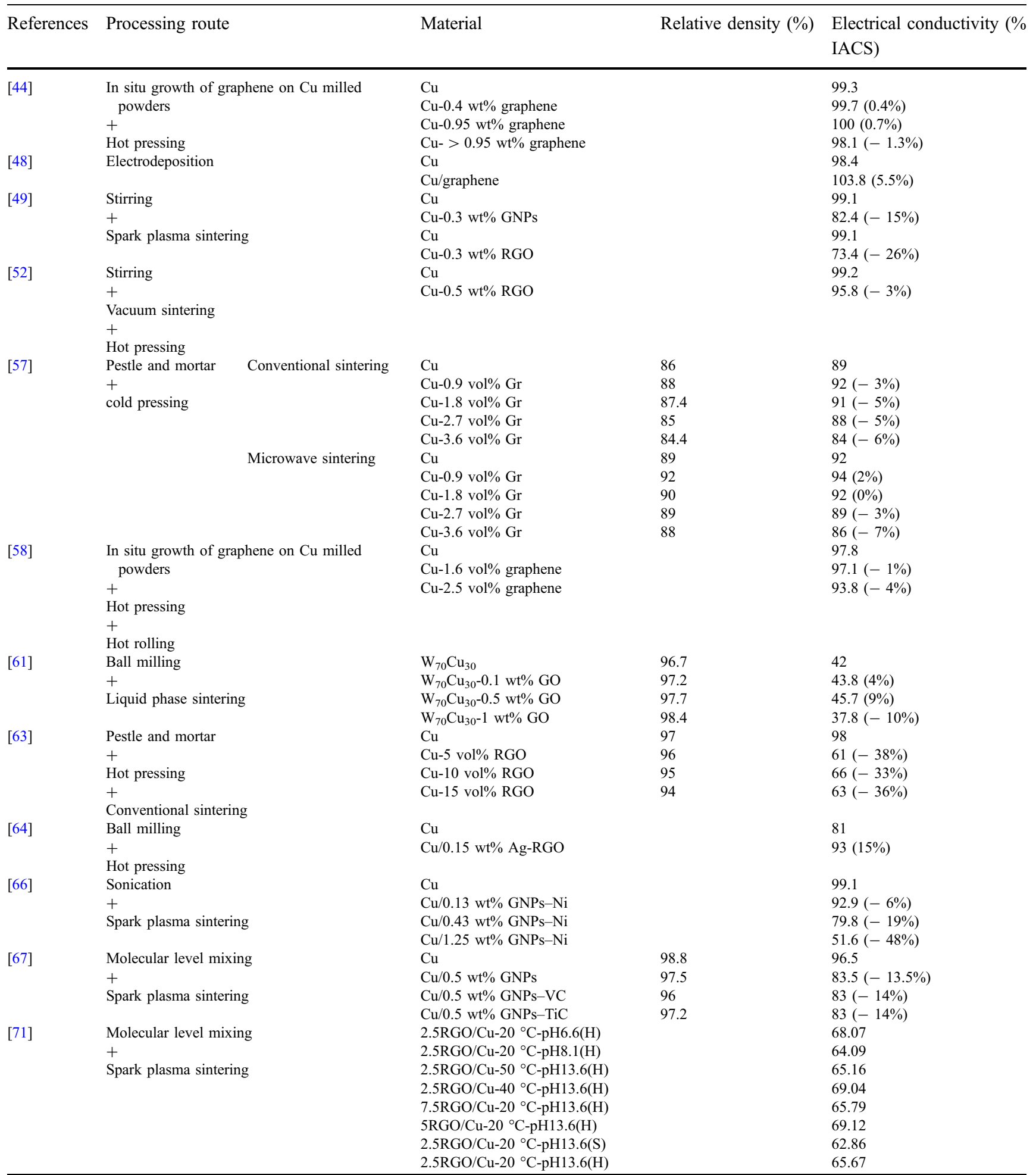


Table 2 continued

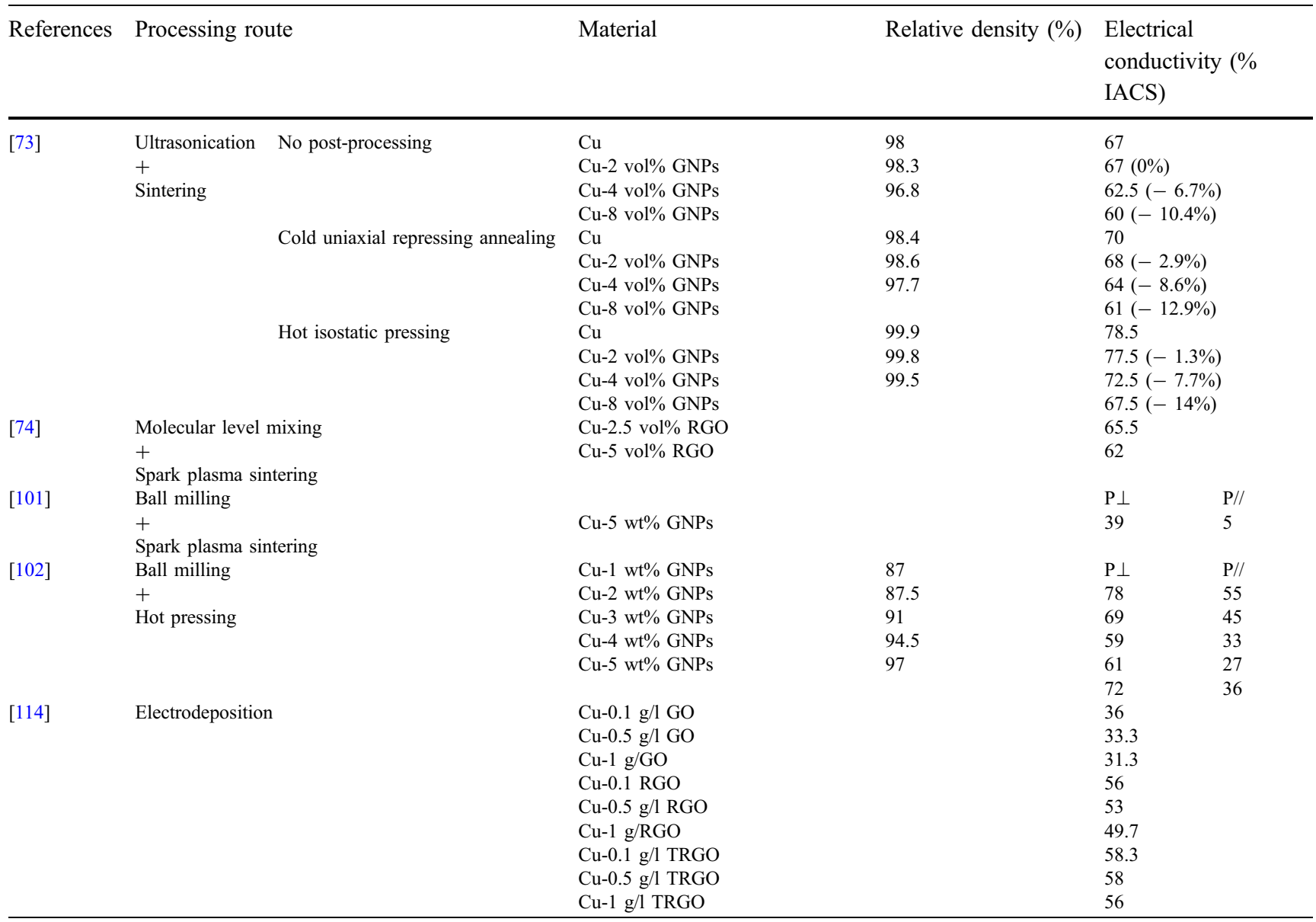

$\mathrm{P} \perp$ and $\mathrm{P} /$ /indicate properties in the directions perpendicular and parallel to the consolidation direction, respectively. The numbers in brackets indicate the percentage increase in the corresponding property compared to the matrix. TRGO stands for thermally reduced graphene oxide. (IACS - International Annealed Copper Standard)

decreases and then increases with the minimum electrical conductivity reached at 3-4 wt\% graphene. At low graphene content, the movement of free electrons, and thus the electrical conductivity, decreases with increase in graphene content. However, compactness is another important factor for electrical conductivity. The density and relative density of the composites is shown in Fig. 28b. It is observed that the relative density of the composites increases with increase in the graphene weight fraction, that could promote an enhancement of the electrical conductivity for graphene contents above 3-4 wt\%. From Fig. 28a, it can be also seen that the composites are anisotropic. So, the electrical conductivity perpendicular $(\mathrm{P} \perp)$ to the direction of sintering pressure is higher than the electrical conductivity parallel $(\mathrm{P} / /)$ to the direction of sintering pressure. This can be explained because graphene usually aligns in the direction perpendicular to the consolidation force in the $\mathrm{Cu}$ matrix and the electrical conductivity of graphene is much higher in the in-plane than the through-plane direction. It appears, however, that the alignment of the graphene changes with graphene loading.

\section{Influence of processing conditions}

The effect of two different post-processing treatments (cold uniaxial repressing annealing and hot isostatic pressing) on the electrical conductivity of pure $\mathrm{Cu}$ and $\mathrm{Cu} / \mathrm{GNPs}$ composites fabricated by wet mixing and sintering is shown in Fig. 29a [73]. It can be seen that in all the cases the electrical conductivity increases after post-processing, especially after hot 

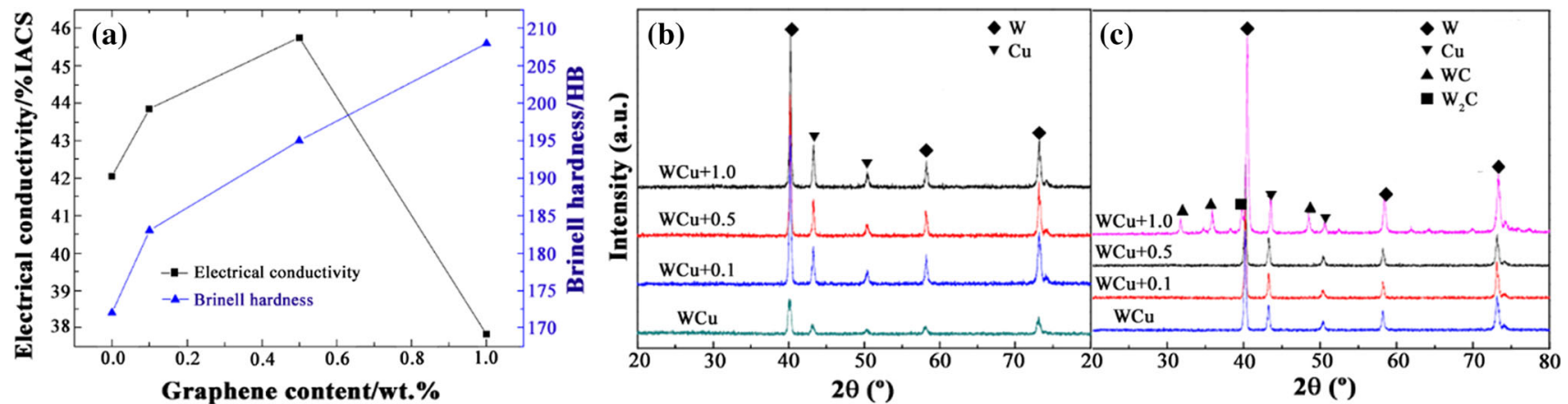

Figure 27 a Variation of Brinell hardness and electrical conductivity of $\mathrm{W} 70 \mathrm{Cu} 30 /$ graphene composites as a function of graphene content. XRD patterns of $\mathbf{b} \mathrm{W} 70 \mathrm{Cu} 30 /$ graphene powders

and $\mathbf{c} \mathrm{W}_{70} \mathrm{Cu}_{30} /$ graphene bulk composites doped with different graphene weight percentages. Reproduced with permission from [61].
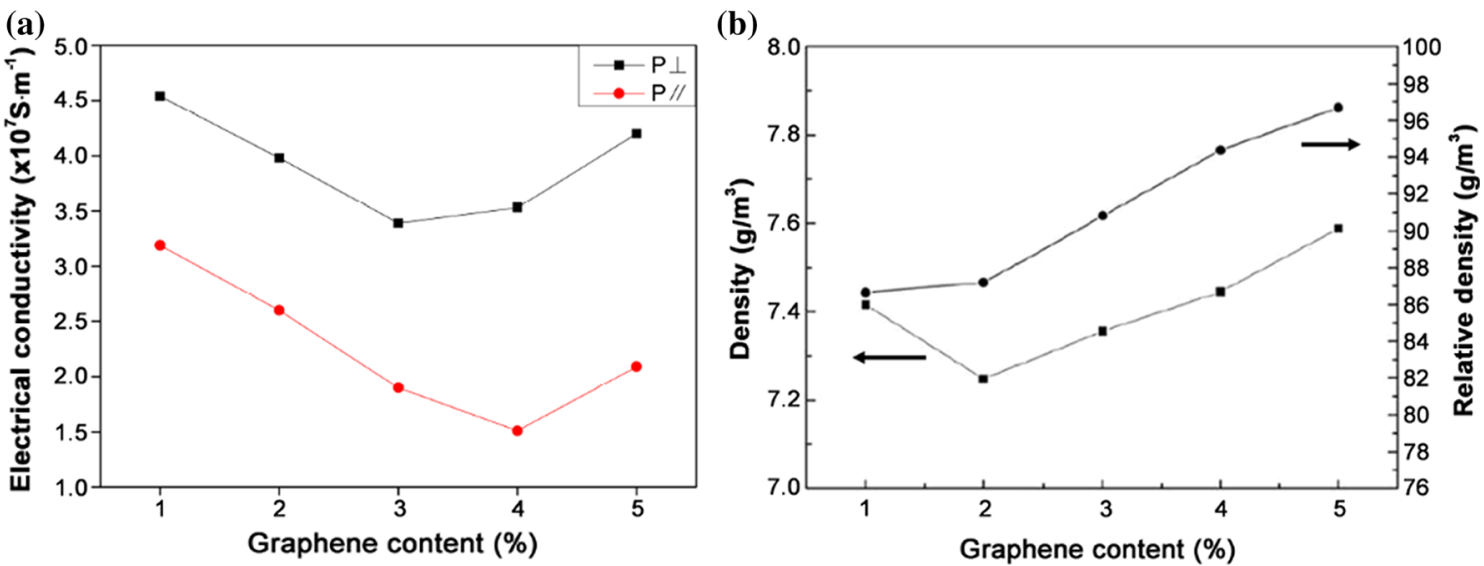

Figure 28 a Electrical conductivity and $\mathbf{b}$ density of $\mathrm{Cu} / \mathrm{GNPs}$ composites as a function of the graphene content. $\mathrm{P} \perp$ and $\mathrm{P} / /$ indicate the directions perpendicular and parallel to the consolidation direction, respectively. Reproduced with permission from [102].

isostatic pressing, which can be mainly attributed to a decrease of the residual porosity. Figure $29 \mathrm{~b}$ shows the comparison of the theoretical and measured densities of $\mathrm{Cu}$ as a function of graphene content. In agreement with the relative electrical properties, it is evident that the densities of pure $\mathrm{Cu}$ and $\mathrm{Cu}$ composites increased when using post-processing techniques, especially with hot isostatic pressing.
The electrical conductivity of $\mathrm{Cu}-2.4$ vol\% RGO composites fabricated by MLM using 350, 450 or $550{ }^{\circ} \mathrm{C}$ as the $\mathrm{H}_{2}$ reduction temperature and then consolidated by SPS is shown in Fig. 30 [109]. It can be seen that the conductivity of the $\mathrm{Cu} / \mathrm{RGO}-450$ is the highest among those of the three composites. In order to understand the change of conductivity, the measured results of density show that the relative
Figure 29 a Electrical conductivity and $\mathbf{b}$ theoretical and measured densities of pure $\mathrm{Cu}$ and its composites as a function of graphene content for the as-sintered and postprocessed samples.

Reproduced with permission from [73].
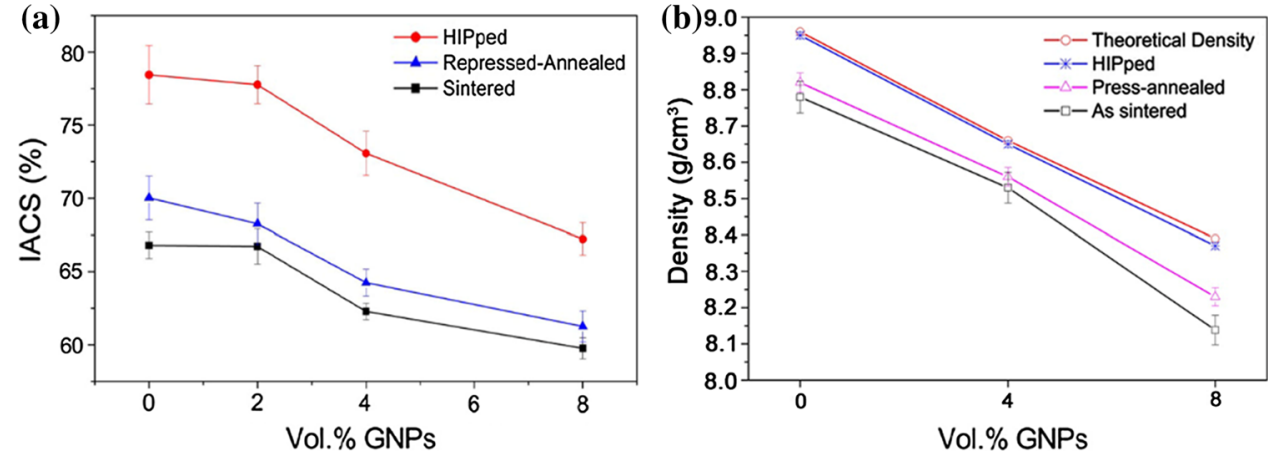


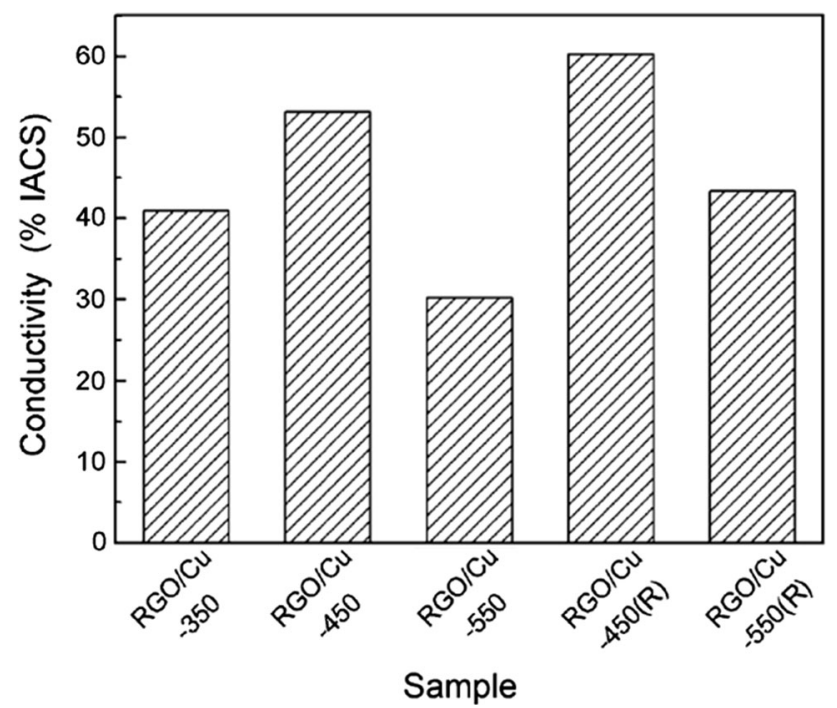

Figure 30 Electrical conductivity of $\mathrm{Cu} / \mathrm{RGO}$ composites fabricated by molecular level mixing at different reduction temperatures $\left(350,450\right.$ and $550{ }^{\circ} \mathrm{C}$ ) followed by spark plasma sintering (SPS). R indicates rolling after SPS. Reproduced with permission from [109].

densities of the $\mathrm{Cu} / \mathrm{RGO}$ composites reduced at temperatures of 350,450 and $550{ }^{\circ} \mathrm{C}$ are $87.3,93.5$ and $88.9 \%$, respectively. It is worth noting that the variation trend of the conductivity is similar to that of the density of the composites, suggesting again that porosity is the key factor for the change of electrical conductivity. It can be also seen that the conductivities of the composites treated by hot rolling after SPS are higher than those of the composites before hot rolling. So, hot rolling can improve the electrical conductivity of the composites. This has been mainly attributed to a reduction in porosity.

\section{Influence of graphene derivative and size}

Li et al. [40] reported better electrical conductivity for the CMCs containing HQG than for those containing regular RGO. The higher electrical conductivity of the $\mathrm{Cu} / \mathrm{HQG}$ composites for graphene contents lower than $5 \mathrm{wt} \%$ was attributed to the much higher electrical conductivity in HQG than in RGO. It was also shown that, when the HQG content is lower than $1 \mathrm{wt} \%$, the electrical conductivity increased gradually with increase in the graphene content. However, when the HQG content was higher than $1 \mathrm{wt} \%$, the electrical conductivity began to decrease. SEM examination revealed that with

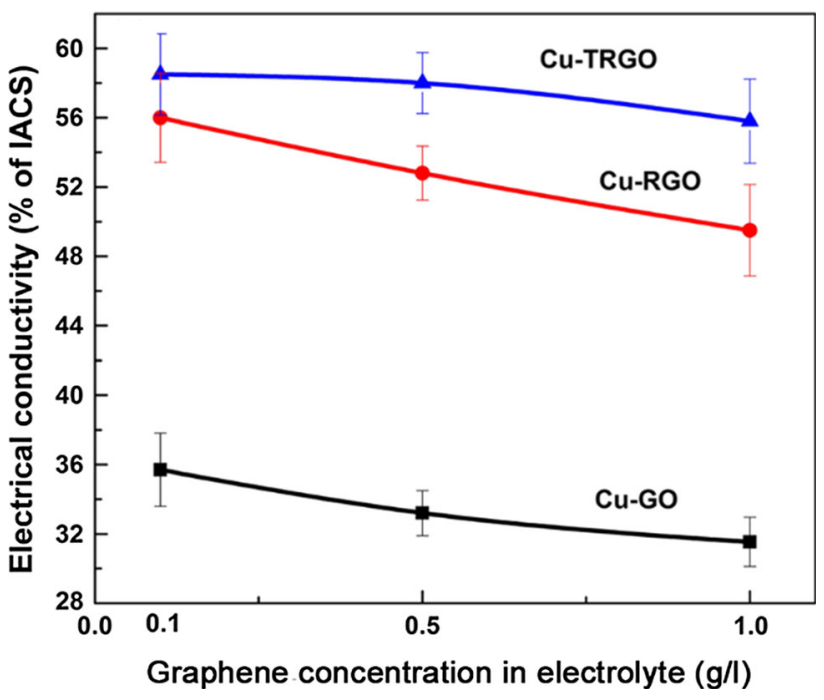

Figure 31 Electrical conductivity of $\mathrm{Cu} /$ graphene oxide (GO), $\mathrm{Cu} /$ chemically reduced $\mathrm{GO}(\mathrm{RGO})$ and $\mathrm{Cu} /$ thermally reduced $\mathrm{GO}$ (TRGO) composite coatings produced by electrodeposition. Reproduced with permission from [114].

increase in the HQG content, the cavities in the composite gradually increased in quantity and size because of the poor wettability between graphene and $\mathrm{Cu}$. This is the reason why the electrical conductivity of the composites was reduced over the optimum HQG content.

The electrical conductivity of CMC coatings filled with different contents of GO, chemically reduced GO (RGO) and thermally reduced GO (TRGO) is presented in Fig. 31 [114]. It can be observed that the $\mathrm{Cu} / \mathrm{GO}$ composite coatings show very low conductivity compared to the $\mathrm{Cu} / \mathrm{RGO}$ and the $\mathrm{Cu} / \mathrm{TRGO}$ composite coatings, which is due to the insulating nature of GO caused by the presence of a high amount of oxygen. In contrast, the better electrical conductivity of the $\mathrm{Cu}$ / RGO and the $\mathrm{Cu} / \mathrm{TRGO}$ coatings was attributed to the reduction in major oxygen-containing functional groups during the reduction process, especially during thermal reduction.

\section{Effect of graphene modification}

Transition metal carbide ( $\mathrm{TiC}$ and VC) coatings were synthesised on GNPs to improve the interfacial properties of $\mathrm{Cu} / \mathrm{GNPs}$ composites fabricated by MLM [67]. However, this had no effect on the electrical conductivity of the $\mathrm{Cu} / \mathrm{GNPs}$ composites, which probably due to the presence of pores, is lower than that of pure $\mathrm{Cu}$ (Fig. 32). On the contrary, the 


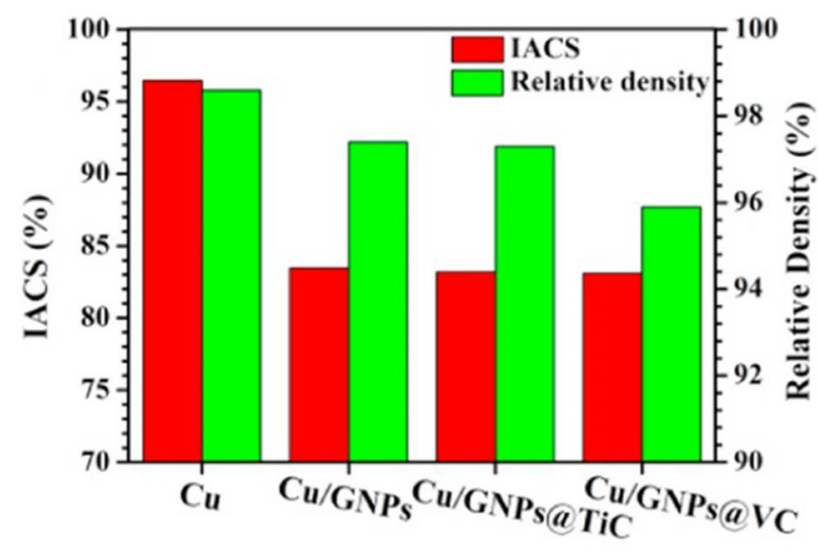

Figure 32 Electrical conductivity and relative density of pure $\mathrm{Cu}$ and the $\mathrm{Cu} / 0.5 \mathrm{wt} \% \mathrm{GNPs}, \mathrm{Cu} / 0.5 \mathrm{wt} \%$ GNPs-TiC and $\mathrm{Cu} /$ $0.5 \mathrm{wt} \%$ GNPs-VC composites. Reproduced with permission from [67].

good electrical conductivity of the Cu- $0.15 \mathrm{wt} \% \mathrm{Ag} /$ RGO composite, which is $15 \%$ higher than that of pure $\mathrm{Cu}$ synthetised by the same route, could be attributed to the good bonding interface of $\mathrm{Ag}-\mathrm{Cu}$ and Ag-RGO (Fig. 22a) [64].

\section{Arc erosion}

The effect of graphene addition on arc ablation behaviour of $\mathrm{W}_{70} \mathrm{Cu}_{30}$ contacts was investigated by Dong et al. [62] from the measurement of weight loss and vacuum electrical breakdown tests. A pure $\mathrm{W}$ rod with a tip radius of $3 \mathrm{~mm}$ was used as an anode. Samples of $\mathrm{W}_{70} \mathrm{Cu}_{30}-0.5 \mathrm{wt} \%$ graphene fabricated by $\mathrm{BM}$ and LPS were put onto the objective table just below the anode as a cathode. When the work chamber was evacuated to $1.5 \times 10^{-2} \mathrm{~Pa}$, the capacitor of $120 \mu \mathrm{F}$ was charged to a voltage of $10 \mathrm{kV}$ and the lower cathode moved upward at a speed of $0.01 \mathrm{~mm} / \mathrm{s}$ until the gap was broken down. After the arc extinguished, the electrical breakdown test was repeated 100 times. The weight loss after arc ablation was measured using an electronic balance. The breakdown strength was calculated by the distance between 2 electrodes, measured by a digital micrometre.

Relationships between dielectric strength and number of breakdowns of $\mathrm{W}_{70} \mathrm{Cu}_{30}$ alloys without and with $0.5 \mathrm{wt} \%$ graphene were investigated [62]. It was found that the breakdown strength of the $\mathrm{W}_{70} \mathrm{Cu}_{30}$ alloys remained approximately constant at $5.5 \times 10^{6} \mathrm{~V} / \mathrm{m}$, while for $\mathrm{W}_{70} \mathrm{Cu}_{30}-0.5 \mathrm{wt} \%$ graphene composite, the breakdown strength increased with increase in the breakdown times, reaching values of about $8 \times 10^{6} \mathrm{~V} / \mathrm{m}$. However, when the arc breakdowns are below 20 times, the breakdown strength of the composite was lower than that of the $\mathrm{W}_{70} \mathrm{Cu}_{30}$ alloys. In contrast, above 20 arc breakdowns, the breakdown strength of the composite was higher than that of the alloy without graphene additions.

The enhancement of the breakdown strength of the $\mathrm{W}_{70} \mathrm{Cu}_{30}$ alloys with graphene additions was explained as follows [62]. Firstly, under the same circumstances, arc breakdown is usually formed at the phase with lowest work function $(\varphi)$. So, in $\mathrm{W}_{70} \mathrm{Cu}_{30}$ alloys the arc breakdown focuses on the $\mathrm{Cu}$ phase, while in the $\mathrm{W}_{70} \mathrm{Cu}_{30}$ /graphene composites it concentrates on graphene phase due to its lower work function $\left(\varphi_{\text {graphene }}(4.2 \mathrm{eV})<\varphi_{\mathrm{Cu}}(4.36\right.$ $\left.\mathrm{eV})<\varphi_{\mathrm{W}}(4.55 \mathrm{eV})\right)$. Moreover, graphene has a high melting point and relatively high conductivity, and thus can consume arc energy when the arc breakdown primarily occurs through graphene. Secondly, graphene can effectively refine $\mathrm{W}$ particles and also improve the wettability of $\mathrm{W}$ and $\mathrm{Cu}$. As a result, $\mathrm{Cu}$ phase is distributed more homogeneously in the $\mathrm{W}$ skeleton. Figure 33 depicts the surface SEM micrographs and EDS patterns of the samples after 100 breakdowns. As seen from Fig. 33a, a number of arc erosion pits are present in the $\mathrm{W}_{70} \mathrm{Cu}_{30}$ alloy. Further magnifications (Fig. 33b) show the presence of deep holes and particles on the surface. The EDS analyses reveal that in the holes $\mathrm{Cu}$ disappear (Fig. 33e), while the particles are mainly composed of $\mathrm{Cu}$ (Fig. 33f). This proves that the $\mathrm{Cu}$ phase is splashed out during the process of breakdown. After solidification, the sputtered molten $\mathrm{Cu}$ forms particles on the surface. Compared with the $\mathrm{W}_{70} \mathrm{Cu}_{30}$ alloy, it was found that the surface of the $\mathrm{W}_{70} \mathrm{Cu}_{30}$ /graphene composites is flatter and shows smaller erosion areas (Fig. 33c, d). Moreover, in Fig. 33g, a carbon peak is observed, confirming that the arc focuses on graphene in the composite materials. Although this work has given useful insight into the mechanisms involved in arc erosion, a more complete picture might be obtained through depth profiling of the graphene content. 

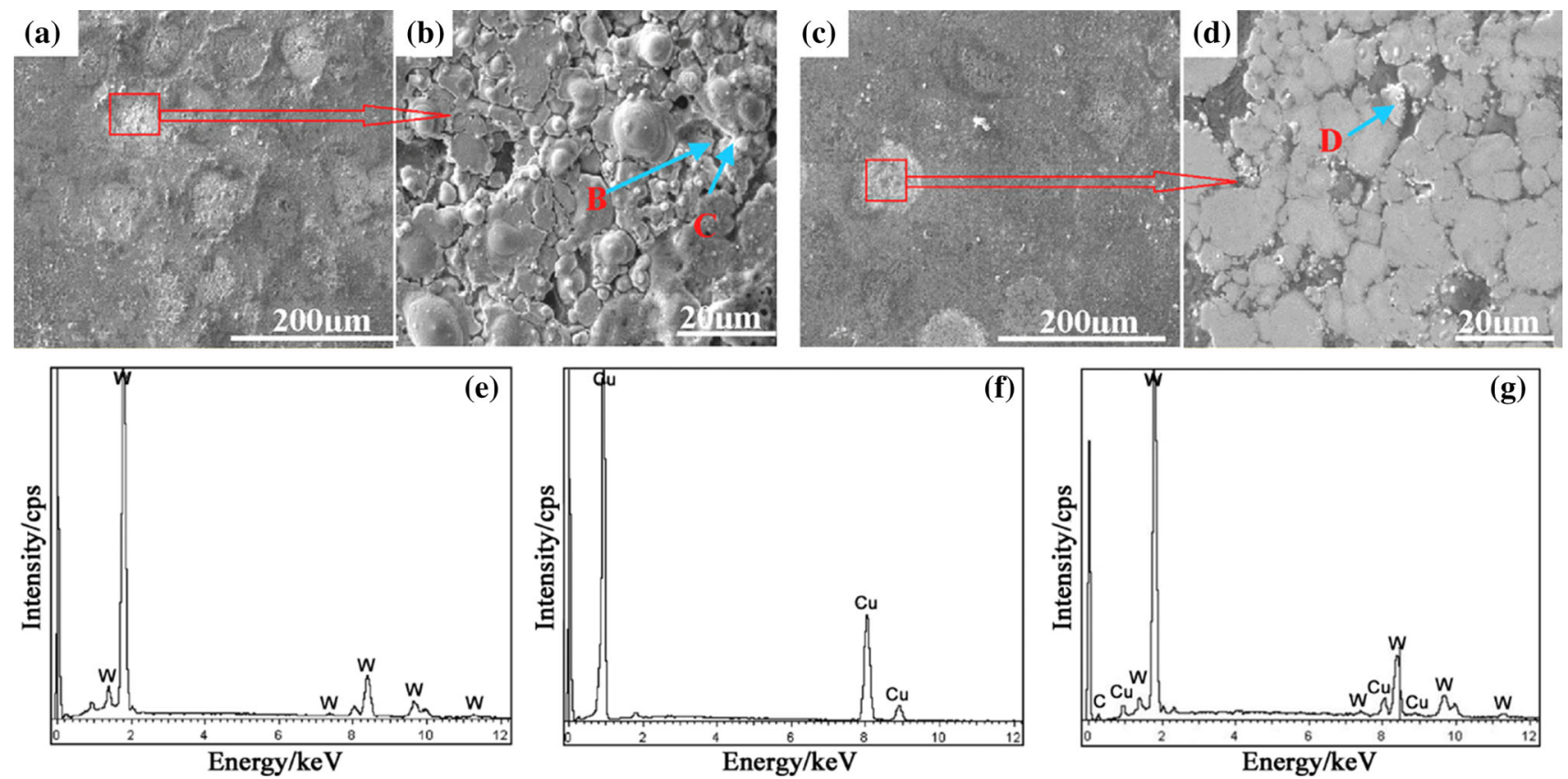

Figure 33 SEM images of the $\mathbf{a}, \mathbf{b} \mathrm{W}_{70} \mathrm{Cu}_{30}$ alloy and the $\mathbf{c}$, $\mathrm{d} \mathrm{W}_{70} \mathrm{Cu}_{30^{-}}-0.5 \mathrm{wt} \%$ graphene composite after 100 breakdowns at $\mathbf{a}, \mathbf{c})$ low and $\mathbf{b}, \mathbf{d}$ high magnifications. EDS spectra of the areas

\section{Thermal properties}

\section{Thermal conductivity}

With increase in power levels in modern microelectronic devices and miniaturisation of personal computers, the premature failure of those devices due to overheating or thermally induced mechanical stresses caused by significant temperature changes becomes paramount [1, 2]. Accordingly, thermal management is a very critical issue for electronic devices and packaging materials and only fast heat dissipation can ensure their effective performance. Graphene is known to have a very high thermal conductivity and very low CTE. Thermal conductivity of an individual graphene sheet (4840-5300 W/ $\mathrm{mK})$ is significantly higher than that of metals. Moreover, graphene shows negative CTE, with a RT value of $-8 \times 10^{-6} \mathrm{~K}^{-1}$. In this regard, the incorporation of graphene into $\mathrm{Cu}$ can significantly improve its thermal conductivity and reduce CTE, so that $\mathrm{Cu}$ /graphene composites have a great potential to be used for thermal management. In general, the best improvements in thermal conductivity are found for composite films, exhibiting enhancements of $20-35 \%[21,24,59]$. Nevertheless, the available results reveal that, although still high, the enhancement of denoted by e B, $\mathbf{f} \mathrm{C}$ and $\mathbf{g} \mathrm{D}$ in the micrographs. Reproduced with permission from [62].

thermal conductivity of $\mathrm{Cu}$ /graphene composites is sometimes quite modest or negative compared with pure $\mathrm{Cu}$ (Table 3 ), the exact values being again governed by the interfacial characteristics, the formation of pores, the matrix microstructure and the graphene characteristics, which affect the mobility of the heat carriers and which are dependent on the graphene content, the processing route and conditions and the graphene derivative. It should be mentioned that the role of the interface conductance is quite controversial. So, some authors claim it is a key factor [64, 70]. However, some other works suggest that the thermal resistance either in the cross-plane direction or in the planar direction is not a limiting factor for the improvement in the thermal conductivity of the $\mathrm{Cu}$ /graphene composites [19, 21, 53].

\section{Influence of graphene content}

Chen et al. [43] fabricated Cu/GNPs composites via MLM and SPS. Since the orientation of graphene was affected by content, the thermal diffusivity of the composites was tested vertical $\left(\alpha_{\text {vertical }}\right)$ and horizontal $\left(\alpha_{\text {horizontal }}\right)$ to the direction of the consolidation force. The thermal diffusivity $(\alpha)$ is expressed as: 
Table 3 Thermal conductivity of $\mathrm{Cu}$ /graphene composites prepared by different methods employing different graphene derivatives

\begin{tabular}{|c|c|c|c|c|c|c|c|}
\hline \multirow{4}{*}{$\begin{array}{l}\text { References } \\
{[19]}\end{array}$} & \multicolumn{2}{|l|}{ Processing route } & \multirow{2}{*}{ Material } & \multirow{2}{*}{$\begin{array}{l}\text { Relative } \\
\text { density (\%) }\end{array}$} & \multicolumn{3}{|c|}{ Thermal conductivity $(\mathrm{W} / \mathrm{mK})$} \\
\hline & \multirow{3}{*}{\multicolumn{2}{|c|}{$\begin{array}{l}\text { Layer-by layer assembling of } 6 \\
\mathrm{Cu} / \text { graphene layers on a } \mathrm{Cu} \\
\text { substrate }\end{array}$}} & & & $-23{ }^{\circ} \mathrm{C}$ & $27{ }^{\circ} \mathrm{C}$ & $77^{\circ} \mathrm{C}$ \\
\hline & & & & & 435 & 420 & 370 \\
\hline & & & $\mathrm{Cu} /$ graphene layers & & $\begin{array}{l}155 \\
(-64 \%)\end{array}$ & $\begin{array}{l}150 \\
(-64 \%\end{array}$ & $\begin{array}{l}120 \\
(-68 \%)\end{array}$ \\
\hline \multirow[t]{3}{*}[21]{} & \multirow{3}{*}{\multicolumn{2}{|c|}{ Electrodeposition }} & $\mathrm{Cu}$ & & $-23^{\circ} \mathrm{C}$ & $27^{\circ} \mathrm{C}$ & $77^{\circ} \mathrm{C}$ \\
\hline & & & $\mathrm{Cu} /$ graphene & & 400 & 380 & 370 \\
\hline & & & & & $510(28 \%)$ & $460(21 \%$ & $440(19 \%)$ \\
\hline \multirow[t]{12}{*}{ [24] } & \multirow[t]{12}{*}{ Electrodeposition } & \multirow{6}{*}{$\begin{array}{l}\text { Without } \\
\text { stirring }\end{array}$} & $\mathrm{Cu}$ & & 380 & & \\
\hline & & & $\mathrm{Cu}$-graphene1 & & $500(32 \%)$ & & \\
\hline & & & $\mathrm{Cu}$-graphene2 & & $480(26 \%)$ & & \\
\hline & & & $\mathrm{Cu}$-graphene3 & & $460(21 \%)$ & & \\
\hline & & & $\mathrm{Cu}$-graphene4 & & $440(16 \%)$ & & \\
\hline & & & $\begin{array}{l}\text { (The content of graphene decreases when going from } \\
\mathrm{Cu} \text {-graphene1 to } \mathrm{Cu} \text {-graphene } 4 \text { ) }\end{array}$ & & & & \\
\hline & & \multirow{6}{*}{$\begin{array}{l}\text { With } \\
\text { stirring }\end{array}$} & $\mathrm{Cu}$ & & 380 & & \\
\hline & & & $\mathrm{Cu}$-graphene5 & & $500(32 \%)$ & & \\
\hline & & & $\mathrm{Cu}$-graphene6 & & $480(26 \%)$ & & \\
\hline & & & $\mathrm{Cu}$-graphene7 & & $460(21 \%)$ & & \\
\hline & & & $\mathrm{Cu}$-graphene8 & & $440(16 \%)$ & & \\
\hline & & & $\begin{array}{l}\text { (The content of graphene decreases when going from } \\
\mathrm{Cu} \text {-graphene5 to } \mathrm{Cu} \text {-graphene8) }\end{array}$ & & & & \\
\hline \multirow[t]{8}{*}{ [30] } & \multirow{8}{*}{$\begin{array}{l}\text { CVD on both } \\
\text { sides of }\end{array}$} & $9-\mu \mathrm{m}$-thick & $\mathrm{Cu}$ & & 290 & & \\
\hline & & $\mathrm{Cu}$ foil & Annealed $\mathrm{Cu}$ & & 329.5 & & \\
\hline & & & $\mathrm{Cu}$ with single-layer graphene & & 369.5 & & \\
\hline & & & $\mathrm{Cu}$ with multilayer graphene & & 364.3 & & \\
\hline & & $25-\mu \mathrm{m}$-thick & $\mathrm{Cu}$ & & 313 & & \\
\hline & & $\mathrm{Cu}$ foil & Annealed $\mathrm{Cu}$ & & 337.2 & & \\
\hline & & & $\mathrm{Cu}$ with single-layer graphene & & 363 & & \\
\hline & & & $\mathrm{Cu}$ with multilayer graphene & & 376.4 & & \\
\hline$[43]$ & Molecular level $\mathrm{m}$ & xing & & & $\mathrm{P} \perp$ & $\mathrm{P} / /$ & \\
\hline & + & & $\mathrm{Cu}$ & 97.5 & 373 & 373 & \\
\hline & Spark plasma sint & ring & $\mathrm{Cu}-0.2$ vol $\%$ GNPs & 97 & $362(-3 \%)$ & 345 & $(-8 \%)$ \\
\hline & & & $\mathrm{Cu}-0.4$ vol $\%$ GNPs & & & & \\
\hline & & & $\mathrm{Cu}-0.6$ vol $\%$ GNPs & & & & \\
\hline & & & $\mathrm{Cu}-0.8$ vol $\%$ GNPs & 96.5 & $356(-5 \%)$ & 338 & $(-9 \%)$ \\
\hline & & & $\mathrm{Cu}-2$ vol $\%$ GNPs & 96 & $335(-10 \%)$ & & $(-38 \%)$ \\
\hline & & & $\mathrm{Cu}-4$ vol\% GNPs & 95.6 & $270(-28 \%)$ & & $(-38 \%)$ \\
\hline [47] & Stirring & & $\mathrm{Cu}$ & & 360 & & \\
\hline & + & & $\mathrm{Cu}-0.1 \mathrm{wt} \% \mathrm{GO}$ & & $370(3 \%)$ & & \\
\hline & Hot pressing & & $\mathrm{Cu}-0.3 \mathrm{wt} \% \mathrm{GO}$ & & $396(10 \%)$ & & \\
\hline & & & $\mathrm{Cu}-0.5 \mathrm{wt} \% \mathrm{GO}$ & & $383(6 \%)$ & & \\
\hline [48] & Electrodeposition & & $\mathrm{Cu}$ & & 286.5 & & \\
\hline & & & $\mathrm{Cu} /$ graphene & & $300.5(5 \%)$ & & \\
\hline [53] & Direct deposition & f graphene on & & & $\mathrm{P} \perp$ & & // \\
\hline & $\mathrm{Cu}$ foil & & $\mathrm{Cu}$ & & 361 & & 58 \\
\hline & + & & $\mathrm{Cu} /$ graphene & & $352(-2.5 \%)$ & & $21(-10 \%)$ \\
\hline & Stacking & & & & & & \\
\hline & + & & & & & & \\
\hline & Spark plasma sint & ring & & & & & \\
\hline & Ball milling & & $\mathrm{Cu}$ & 100 & 390 & & \\
\hline & + & & $\mathrm{Cu}-1$ vol$\%$ GNPs & 97.9 & $359(-8 \%)$ & & \\
\hline & Spark plasma sint & & $\mathrm{Cu}-3$ vol$\%$ GNPs & & $340(-13 \%)$ & & \\
\hline & & & $\mathrm{Cu}-5$ vol\% GNPs & & $292(-25 \%)$ & & \\
\hline & & & Cu-10 vol $\%$ GNPs & & $221(-43 \%)$ & & \\
\hline [59] & Pasting on $\mathrm{Cu}$ foil & & $\mathrm{Cu}$ & & 333.53 & & \\
\hline & & & $\mathrm{Cu} / 89 \mathrm{wt} \% \mathrm{GNPs}$ & & $445.91(34 \%)$ & & \\
\hline & & & $\mathrm{Cu} / 89 \mathrm{wt} \%$ GNPs- $-\mathrm{N}$ & & $542.9(63 \%)$ & & \\
\hline [64] & Ball milling & & $\mathrm{Cu}$ & & 282 & & \\
\hline & & & $\mathrm{Cu} / 0.15 \mathrm{wt} \% \mathrm{Ag}-\mathrm{RGO}$ & & $296(15 \%)$ & & \\
\hline & Hot pressing & & & & & & \\
\hline [67] & Molecular level $\mathrm{m}$ & xing & $\mathrm{Cu}$ & 97.8 & 359 & & \\
\hline & + & & $\mathrm{Cu} / 0.5 \mathrm{wt} \%$ GNPs & 96 & $294(-18 \%)$ & & \\
\hline & Spark plasma sint & ring & $\mathrm{Cu} / 0.5 \mathrm{wt} \%$ GNPs-VC & 95.8 & $304(-15 \%)$ & & \\
\hline & & & $\mathrm{Cu} / 0.5 \mathrm{wt} \% \mathrm{GNPs}-\mathrm{TiC}$ & 96.3 & $311(-13 \%)$ & & \\
\hline
\end{tabular}


Table 3 continued

\begin{tabular}{|c|c|c|c|c|c|c|}
\hline \multirow{2}{*}{$\frac{\text { References }}{[68]}$} & \multicolumn{2}{|l|}{ Processing route } & \multirow[t]{2}{*}{ Material } & \multirow[t]{2}{*}{ Relative density (\%) } & \multicolumn{2}{|c|}{ Thermal conductivity $(\mathrm{W} / \mathrm{mK})$} \\
\hline & Sonication and vortex $\mathrm{m}$ & xing & & & $\mathrm{P} \perp$ & $\mathrm{P} / /$ \\
\hline & + & & $\mathrm{Cu}$ & & 340 & 340 \\
\hline & Vacuum infiltration & & $\mathrm{Cu}-10$ vol$\%$ GNPs & & $375(10 \%)$ & $150(-10 \%)$ \\
\hline & + & & $\mathrm{Cu}-20$ vol$\%$ GNPs & & $410(21 \%)$ & $75(-21 \%)$ \\
\hline & Spark plasma sintering & & $\mathrm{Cu} 30 \mathrm{vol} \%$ GNPs & & $450(32 \%)$ & $58(-32 \%)$ \\
\hline \multirow[t]{16}{*}[70]{} & Vacuum infiltration & Vortex mixing & & & $\mathrm{P} \perp$ & $\mathrm{P} / /$ \\
\hline & & & $\mathrm{Cu}$ & & 350 & 350 \\
\hline & Spark plasma sintering & & Cu-5 vol\% large-sized GNPs & & $358(2 \%)$ & $311.5(-11 \%)$ \\
\hline & & & $\mathrm{Cu}-12$ vol$\%$ large-sized GNPs & & $371(6 \%)$ & $277(-21 \%)$ \\
\hline & & & $\mathrm{Cu}-20$ vol\% large-sized GNPs & & $392(12 \%)$ & $238.5(-32 \%)$ \\
\hline & & & $\mathrm{Cu}-27$ vol\% large-sized GNPs & & $475(36 \%)$ & $211.5(-40 \%)$ \\
\hline & & & $\mathrm{Cu}-35$ vol\% large-sized GNPs & & $525(50 \%)$ & $200(-43 \%)$ \\
\hline & & & Cu-35 vol\% small-sized GNPs & & $275(-21 \%)$ & \\
\hline & & Ball milling & $\mathrm{Cu}-35$ vol$\%$ large-sized GNPs & & $425(21 \%)$ & \\
\hline & Vortex mixing & & $\mathrm{Cu}$ & & $\mathrm{P} \perp$ & $\mathrm{P} / /$ \\
\hline & + & & $\mathrm{Cu}-5$ vol$\%$ large-sized GNPs & & 350 & 350 \\
\hline & Air-drying & & $\mathrm{Cu}-12$ vol\% large-sized GNPs & & $333(-5 \%)$ & $277(-21 \%)$ \\
\hline & + & & $\mathrm{Cu}-20$ vol\% large-sized GNPs & & $312.5(-11 \%)$ & $188.5(-46 \%)$ \\
\hline & Spark plasma sintering & & $\mathrm{Cu}-27$ vol\% large-sized GNPs & & $287.5(-18 \%)$ & $169(-52 \%)$ \\
\hline & & & $\mathrm{Cu}-35$ vol\% large-sized GNPs & & $279(-20 \%)$ & $127(-64 \%)$ \\
\hline & & & & & $267(-24 \%)$ & $108(-69 \%)$ \\
\hline \multirow[t]{3}{*}{ [101] } & Ball milling & & & & $\mathrm{P} \perp$ & $\mathrm{P} / /$ \\
\hline & & & $\mathrm{Cu}-5 \mathrm{wt} \%$ GNPs & & 178 & 94 \\
\hline & Spark plasma sintering & & & & & \\
\hline \multirow[t]{6}{*}[102]{} & Ball milling & & & & $\mathrm{P} \perp$ & $\mathrm{P} / /$ \\
\hline & + & & $\mathrm{Cu}-1 \mathrm{wt} \%$ GNPs & 87 & 253 & 170 \\
\hline & Hot pressing & & $\mathrm{Cu}-2 \mathrm{wt} \%$ GNPs & 87.5 & 243 & 160 \\
\hline & & & $\mathrm{Cu}-3 \mathrm{wt} \%$ GNPs & 91 & 230 & 140 \\
\hline & & & $\mathrm{Cu}-4 \mathrm{wt} \%$ GNPs & 94.5 & 220 & 133 \\
\hline & & & $\mathrm{Cu}-5 \mathrm{wt} \%$ GNPs & 97 & 297 & 190 \\
\hline
\end{tabular}

$\mathrm{P} \perp$ and $\mathrm{P} / /$ indicate the directions perpendicular and parallel to the consolidation direction, respectively. The numbers in brackets indicate the percentage change in the corresponding property compared to the matrix

$\alpha=\frac{k}{\rho C_{p}}$

where $k$ is the thermal conductivity, $\rho$ is the density, and $C_{\mathrm{p}}$ is the specific heat capacity.

It was found that the thermal performance of $\mathrm{Cu}$ deteriorated upon the addition of graphene. Both $\alpha_{\text {vertical }}$ and $\alpha_{\text {horizontal }}$ decreased significantly with the increase in graphene concentration, especially when the graphene content was over $0.8 \mathrm{vol} \%$. The decrease of thermal diffusivity induced by graphene additions was attributed to the decrease of the meanfree path of heat carriers, the interfacial thermal resistance and the voids formed during sintering, that serve as insulating barriers to the heat flow. By comparing $\alpha_{\text {vertical }}$ and $\alpha_{\text {horizontal }}$ of each composite, it was found that the difference between the values is varied with the graphene content. For the composites with 0.2 and 0.8 vol $\%$ graphene, $\alpha_{\text {horizontal }}$ was almost equivalent to $\alpha_{\text {vertical }}$. However, for the composites with 2 and 4 vol $\%$ graphene, $\alpha_{\text {horizontal was }}$ considerably higher than $\alpha_{\text {vertical }}$. This was attributed to the difference of graphene alignment in the composites. As the GNPs were oriented randomly in the composite with 0.2 and 0.8 vol $\%$ GNPs, there was no difference between the thermal diffusivity in the two directions. For the composites with 2 and 4 vol\% graphene, as the GNPs are aligned along the direction perpendicular to the consolidation force, $\alpha_{\text {hori- }}$ zontal and $\alpha_{\text {vertical }}$ are the thermal diffusivity along the in-plane and the through-plane direction of graphene, respectively. It is well known that the thermal diffusivity of graphene at the in-plane direction is much higher than that at the through-plane direction. This explains the large difference between $\alpha_{\text {horizontal }}$ and $\alpha_{\text {vertical }}$ for the highest loadings.

Gao et al. [47] mixed GO with cationic surface agent coated $\mathrm{Cu}$ powders to obtain $\mathrm{Cu} / \mathrm{GO}$ powders by electrostatic self-assembly. Afterwards, the composite powders were consolidated by HP. Figure 34 shows the thermal conductivity of the synthesised 


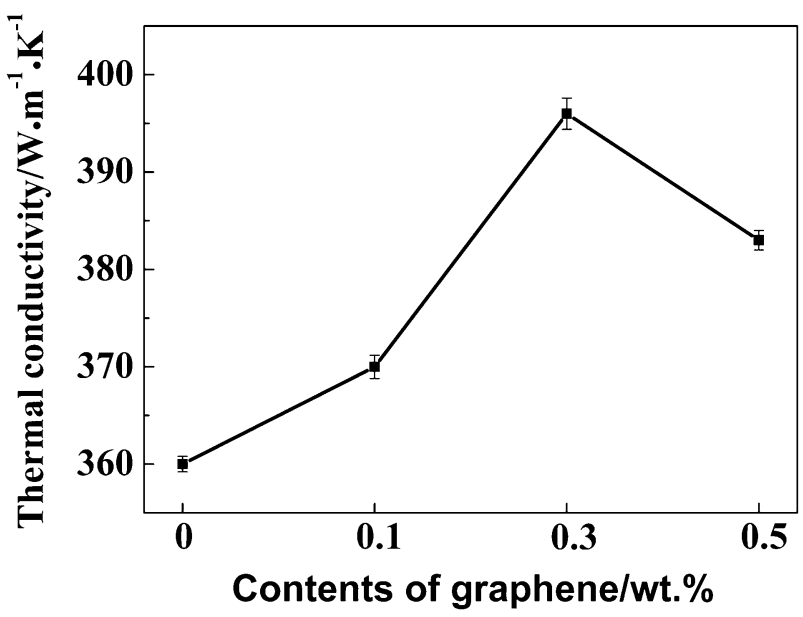

Figure 34 Thermal conductivity of $\mathrm{Cu} / \mathrm{GO}$ composites with different graphene contents. Reproduced with permission from [47].

$\mathrm{Cu} / \mathrm{GO}$ composites as a function of the graphene content. It can be seen that the addition of graphene into the $\mathrm{Cu}$ matrix can improve the thermal conductivity. When the content of graphene is small, the thermal conductivity gradually increases with increase in the graphene content, reaching its maximum at $0.3 \mathrm{wt} \% \mathrm{GO}$. However, for higher graphene contents, the thermal conductivity significantly decreases. The reason was the formation of agglomerates, resulting in the loss of associativity among the $\mathrm{Cu}$ grains. Moreover, pores and defects at the interfaces could promote the presence of interfacial thermal resistance contacts in the composites, acting as sites for phonon scattering.

The thermal conductivity at different temperatures of pure $\mathrm{Cu}$ and $\mathrm{Cu} / \mathrm{GNPs}$ composites fabricated by wet mixing, sintering and hot isostatic pressing has also been investigated [73]. The samples containing $1 \mathrm{vol} \%$ GNPs present an improved thermal conductivity (up to 17\%) with respect to pure $\mathrm{Cu}$. However, when 2 vol\% were added, only a slight increase was achieved with respect to pure $\mathrm{Cu}$, indicating that there is a critical graphene content for the attainment of the maximum thermal conductivity. For higher graphene contents, the thermal conductivity of the composites is lower than that of pure $\mathrm{Cu}$. This could be mainly attributed to the tendency of graphene to form agglomerates with increase in content. It was found that increasing the graphene content from 4 to $8 \mathrm{vol} \%$ increases the presence of clusters in the $\mathrm{Cu}$ matrix [73].

\section{Influence of processing conditions}

Cu-35 vol\% GNPs composites were prepared by vacuum filtering and SPS from mixed powders obtained by either vortex mixing or ball milling [70]. As shown in Fig. 35a, the in-plane thermal conductivity (TC) of the composite derived from the ballmilled powders was $18.5 \%$ lower than that of the composite derived from the vortex-mixed powders. Raman spectra shown in Fig. 35b clearly revealed that the D band intensity of ball-milled powders was apparently higher than that of vortex-mixed powders, demonstrating that graphene structural defects were introduced during the BM process. These extra defects can impair the intrinsic TC of GNPs by acting as obstacles for strong phonon scattering, resulting in a diminished in-plane TC. Therefore, vortex mixing is superior to $\mathrm{BM}$ for the $\mathrm{V}-\mathrm{GNP} / \mathrm{Cu}$ composites in terms of achieving a high in-plane TC, because there are almost no extra graphene defects introduced during the vortex-mixing process.
Figure 35 a In-plane thermal conductivity of $\mathrm{Cu}-35 \mathrm{vol} \%$ GNPs bulk composites obtained from either vortexmixed or ball-milled powders. b Raman spectra of the two different mixed powders. Reproduced with permission from [70].
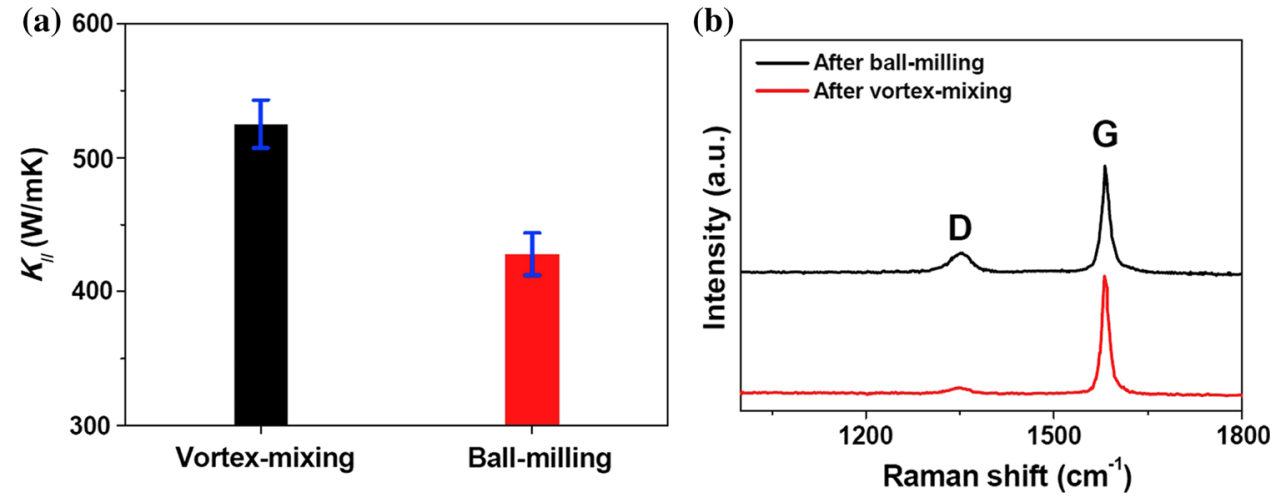
Figure 36 a In-plane thermal conductivity of $\mathrm{Cu}-35 \mathrm{vol} \%$ GNPs bulk composites obtained from either largesized $(25 \mu \mathrm{m}$ in average lateral size) or small-sized ( $3 \mu \mathrm{m}$ in average lateral size). b SEM image of the composite with small-sized GNPs.

Reproduced with permission from [70].
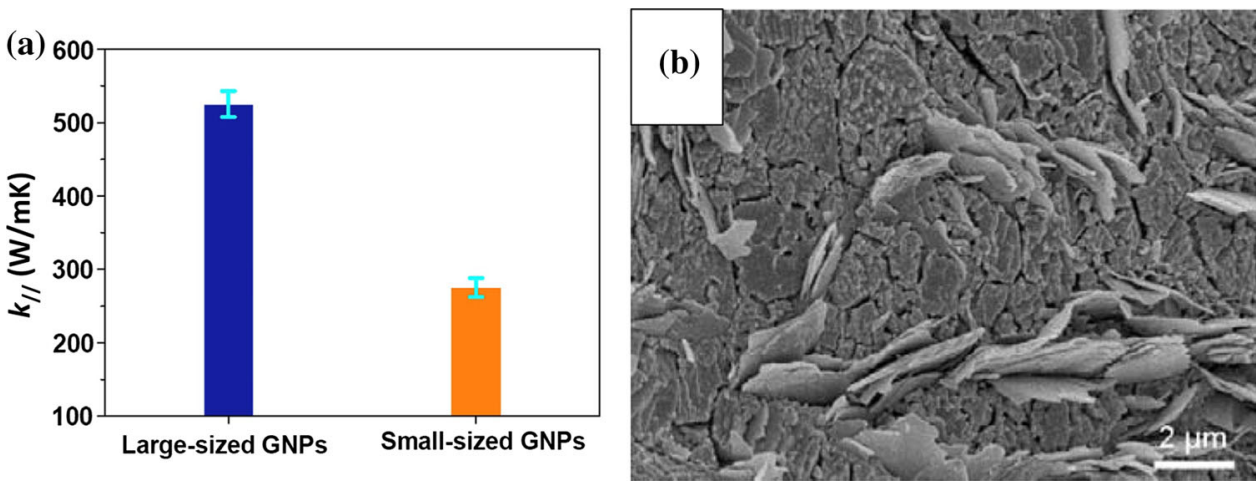

\section{Influence of graphene size}

Cu-35 vol\% GNPs composites were prepared by vortex mixing and vacuum filtering followed by SPS from either large-sized ( $25 \mu \mathrm{m}$ in average lateral size) or small-sized ( $\sim 3 \mu \mathrm{m}$ in average lateral size) [70]. Figure 36a shows that the in-plane thermal conductivity (TC) of the composites exhibits an astonishing drop from $525 \mathrm{~W} / \mathrm{mK}$ to $275 \mathrm{~W} / \mathrm{mK}$ when the GNP lateral size changes from 25 to $3 \mu \mathrm{m}$, suggesting that the GNP lateral size plays a paramount role in dictating the in-plane TC. This surprisingly low in-plane TC of the composites with small-sized GNPs was ascribed to two factors. First, reducing GNP lateral size creates more $\mathrm{Cu}-\mathrm{GNP}$ interfaces, especially GNP edge- $\mathrm{Cu}$ interfaces, which cause a large thermal resistance. Second, as shown in Fig. 36b, the smallsized GNPs tend to be randomly distributed in the $\mathrm{Cu}$ matrix rather than aligned in one direction, as the large-sized GNPs are, regardless of using vacuum filtration, which hinders the effective TC contribution of GNPs.

Regarding the graphene thickness, it was found to have a key role on the improvement in the thermal conductivity of the $\mathrm{Cu} /$ graphene composites $[19,21,53]$. In particular, the lower thermal conductivity of smaller graphene particles is considered to be a limiting factor $[19,21]$. On the contrary, thicker graphene platelets with more than three atomic layers are expected to possess higher thermal conductivity in the presence of matrix so that the quenching of phonons that carry the heat in graphene is confined only to the outer layers [21]. It is worth-mentioning that, similarly, single-layer graphene is not expected to give rise to as large an electrical conductivity improvement as graphene platelets or graphene with few atomic layers as the interface carrier scattering is more significant in single-layer graphene. So, as for the thermal conductivity, multilayer graphene is expected to provide better electrical conductivity improvement as the inner atomic layers are free from interface scattering.

\section{Effect of graphene modification}

Figure 37 shows the thermal properties of pure $\mathrm{Cu}$ and $\mathrm{Cu}-0.5$ wt $\%$ GNPs, $\mathrm{Cu}-0.5 \mathrm{wt} \%$ GNPs-TiC and $\mathrm{Cu}-0.5 \mathrm{wt} \%$ GNPs-VC composites fabricated by MLM and SPS [67]. The thermal diffusivity of the composites is lower than that of pure $\mathrm{Cu}$. However, the thermal diffusivity of the $\mathrm{Cu} / \mathrm{GNPs}-\mathrm{TiC}$ and $\mathrm{Cu}$ / GNPs-VC composites, where the interface is

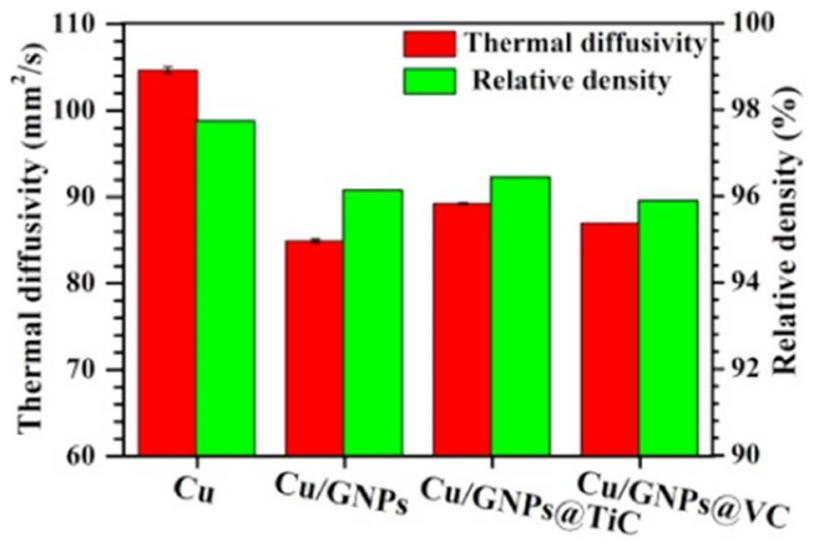

Figure 37 Thermal diffusivity and relative density of pure $\mathrm{Cu}$ and the $\mathrm{Cu}-0.5 \mathrm{wt} \%$ GNPs, $\mathrm{Cu}-0.5 \mathrm{wt} \%$ GNPs-TiC and $\mathrm{Cu}-$ $0.5 \mathrm{wt} \%$ GNPs-VC composites. Reproduced with permission from [67]. 
continuous and tightly bonded is slightly higher than that of the $\mathrm{Cu} / \mathrm{GNPs}$ composite. The TiC and VC interlayers, with a mixture of metallic and covalent bonding, can reduce the energy of electron-phonon coupling and by this decreasing the interfacial thermal resistance. Similarly, the enhancement of the thermal conductivity of $\mathrm{Cu}-0.5 \mathrm{wt} \% \mathrm{Ag} / \mathrm{RGO}$ composites (Table 3) was attributed to a good interfacial bonding [64]. This is in agreement with some investigations on phonon transmission across the graphene $/ \mathrm{Cu}$ interfaces using different simulation methods, showing the critical importance of interfacial properties of graphene-metal systems, in applications of graphene in integrated electronics, as thermal materials, and in electromechanical devices [93, 94, 153, 154].

\section{Coefficient of thermal expansion}

Many materials experience a physical expansion or contraction resulting from a change in temperature [1]. The coefficient of thermal expansion (CTE) represents the change in unit length of a bulk material due to a rise or drop in temperature and can be expressed as:

$\mathrm{CTE}=\frac{\Delta l}{l_{i} \Delta T}$

where $\Delta l$ is the thermal expansion displacement, $l_{i}$ is the initial length, and $\Delta T$ is temperature change.

Wang et al. investigated the thermal expansion behaviour of $\mathrm{Cu}-0.5 \mathrm{wt} \%$ graphene $(\mathrm{Cu}-\mathrm{GN})$ and $\mathrm{Cu}-$ $0.5 \mathrm{wt} \%$ graphite (Cu-GP) composites at different temperatures [52]. They observed an obvious reduction in the CTE for both composites between 100 and $750{ }^{\circ} \mathrm{C}$ compared with pure $\mathrm{Cu}$. This reduction in CTE was observed to be higher for the $\mathrm{Cu}-\mathrm{GN}$ composite than for the $\mathrm{Cu}-\mathrm{GP}$ composite between 100 and $300{ }^{\circ} \mathrm{C}$. This was attributed to the ribbon-like graphene with a very high ratio anchored on the $\mathrm{Cu}$ grain surface to form a continuous elongated interphase boundary. The compressive stress applied on the $\mathrm{Cu}$ grain growth by graphene could restrain the expansion of $\mathrm{Cu}$ to a large extent in the initial heating stage. Consequently, the decreased CTE of $\mathrm{Cu}-\mathrm{GN}$ composite was related to the high pronounced drag force on grain boundary motion produced by graphene at high temperatures.

Figure 38 shows a plot the CTE against the content of GNPs for $\mathrm{Cu} / \mathrm{GNPs}$ composites possessing highly

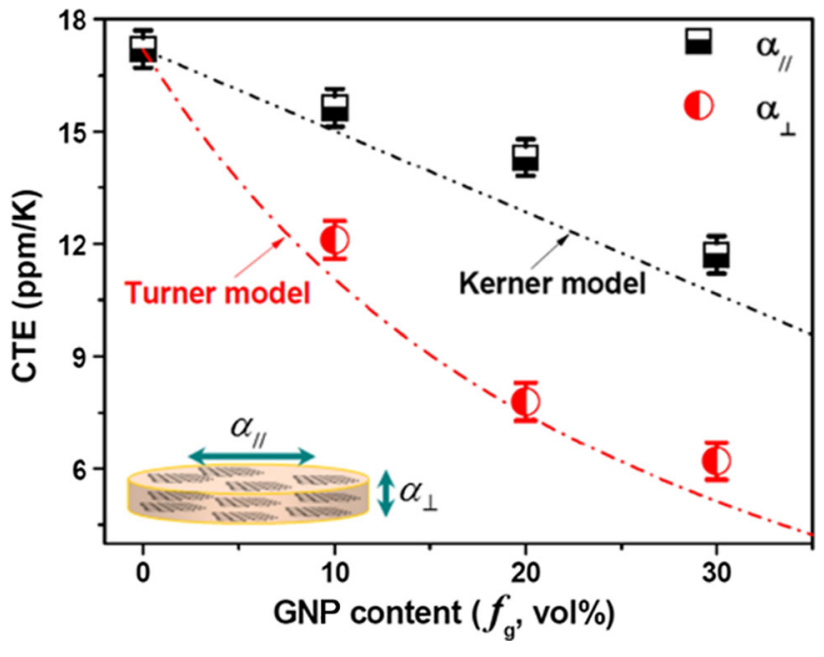

Figure 38 Coefficient of thermal expansion (CTE) measurements and Kerner/Turner model predictions of $\mathrm{Cu} / \mathrm{GNPs}$ composites at different GNP content along the in-plane (//) and through-plane $(\perp)$ directions. Reproduced with permission from [68].

aligned GNPs [68]. It is clear that through-plane CTE is lower than the in-plane CTE, especially with increase in the volume fraction of GNPs. This phenomenon seems counter intuitive considering the fact that the intrinsic in-plane CTE of graphene is negative, substantially lower than the through-plane CTE. This was attributed to the temperature-dependent in-plane strain introduced during the consolidation process. The residual in-plane strain after consolidation could lead to a larger shrinkage of elastic constants along the through-plane direction than those in the in-plane direction. Hence, the SPS-introduced in-plane strain makes the GNPs in $\mathrm{Cu}$ matrix actually exhibit a stronger shrinkage than $\mathrm{Cu}$ rather than a stronger expansion than $\mathrm{Cu}$ along the through-plane direction.

\section{Tribological properties}

Friction is the force resisting the relative motion of two surfaces in contact against each other [155]. The frictional force or force of friction between the two surfaces $\left(F_{\mathrm{f}}\right)$ displays a linear relationship with the force pressing them together or normal force $\left(F_{n}\right)$, which can be expressed as:

$F_{\mathrm{f}}=\mu F_{\mathrm{n}}$

where $\mu$ is the coefficient of friction (COF) and is different for each material. As shown in Table 4, the addition of graphene to $\mathrm{Cu}$ usually results in a remarkable decreased in the COF, especially with 


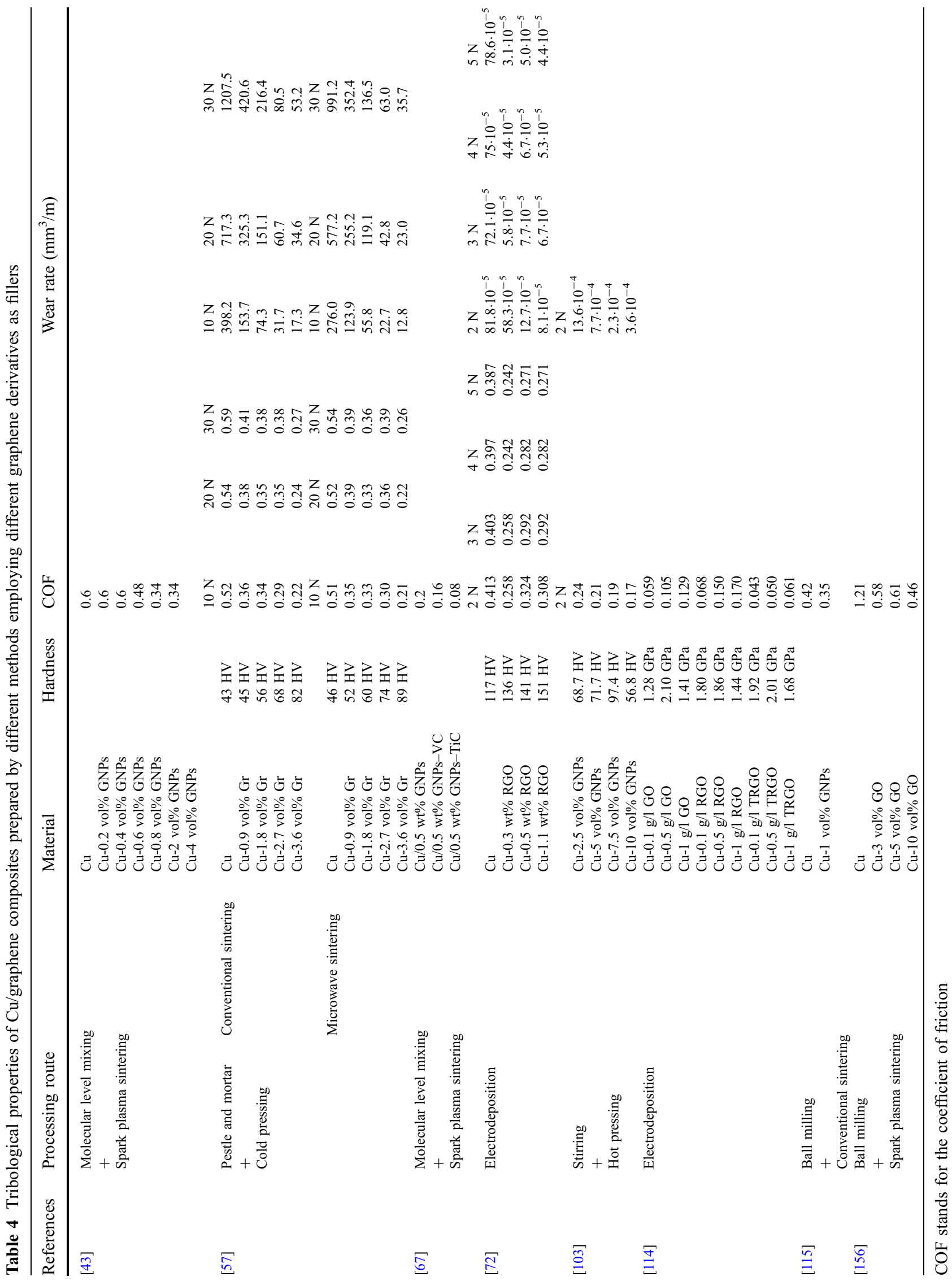




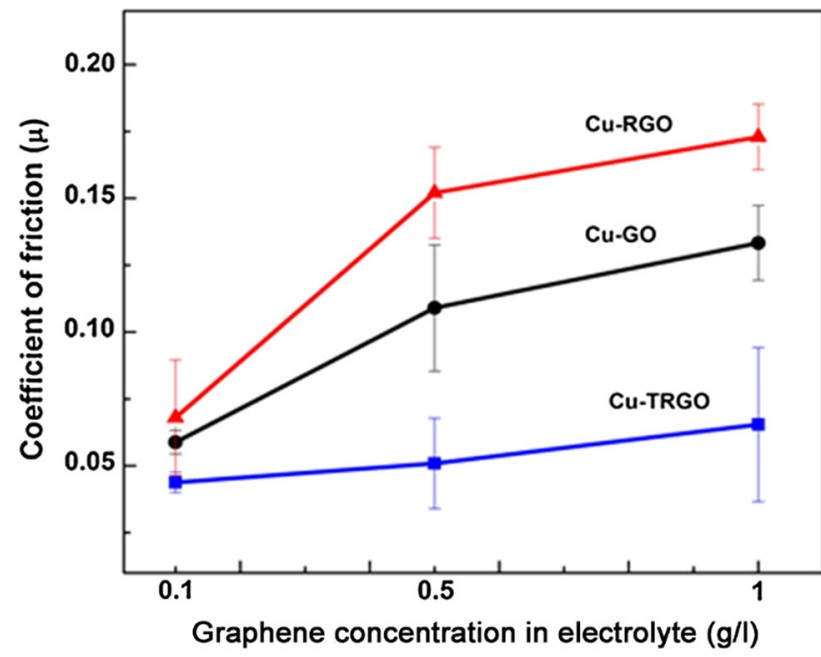

Figure $39 \mathrm{COF}$ of different $\mathrm{Cu}$ /graphene oxide (GO), $\mathrm{Cu} /$ chemically reduced $\mathrm{GO}(\mathrm{RGO})$ and $\mathrm{Cu} /$ thermally reduced GO (TRGO) coatings. Reproduced with permission from [114].

increase in the graphene content $[43,46,57,67,72$, $103,115]$. This has been attributed to the high lubricating efficiency of graphene, which has an ultra-low COF ( 0.03). This behaviour is not surprising since graphite has been employed as a low friction material since the middle ages.

During the sliding process, graphene is squeezed out of the composites and forms a lubricating film which reduces the contact between the surfaces. With increase in the graphene content, such graphene-rich films usually become more continuous and get thicker, causing a further decrease of the friction coefficient. However, an increase in the friction coefficient with increase in the graphene content [72, 114] has been occasionally observed (Fig. 39). This has been attributed to stick-slip behaviour due to an excess of graphene layers. An influence of the graphene derivative has also been observed. So, for example, Maharana et al. [114] found that, for the same content, the COFs of electrodeposited CMCs coatings filled with GO, chemically reduced GO (RGO) and thermally reduced GO (TRGO) are very different (Fig. 39). So, due to the formation of extremely adherent and continuous graphene layers at the sliding surfaces, the TRGO-based coating exhibits the lowest COFs. Moreover, the GO-based coatings show lower COF than the RGO-based coatings due to the breakage of the graphene layers during the chemical treatment which is required to synthesise RGO.

The effective role of graphene as a solid lubricant or, in other words, the decrease of the COF with the graphene additions also leads to an improved wear resistance in the $\mathrm{Cu}$ /graphene composites compared with pure $\mathrm{Cu}$ [114]. However, according to Archard's theory [157], an increase in hardness results in an improvement in wear resistance. This means that, the wear rate, computed from the slope of wear volume or weight loss under friction conditions versus the sliding distance, depends not only on the COF, but also on the mechanical strength.

Due to the excellent tribological properties of $\mathrm{Cu}$ $\mathrm{NPs}$ and graphene, $\mathrm{Cu}$ /graphene composite powders can be also used as additives in lubricant oils to improve their tribological properties [107, 110]. Jia et al. investigated the friction and wear properties of oleic acid (OA) modified $\mathrm{Cu} / \mathrm{RGO}$ composite powders (fabricated by one step in situ reduction method) as additives in poly-alpha-olefin (PAO) using fourball wear test [110]. It was observed that under a load of $392 \mathrm{~N}$ the wear scar diameters (WSD) were decreased with the addition of OA modified $\mathrm{Cu} /$ RGO composites into the base oil. Namely, when only $0.5 \mathrm{wt} \%$ OA modified $\mathrm{Cu} / \mathrm{RGO}$ is added, the WSD was decreased from $0.75 \mathrm{~mm}$ to about $0.4 \mathrm{~mm}$. Under the lubrication of PAO containing $\mathrm{Cu} / \mathrm{RGO}$ composites, a lower friction coefficient was recorded than that of pure PAO. With the concentration of $1 \mathrm{wt} \%$, the average friction coefficient of PAO containing $\mathrm{Cu} / \mathrm{RGO}$ was about 0.06 , being lower than that of PAO (0.10). The modifier of the composite powders (OA) exhibited superior properties than the modified composites, when the concentration was more than $0.5 \mathrm{wt} \%$. Even so, the results demonstrated that the $\mathrm{Cu} / \mathrm{RGO}$ composite powders exhibit excellent anti-friction and anti-wear performance, so that, with an appropriate loading, they can improve the tribological properties of lubricant oils.

\section{Corrosion properties}

\section{Corrosion}

$\mathrm{Cu}$ and its alloys are of great interest for engineering applications in sea water due to their corrosion resistance, so that they could be used as coatings for corrosion protection. Electrochemical corrosion studies in $3.5 \% \mathrm{NaCl}$ medium revealed that $\mathrm{Cu} /$ graphene composites are more corrosion resistant than pure $\mathrm{Cu}[112,113]$. The Tafel curves obtained from bare mild steel (MS) and MS coated 


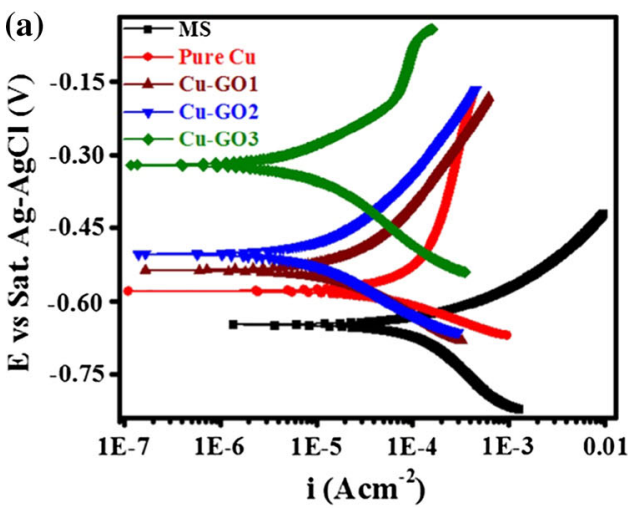

Figure 40 Tafel polarisation curves obtained from bare mild steel (MS) and MS coated with pure $\mathrm{Cu}$ and $\mathrm{Cu} / \mathrm{GO}$ composites a in the as-deposited state and $\mathbf{b}$ after 5 day exposure in $3.5 \% \mathrm{NaCl}$. The

with electrodeposited pure $\mathrm{Cu}$ and $\mathrm{Cu}$ /graphene composites (Fig. 40a) revealed that when compared to bare MS, the coated MS samples consistently yielded greater corrosion potential $\left(E_{\text {corr }}\right)$ and lower corrosion current density $\left(i_{\text {corr }}\right)$ [113]. Additionally, $E_{\text {corr }}$ was found to increase and $i_{\text {corr }}$ to decrease when going from the $\mathrm{Cu}-\mathrm{GO} 1$ to the $\mathrm{Cu}-\mathrm{GO} 3$ sample or, in other words, with increase in the graphene content. This shows that $\mathrm{Cu}$ is effective in inhibiting the extent of corrosion in $\mathrm{Cl}^{-}$environment, but the incorporation of graphene in the coatings leads to the enhancement in the resistance to anodic dissolution or to a reduced corrosion rate (CR), which is linearly related to $i_{\text {corr }}$ by the following expression:

$\mathrm{CR}(\mathrm{mpy})=\frac{0.129 \times i_{\text {corr }} \times M}{z \times \rho}$

where $M$ is the atomic weight of the metal, $z$ is the number of electrons that is lost per metal atom during anodic dissolution, and $\rho$ is the density of the metal undergoing corrosion.

After 5-day-long exposure to $3.5 \% \mathrm{NaCl}$ media, all the coatings showed increased corrosion rate when compared with the as-deposited state (Fig. 40b). However, the corrosion rates exhibited by the $\mathrm{Cu}$ /graphene coatings are still small compared with pure $\mathrm{Cu}$ coatings. So, the addition of graphene into the $\mathrm{Cu}$ matrix can not only enhance corrosion resistance in the as-deposited state, but can also be used to achieve long-term electrochemical stability in aggressive environment such as $\mathrm{Cl}^{-}$.

The protective nature of the electrodeposited $\mathrm{Cu}$ and $\mathrm{Cu}$ /graphene coatings has been attributed to the thin surface passive films, comprising primarily

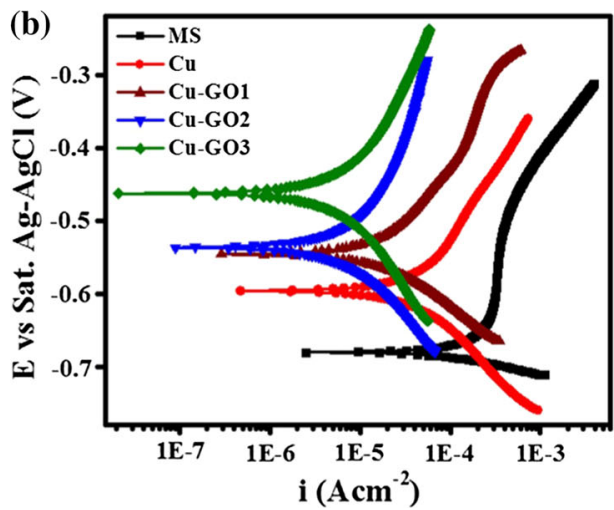

graphene content in the composite coatings increases when going from the $\mathrm{Cu}-\mathrm{GO} 1$ to the $\mathrm{Cu}-\mathrm{GO} 3$ sample. Reproduced with permission from [113].

$\mathrm{Cu}_{2} \mathrm{O}$ [112, 113]. These films, whose formation is promoted by the fine-grained structures induced by graphene additions, are generally known to protect the underlying metal from corrosion and thus to impart corrosion resistance to $\mathrm{Cu}$. The enhancement of the corrosion resistance with increase in the graphene content can be attributed to the high impermeability of graphene to ions and small molecules, which can impede the diffusion of $\mathrm{Cu}^{+}$ions and $\mathrm{O}_{2}$ across the coating cross section and coating-electrolyte interface. The reduction in corrosion resistance of the coatings upon long exposure can be directly attributed to dissolution or breakdown of $\mathrm{Cu}_{2} \mathrm{O}$-based passive films caused by aggressive $\mathrm{Cl}^{-}$ ions. Passive film becomes very unstable against local high concentrations of $\mathrm{Cl}^{-}$ions, which subsequently leads to its breakdown and gradual removal. In contrast, Xie et al. [33] reported a reduced corrosion resistance of $\mathrm{Cu} / \mathrm{RGO}$ composite films compared with electrodeposited $\mathrm{Cu}$ films, this being attributed to an enhanced electron transfer at the film-electrolyte interface or an enhanced electroactivity of the composite films promoted by graphene. It should be noted, however, that in this study the RGO films do not fully cover the whole surface. Hence, transport of corrosive ions in the electrolyte towards the $\mathrm{Cu}$ substrate cannot be totally suppressed by the RGO sheets and only the regions covered with RGO sheets are protected.

\section{Oxidation}

As well as improving the corrosion resistance, it has been demonstrated by Maharana et al. [158] that an 
Figure 41 Isothermal oxidation plot (mass gain vs. time) of coated specimens at a 406 and b $542{ }^{\circ} \mathrm{C}$.

Reproduced with permission from [158].

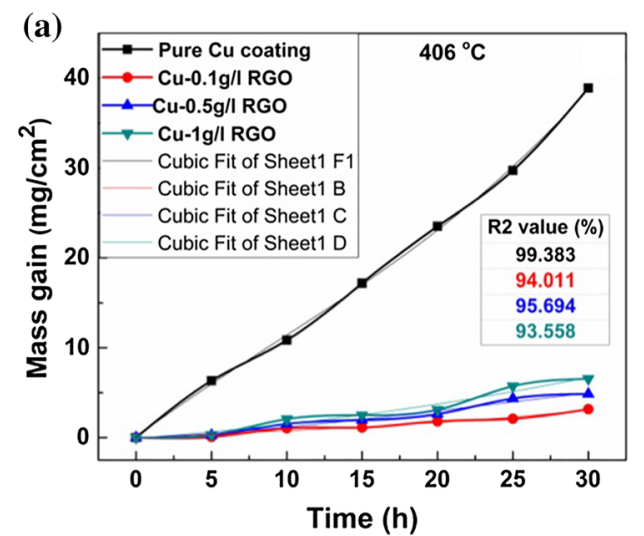

electrodeposited RGO reinforced copper coating on a copper substrate can also improve the oxidation resistance compared with a pure copper coating. The isothermal oxidation behaviour of the specimens with the different coatings at 406 and $542{ }^{\circ} \mathrm{C}$ in air is shown in Fig. 41. It can be seen that the mass gain of all the RGO-coated specimens is significantly less than that of the pure copper coatings. The oxidation protection mechanism is thought to be due to the RGO acting as an inherent barrier to diffusing gases [158].

\section{Potential applications}

The prospects for the application of composites produced by the incorporation of nanotubes or graphene as high-strength, low-density, high-conductivity materials have been reviewed recently by Kinloch et al. [159]. Cu/graphene composites clearly fall into this category of materials, but to the authors' best knowledge, there are no commercial applications or commercial products based on $\mathrm{Cu} /$ graphene composites available yet.

There are, however, several potential applications for such composites. The electrical and construction industries are the largest users of copper and $\mathrm{Cu}$ and its alloys also find applications in electronics and transportation. The enhancement of certain properties with graphene additions would allow improvement of the performance of some current $\mathrm{Cu}$ products as well as enabling new applications. For example, $\mathrm{Cu} /$ graphene composite films could be used for electro-friction applications due to their higher electrical and thermal conductivities together with low coefficient of friction and wear [20]. Electrofriction materials are used as sliding/rotating electrical contacts such as electrical brushes in generators and motors and are subjected to dry friction and high voltage or high current density. In addition, superior strength and stiffness and lower coefficient of thermal expansion and density combined with good electrical and thermal conductivity render $\mathrm{Cu}$ /graphene composites to be ideal structural heat sink materials for microelectronic devices or electrical contacts [19]. It has been also shown that graphene additions can improve the arc stability of the $\mathrm{WCu}$ alloys, prolonging the arc resistance life of the classic $\mathrm{WCu}$ alloy contacts [62]. This means that $\mathrm{WCu} /-$ graphene composites could serve as contact materials for long-life switches in high voltage applications.

Liquid and grease-type lubricants are usually undesirable in tribological systems because of environmental concerns. The friction and wear reducing effect of $\mathrm{Cu}$ NPs/graphene hybrids as additives would lead to lower required amounts of such lubricants [107, 110]. Furthermore, the good tribological properties of the $\mathrm{Cu}$ /graphene composites or offers the possibility of replacing the use of liquid lubricants for solid lubricant coatings in these systems, which in addition provides good levels of performance and durability. What is more, the intrinsic lubricity of graphene eliminates the need of coatings by simply adding graphene to the metals in contact.

Corrosion of steels is a major threat to their engineering applications. This can be prevented by the use of surface coatings. Based on the electrochemical corrosion studies performed on $\mathrm{Cu}$ and $\mathrm{Cu}$ /graphene coatings, it can be concluded that $\mathrm{Cu} /$ graphene composite coatings could be promising anti-corrosive coatings for long-term corrosion protection of steel in chloride environments such as sea water $[112,113]$. 
Moreover, the enhancement corrosion resistance of such composite coatings can facilitate reductions in the required coating thickness and thus material costs in a given application.

\section{Acknowledgements}

This work was supported by a Science and Technology Project of the State Grid Corporation of China (SGCC) entitled "A Study of Transition Metal-Based Graphene Material for High-Power SF6 CircuitBreaker Contacts" (Nr. SGRIDGKJ[2016]795).

Open Access This article is distributed under the terms of the Creative Commons Attribution 4.0 International License (http://creativecommons.org/ licenses/by/4.0/), which permits unrestricted use, distribution, and reproduction in any medium, provided you give appropriate credit to the original author(s) and the source, provide a link to the Creative Commons license, and indicate if changes were made.

\section{References}

[1] Tjong SC (2013) Recent progress in the development and properties of novel metal matrix nanocomposites reinforced with carbon nanotubes and graphene nanosheets. Mater Sci Eng R 74:281-350

[2] Bakshi SR, Lahiri D, Agarwal A (2010) Carbon nanotube reinforced metal matrix composites - a review. Int Mater Rev 55:41-64

[3] Kotov NA (2006) Carbon sheet solutions. Nature 442:254-255

[4] Singh V, Joung D, Zhai L, Das S, Khondaker SI, Seal S (2011) Graphene based materials: past, present and future. Prog Mater Sci 56:1178-1271

[5] Young RJ, Kinloch IA, Gong L, Novoselov KS (2012) The mechanics of graphene nanocomposites: a review. Compos Sci Technol 71:1459-1476

[6] Papageorgiou DG, Kinloch IA, Young RJ (2015) Graphene/ elastomer nanocomposites. Carbon 95:460-484

[7] Papageorgiou DG, Kinloch IA, Young RJ (2017) Mechanical properties of graphene-based nanocomposites. Prog Mater Sci 90:75-127

[8] Kumar HGP, Xavior MA (2014) Graphene reinforced metal matrix composites (GRMMC): a review. Procedia Eng 97:1033-1040
[9] Ovid'ko IA (2014) Metal-graphene nanocomposites with enhanced mechanical properties: a review. Rev Adv Mater Sci 38:190-200

[10] Hu Z, Tong G, Lin D, Chen C, Guo H, Xu J, Zhou L (2016) Graphene-reinforced metal matrix nanocomposites-a review. Mater Sci Technol 32:930-953

[11] Sadowski P, Kowalczyk-Gajewska K, Stupkiewicz S (2015) Classical estimates of the effective thermoelastic properties of copper-graphene composites. Compos Part B Eng 80:278-290

[12] Chu K, Jia C (2014) Enhanced strength in bulk graphenecopper composites. Phys Status Solidi A 211:184-190

[13] Barshirvand S, Montazeri A (2016) New aspects on the mechanical reinforcement by carbon nanofillers: a molecular dynamics study. Mater Des 91:306-313

[14] Davis JR (2001) ASM specialty handbook: copper and copper alloys. ASM International, Materials Park

[15] Ibrahim IA, Mohamed FA, Lavernia EJ (1991) Particulate reinforced metal matrix composites - a review. J Mater Sci 26:1137-1156. https://doi.org/10.1007/BF00544448

[16] Miracle DB (2005) Metal matrix composites-from science to technological significance. Compos Sci Technol 65:2526-2540

[17] Tjong SC (2007) Novel nanoparticle-reinforced metal matrix composites with enhanced mechanical properties. Adv Eng Mater 9:639-652

[18] Mortensen A, Llorca J (2010) Metal matrix composites. Annu Rev Mater Res 40:243-270

[19] Jagannadham K (2011) Orientation dependence of thermal conductivity in copper-graphene composites. J Appl Phys 110:074901

[20] Jagannadham K (2012) Electrical conductivity of coppergraphene composite films synthesized by electrochemical deposition with exfoliated graphene platelets. J Vac Sci Technol, B 30:03D109

[21] Jagannadham K (2012) Thermal conductivity of coppergraphene composite films synthesized by electrochemical deposition with exfoliated graphene platelets. Metall Mater Trans B 43:316-324

[22] Koltsova TS, Nasibulina LI, Anoshlin IV, Mishin VV, Kauppinen EI, Tolochko OV, Nasibulin AG (2012) New hybrid copper composite materials based on carbon nanostructures. J Mater Sci Eng B 2:240-246

[23] Hwang J, Yoon T, Jin H, Lee J, Kim TS, Hong SH, Jeon S (2013) Enhanced mechanical properties of graphene/copper nanocomposites using a molecular-level mixing process. Adv Mater 25:6724-6729

[24] Jagannadham K (2013) Volume fraction of graphene platelets in copper-graphene composites. Metall Mater Trans A 44:552-559 
[25] Kim Y, Lee J, Yeom MS, Shin JW, Kim H, Cui Y, Kysar JW, Hone J, Jung J, Jeon S, Han SM (2013) Strengthening effect of single-atomic-layer graphene in metal-graphene nanolayered composites. Nat Commun 4:2114

[26] Nasibulin AG, Koltsova T, Nasibulina LI, Anoshkin IV, Semencha A, Tolochko OV, Kauppinen EI (2013) A novel approach to composite preparation by direct synthesis of carbon nanomaterial on matrix or filler particles. Acta Mater 61:1862-1871

[27] Cui Y, Wang L, Li B, Cao G, Fei W (2014) Effect of ballmilling on the defeat of few-layer graphene and properties of copper matrix composites. Acta Metall Sin (Engl Lett) 27:937-943

[28] Kim WJ, Lee TJ, Han SH (2014) Multi-layer graphene/copper composites: preparation using high-ratio differential speed rolling, microstructure and mechanical properties. Carbon 69:55-65

[29] Li M, Che H, Liu X, Liang S, Xie H (2014) Highly enhanced mechanical properties in $\mathrm{Cu}$ matrix composites reinforced with graphene decorated metallic nanoparticles. J Mater Sci 49:3725-3731. https://doi.org/10.1007/s10853014-8082-x

[30] Goli P, Ning H, Li X, Lu CY, Novoselov KS, Balandin AA (2014) Thermal properties of graphene-copper-graphene heterogeneous films. Nano Lett 14:1497-1503

[31] Pavithra CLP, Sarada BV, Rajulapati KV, Rao TN, Sundararajan G (2014) A new electrochemical approach for the synthesis of copper-graphene nanocomposites foils with high hardness. Sci Rep 4:4049

[32] Tang Y, Yang X, Wang R, Li M (2014) Enhancement of the mechanical properties of graphene-copper composites with graphene-nickel hybrids. Mater Sci Eng A 599:247-254

[33] Xie G, Forslund M, Pan J (2014) Direct electrochemical synthesis of reduced graphene oxide (rGO)/copper composite films and their electrical/electroactive properties. Appl Mater Interfaces 6:7444-7455

[34] Zhao C, Wang J (2014) Fabrication and tensile properties of graphene/copper composites prepared by electroless plating for structural applications. Phys Status Solidi A 211:2878-2885

[35] Li MX, Xie J, Li YD, Xu HH (2015) Reduced graphene oxide dispersed in copper matrix composites: facile preparation and enhanced mechanical properties. Phys Status Solidi A 212:2154-2161

[36] Dutkiewicz J, Ozga P, Mariarz W, Pstruś J, Kania B, Boborowski P, Stolarska J (2015) Microstructure and properties of bulk copper matrix composites strengthened with various kinds of graphene nanoplatelets. Mater Sci Eng A 628:124-134
[37] Liu X, Wei D, Zhuang L, Cai C, Zhao Y (2015) Fabrication of high-strength graphene nanosheets/Cu composites by accumulative roll bonding. Mater Sci Eng A 642:1-6

[38] Varol T, Canakci A (2015) Microstructure, electrical conductivity and hardness of multilayer graphene/copper nanocomposites synthesized by flake powder metallurgy. Met Mater Int 21:704-712

[39] Wang L, Cui Y, Li B, Yang S, Li R, Liu Z, Vajtai R, Fei W (2015) High apparent strengthening efficiency for reduced graphene oxide in copper matrix composites produced by molecule-lever mixing and high shear mixing. RSC Adv 5:51193-51200

[40] Li W, Li D, Fu Q, Pan C (2015) Conductive enhancement of copper/graphene composites based on high-quality graphene. RSC Adv 5:80428-80433

[41] Xiong DB, Cao M, Guo Q, Tan Z, Fan G, Li Z, Zhang D (2015) Graphene-and-copper artificial nacre fabricated by a preform impregnation process: bioinspired strategy for strengthening-toughening of metal matrix composite. ACS Nano 9:6934-6943

[42] Babul T, Baranowski M, Sobczak N, Homa M, Leśniewski W (2016) Thermophysical properties of Cu-matrix composites manufactured using $\mathrm{Cu}$ powder coated with graphene. J Mater Eng Perform 25:3146-3151

[43] Chen F, Ying J, Wang Y, Du S, Liu Z, Huang Q (2016) Effects of graphene content on the microstructure and properties of $\mathrm{Cu}$ matrix composites. Carbon 96:836-842

[44] Chen Y, Zhang X, Liu E, He C, Shi C, Li J, Nash P, Zhao N (2016) Fabrication of in situ grown graphene reinforced $\mathrm{Cu}$ matrix composites. Sci Rep 6:19363

[45] Xiong DB, Cao M, Guo Q, Tan Z, Fan G, Li Z, Zhang D (2016) High content reduced graphene oxide reinforced copper with a bioinspired nano-laminated structure and large recoverable deformation ability. Sci Rep 6:33801

[46] Xiao Q, Yi X, Jiang B, Qin ZH, Hu J, Jiang Y, Liu HQ, Wang B, Yi DQ (2017) In-situ synthesis of graphene on surface of copper powder by rotary CVD and its application in fabrication of reinforced $\mathrm{Cu}$-matrix composites. Adv Mater Sci 2:1-6

[47] Gao X, Yue H, Guo E, Zhang H, Lin X, Yao L, Wang B (2016) Mechanical properties and thermal conductivity of graphene reinforced copper matrix composites. Powder Technol 301:601-607

[48] Huang G, Wang H, Wang H, Sun B, Sun S, Zhang C, Chen M, Ding G (2016) Preparation and characterization of the graphene- $\mathrm{Cu}$ composite film by electrodeposition process. Microelectron Eng 157:7-12

[49] Jiang R, Zhou X, Fang Q, Liu Z (2016) Copper-graphene bulk composites with homogeneous graphene dispersion 
and enhanced mechanical properties. Mater Sci Eng A 654:124-130

[50] Zhang DD, Zhan ZJ (2016) Experimental investigation of interfaces in graphene materials/copper composites from a new perspective. RSC Adv 6:52226

[51] Zhang X, Wu K, He M, Ye Z, Tang S, Jiang Z (2016) Facile synthesis and characterization of reduced graphene oxide/copper composites using freeze-drying and spark plasma sintering. Mater Lett 166:67-70

[52] Wang X, Li J, Wang Y (2016) Improved high temperature strength of copper-graphene composite material. Mater Lett 181:309-312

[53] Wejrzanowski T, Grybczuk M, Chmielewski M, Pietrzak K, Kurzydlowski KJ, Strojny-Nedza A (2016) Thermal conductivity of metal-graphene composites. Mater Des 99:163-173

[54] Zhang D, Zhan Z (2016) Strengthening effect of graphene derivatives in $\mathrm{Cu}$ matrix composites. J Alloys Compd 654:226-233

[55] Zhang D, Zhan Z (2016) Preparation of graphene nanoplatelets-copper composites by a modified semi-powder method and their mechanical properties. J Alloys Compd 658:663-671

[56] Chen Y, Zhang X, Liu E, He C, Han Y, Li Q, Nash P, Zhao $\mathrm{N}$ (2016) Fabrication of three-dimensional graphene/Cu composites by in situ CVD and its strengthening mechanism. J Alloys Compd 688:69-76

[57] Ayyappadas C, Muthuchamy A, Annamalai AR, Agrawal DK (2017) An investigation on the effect of sintering mode on various properties of copper-graphene metal matrix composite. Adv Powder Technol 28:1760-1768

[58] Cao M, Xiong DB, Tan Z, Ji G, Amin-Ahmadi B, Guo Q, Fan G, Guo C, Li Z, Zhang D (2017) Aligning graphene in bulk copper: Nacre-inspired nanolaminated architecture coupled with in situ processing for enhanced mechanical properties and high electrical conductivity. Carbon 117:65-74

[59] Hsieh CC, Liu WR (2017) Synthesis and characterization of nitrogen-doped graphene nanosheets/copper composite film for thermal dissipation. Carbon 118:1-7

[60] Yue H, Yao L, Gao X, Zhang S, Guo E, Zhang H, Lin X, Wang B (2017) Effect of ball-milling and graphene contents on the mechanical properties and fracture mechanisms of graphene nanosheets reinforced copper matrix composites. J Alloys Compd 691:755-762

[61] Dong L, Chen W, Zheng C, Deng N (2017) Microstructure and properties characterization of tungsten-copper composite materials doped with graphene. J Alloys Compd 695:1637-1646
[62] Dong L, Chen W, Deng N, Song J, Wang J (2017) Investigation on arc erosion behaviors and mechanisms of W70Cu30 electrical contact materials adding graphene. J Alloys Compd 696:923-930

[63] Khobragade N, Kumar B, Bera S, Roy D (2017) Studies on graphene reinforced $\mathrm{Cu}$ base composites prepared by two step thermal processing method. Mater Today-Proc 4:8045-8051

[64] Luo H, Sui Y, Qi J, Meng Q, Wei F, He Y (2017) Copper matrix composites enhanced by silver/reduced graphene oxide hybrids. Mater Lett 196:354-357

[65] Ponraj NV, Azhagurajan A, Vettivel SC, Shajan XS, Nabhiraj PY, Sivapragash M (2017) Graphene nanosheet as reinforcement agent in copper matrix composite by using powder metallurgy method. Surf Interfaces 6:190-196

[66] Jiang R, Zhou X, Liu Z (2017) Electroless Ni-plated graphene for tensile strength of copper. Mater Sci Eng A 679:323-328

[67] Si X, Li M, Chen F, Eklund P, Xue J, Huang F, Du S, Huang Q (2017) Effect of carbide interlayers on the microstructure and properties of graphene-nanoplatelet-reinforced copper matrix composites. Mater Sci Eng A 708:311-318

[68] Chu K, Wang XH, Li YB, Huang DJ, Geng ZR, Zhao XL, Liu H, Zhang H (2018) Thermal properties of graphene/ metal composites with aligned graphene. Mater Des 140:85-94

[69] Chu K, Wang F, Wang XH, Huang DJ (2018) Anisotropic mechanical properties of graphene/copper composites with aligned graphene. Mater Sci Eng A 713:269-277

[70] Chu K, Wang XH, Wang F, Li YB, Huang DJ, Liu H, Ma WL, Liu FX, Zhang H (2018) Largely enhanced thermal conductivity of graphene/copper composites with highly aligned graphene network. Carbon 127:102-112

[71] Yang Z, Wang L, Shi Z, Wang M, Cui Y, Wei B, Xu S, Zhu Y, Fei W (2018) Preparation mechanism of hierarchical layered structure of graphene/copper composite with ultrahigh tensile strength. Carbon 127:329-339

[72] Mai YJ, Zhou MP, Ling HJ, Chen FX, Lian WQ, Jie XH (2018) Surfactant-free electrodeposition of reduced graphene oxide/copper composite coatings with enhanced wear resistance. Appl Surf Sci 433:232-239

[73] Saboori A, Pavese M, Badini C, Fino P (2018) A novel approach to enhance the mechanical strength and electrical and thermal conductivity of $\mathrm{Cu}-\mathrm{GNP}$ nanocomposites. Metall Mater Trans A 49:333-345

[74] Wang L, Yang Z, Cui Y, Wei B, Xu S, Sheng J, Wang M, Zhu Y, Fei W (2017) Graphene-copper composite with micro-layered grains and ultrahigh strength. Sci Rep 7:41896 
[75] Wang X, Liang S, Wang B, Zou J (2011) Investigation on microstructure and properties of $\mathrm{WCu}$ alloy fabricated by infiltrating $\mathrm{CuLa}$ mater alloy into $\mathrm{W}$ skeleton. Adv Sci Lett 4:1012-1016

[76] Chen W, Dong L, Zhang Z, Gao H (2016) Investigation and analysis of arc ablation on WCu electrical contact materials.

J Mater Sci: Mater Electron 27:5584-5591

[77] Zhang Q, Liang S, Hou B, Zhou L (2016) The effect of submicron-sized initial tungsten powders on microstructure and properties of infiltrated $\mathrm{W}-25 \mathrm{wt} \% \mathrm{Cu}$ alloys. Int $\mathrm{J}$ Refract Met Hard Mater 59:87-92

[78] Shi XL, Yang H, Shao GQ, Duan XL, Yan L, Xiong Z, Sun $\mathrm{P}$ (2007) Fabrication and properties of $\mathrm{W}-\mathrm{Cu}$ alloy reinforced by multi-walled carbon nanotubes. Mater Sci Eng A 457:18-23

[79] Novoselov NS, Geim AK, Morozov SV, Jiang D, Zhang Y, Dubonos SV, Grogorieva IV, Firsov AA (2004) Electric field effect in atomically thin carbon films. Science 306:666-669

[80] Balandin AA, Ghosh S, Bao W, Calizo I, Teweldebrhan D, Miao F, Lau CN (2008) Superior thermal conductivity of single-layer graphene. Nano Lett 8:902-907

[81] Lee C, Wei XD, Kysar JW, Hone J (2008) Measurement of the elastic properties and intrinsic strength of monolayer graphene. Science 321:385-388

[82] Lewis AM, Derby B, Kinloch IA (2013) Influence of gas phase equilibria on the chemical vapor deposition of graphene. ACS Nano 7:3104-3117

[83] Nicolosi V, Chhowalla M, Kanatzidis MG, Strano MS, Coleman JN (2013) Liquid exfoliation of layered materials. Science 340:1420-1429

[84] Abdelkader AM, Cooper AJ, Dryfe RAW, Kinloch IA (2015) How to get between the sheets: a review of recent works on the electrochemical exfoliation of graphene materials from bulk graphite. Nanoscale 7:6944-6956

[85] Paton KR, Varrla E, Backes C, Smith RJ, Khan U, O’Neill A, Boland C, Lotya M, Istrate OM, King P, Higgins T, Barwich S, May P, Puczkarski P, Ahmed I, Moebius M, Pettersson H, Long E, Coelho J, O'Brien SE, McGuire EK, Sanchez BM, Duesberg GS, McEvoy N, Pennycook TJ, Downing C, Crossley A, Nicolosi V, Coleman JN (2014) Scalable production of large quantities of defect-free fewlayer graphene by shear exfoliation in liquids. Nat Mater 13:624-630

[86] Hummers WS, Offeman RE (1958) Preparation of graphitic oxide. J Am Chem Soc 80:1339

[87] He H, Klinowski J, Forster M, Lerf A (1998) A new structural model for graphite oxide. Chem Phys Lett 287:53-56
[88] Lerf A, He H, Forster M, Klinowski J (1998) Structure of graphite oxide revisited. J Phys Chem B 102:4477-4482

[89] Park S, Rouff RS (2009) Chemical methods for the production of graphene. Nat Nanotechnol 4:217-224

[90] Giovannetti G, Khomyakov PA, Brocks G, Karpan VM, van den Brink J, Kelly PJ (2008) Doping graphene with metal contacts. Phys Rev Lett 101:026803

[91] Khomyakov PA, Giovannetti G, Rusu PC, Brocks G, van den Brink J, Kelly PJ (2009) First-principles study of the interaction and charge transfer between graphene and metals. Phys Rev B 79:195425

[92] Vanin M, Mortensen JJ, Kelkkanen AK, Garcia-Lastra JM, Thygesen KS, Jacobsen KW (2010) Graphene on metals: a van der Waals density functional study. Phys Rev B 81:081408

[93] Xu Z, Buehler MJ (2010) Interface structure and mechanics between graphene and metal substrates: a first principle study. J Phys Condes Matter 22:485301 (5 pp)

[94] Adamska L, Lin Y, Ross AJ, Batzill M, Oleynik II (2012) Atomic and electronic structure of simple metal/graphene and complex metal/graphene/metal interfaces. Phys Rev B 85:195443

[95] Yoon T, Shin WC, Kim TY, Mun JH, Kim TS, Cho BJ (2012) Direct measurement of adhesion energy of monolayer graphene as-grown on copper and its application to renewable transfer process. Nano Lett 12:1448-1452

[96] Zhang L, Pollak E, Wang WC, Jiang P, Glans PA, Zhang Y, Cabana J, Kostecki R, Chang C, Salmeron M, Zhu J, Guo J (2012) Electronic structure study of ordering and interfacial interaction in graphene $/ \mathrm{Cu}$ composites. Carbon 50:5316-5322

[97] Das S, Lahiri D, Lee DY, Agarwal A, Choi W (2013) Measurements of the adhesion energy of graphene to metallic substrates. Carbon 59:121-129

[98] Fang B, Li J, Zhao N, Shi C, Ma L, He C (2017) Boron doping effect on the interface interaction and mechanical properties of graphene reinforced copper matrix composite. Appl Surf Sci 425:811-822

[99] Panchakarla LS, Subrahmanyam KS, Saha SK, Govindaraj A, Krishnamurthy HR, Waghmare UV, Rao CNR (2009) Synthesis, structure, and properties of boron- and nitrogendoped graphene. Adv Mater 21:4726-4730

[100] Mortazavi B, Ahzi S (2012) Molecular dynamics study on the thermal conductivity and mechanical properties of boron doped graphene. Solid State Commun 152:1503-1507

[101] Qu D, Li F, Zhang H, Wang Q, Zhou T, Hu C, Xie R (2014) Preparation of graphene nanosheets/copper composite by spark plasma sintering. Adv Mater Res 833:276-279 
[102] Wei B, Qu D, Hu C, Li F, Zhou T, Xie R, Zhou Z (2014) Synthesis and physical properties of graphene nanosheets reinforced copper composites. Adv Mater Res 833:310-314

[103] Li JF, Zhang L, Xiao JK, Zhou KC (2015) Sliding wear behavior of copper-based composites reinforced with graphene nanosheets and graphite. Trans Nonferrous Met Soc China 25:3354-3362

[104] Ponraj NV, Vettivel SC, Azhagurajan A, Shajan XS, Nabhiraj PY, Theivasanthi T, Selvakumar P, Lenin AH (2017) Effect of milling of dispersion of graphene nanosheet reinforcement in different morphology copper powder matrix. Surf Interfaces 9:260-265

[105] Chen Q, Zhang L, Chen G (2012) Facile preparation of graphene-copper nanoparticle composite by in situ chemical reduction for electrochemical sensing of carbohydrates. Anal Chem 84:171-178

[106] Zhang K (2012) Fabrication of copper nanoparticles/graphene oxide composites for surface-enhanced Raman scattering. Appl Surf Sci 258:7327-7329

[107] Li X, Zhao Y, Wu W, Chen J, Chu G, Zou H (2014) Synthesis and characterizations of graphene-copper nanocomposites and their antifriction application. J Ind Eng Chem 20:2043-2049

[108] Peng Y, Hu Y, Han L, Ren C (2014) Ultrasound-assisted fabrication of dispersed two-dimensional copper/reduced graphene oxide nanosheets nanocomposites. Compos Part B Eng 58:473-477

[109] Wang L, Cui Y, Li R, Cao G, Li B, Fei W (2014) Effect of reduction temperature on the properties of reduced graphene oxide and copper matrix composites. Acta Metall Sin (Eng1 Lett) 27:924-929

[110] Jia Z, Chen T, Wang J, Ni J, Li H, Shao X (2015) Synthesis, characterization and tribological properties of $\mathrm{Cu}$ reduced graphene oxide composites. Tribol Int 88:17-24

[111] Yang J, Shen X, Ji Z, Zhou H, Zhu G, Chen K (2015) Insitu growth of $\mathrm{Cu}$ nanoparticles on reduced graphene oxide nanosheets and their excellent catalytic performance. Ceram Int 41:4056-4063

[112] Kamboj A, Raghupathy Y, Rekha MY, Srivastava C (2017) Morphology, texture and corrosion behavior of nanocrystalline copper-graphene composite coatings. JOM 69:1149-1154

[113] Raghupathy Y, Kamboj A, Rekha MY, Narasimha Rao NP, Srivastava C (2017) Copper-graphene oxide composite coatings for corrosion protection of mild steel in 3.5\% $\mathrm{NaCl}$. Thin Solid Films 636:107-115

[114] Maharana HS, Rai PK, Basu A (2017) Suface-mechanical and electrical properties of pulse electrodeposited $\mathrm{Cu}$-graphene oxide composite coating for electrical contacts.
J Mater Sci 52:1089-1105. https://doi.org/10.1007/s10853016-0405-7

[115] Yin S, Zhang Z, Ekoi EJ, Wang JJ, Dowling DP, Nicolosi V (2017) Novel cold spray for fabricating graphene reinforced metal matrix composites. Mater Lett 196:172-175

[116] Suryanarayana C (2001) Mechanical alloying and milling. Prog Mater Sci 46:1-184

[117] Munir ZA, Anselmi-Tamburini U, Ohyanagi M (2006) The effect of electric field and pressure on the synthesis and consolidation of materials: a review of spark plasma sintering method. J Mater Sci 41:763-777. https://doi.org/10. 1007/s10853-006-6555-2

[118] Li X, Cai W, An J, Kim S (2009) Large-area synthesis of high-quality and uniform graphene films on $\mathrm{Cu}$ foils. Science 324:1312-1314

[119] de Jongh PE, Eggenhuisen TM (2013) Melt infiltration: an emerging technique for the preparation of novel functional nanostructured materials. Adv Mater 25:6672-6690

[120] German RM, Suri P, Park SJ (2009) Review: liquid phase sintering. J Mater Sci 44:1-39. https://doi.org/10.1007/s10 853-008-3008-0

[121] Ryu SS, Kim YD, Noon IH (2002) Dilatometric analysis on the sintering behavior of nanocrystalline $\mathrm{W}-\mathrm{Cu}$ prepared by mechanical alloying. J Alloys Compd 335:233-240

[122] Doré F, Lay S, Eustathopoulos N, Allibert CH (2003) Segregation of $\mathrm{Fe}$ during the sintering of doped $\mathrm{W}-\mathrm{Cu}$ alloys. Scr Mater 49:237-242

[123] Assadi H, Kreye H, Gärtner F, Klassen T (2016) Cold spraying - a materials perspective. Acta Mater 116:382-407

[124] Saito Y, Tsuji N, Utsunomiya H, Sakai T, Hong RG (1998) Ultra-fine grained bulk aluminum produced by accumulative roll-bonding (ARB) process. Scr Mater 9:1221-1227

[125] Tsuji N, Saito Y, Lee SH, Minamino Y (2003) ARB (accumulative roll-bonding) and other new techniques to produce bulk ultrafine grained materials. Adv Eng Mater 5:338-344

[126] Jamaati R, Toroghinejad MR (2010) Application of ARB process for manufacturing high-strength, finely dispersed and highly uniform $\mathrm{Cu} / \mathrm{Al}_{2} \mathrm{O}_{3}$ composite. Mater Sci Eng A 527:4858-4863

[127] Alizadeh M, Paydar MH, Terada D, Tsuji N (2012) Effect of $\mathrm{SiC}$ particles on the microstructure evolution and mechanical properties of aluminum during ARB process. Mater Sci Eng A 540:13-23

[128] Rezayat M, Akbarzadeh A (2012) Bonding behavior of Al$\mathrm{Al}_{2} \mathrm{O}_{3}$ laminations during roll bonding process. Mater Des 36:874-879

[129] Ghaderi O, Toroghinejad MR, Najafizadeh A (2013) Investigation of microstructure and mechanical properties 
of $\mathrm{Cu}-\mathrm{SiC}_{\mathrm{p}}$ composite produced by continual annealing and roll-bonding process. Mater Sci Eng A 565:243-249

[130] Chuan X, Chen D, Zhou X (1997) Intercalation of $\mathrm{CuCl}_{2}$ into expanded graphite. Carbon 35:311-313

[131] Nardone VC, Prewo KM (1986) On the strength of discontinuous silicon carbide reinforced aluminium composites. Scr Metall 20:43-48

[132] Halpin JC, Kardos KL (1976) The Halpin-Tsai equations: a review. Polym Eng Sci 16:344-352

[133] Hall EO (1951) The deformation and ageing of mild steel: III discussion of results. Proc Phys Soc Lond B 64:747-753

[134] Petch NJ (1953) The cleavage strength of polycrystals. J Iron Steel Inst 174:25-28

[135] Orowan E (1934) Zur Kristallplastizität. III. Über den Mechanismus des Gleitvorgages. Z Phys 89:634-659

[136] Ardell AJ (1985) Precipitation hardening. Metall Mater Trans A 16:2131-2165

[137] Clyne TW, Withers PJ (1993) An introduction to metal matrix composites. Cambridge University Press, Cambridge

[138] Arsenault RJ, Shi N (1986) Dislocation generation due to differences between the coefficients of thermal expansion. Mater Sci Eng A 81:175-187

[139] Ashby MF (1970) The deformation of plastically non-homogeneous materials. Philos Mag 21:399-424

[140] Hidalgo-Manrique P, Yan SJ, Lin F, Hong QH, Kinloch IA, Chen X, Young RJ, Zhang XY, Dai SL (2017) Microstructure and mechanical behaviour of aluminium matrix composites reinforced with graphene oxide and carbon nanotubes. J Mater Sci 52:13466-13477. https://doi. org/10.1007/s10853-017-1450-6

[141] Young RJ, Liu MF, Kinloch IA, Li SH, Zhao X, Vallés C, Papageorgiou DG (2018) The mechanics of reinforcement of polymers by graphene nanoplatelets. Compos Sci Technol 154:110-116

[142] Dikin DA, Stankovich S, Zimney EJ, Piner RD, Dommett GHB, Evmenenko G, Nguyen ST, Ruoff RS (2007) Preparation and characterization of graphene oxide paper. Nature 448:457-460

[143] Gómez-Navarro C, Burghard M, Kern K (2008) Elastic properties of chemically-derived single graphene sheets. Nano Lett 8:2045-2049

[144] Suk JW, Piner RD, An J, Ruoff RS (2010) Mechanical properties of monolayer graphene oxide. ACS Nano 4:6557-6564

[145] Ruiz-Vargas CS, Zhuang HL, Huang PY, van der Zande AM, Garg S, McEuen PL, Muller DA, Hennig RG, Park J (2011) Softened elastic response and unzipping in chemical vapor deposition graphene membranes. Nano Lett 11:2259-2263
[146] Nicholl RJT, Conley HJ, Lavrik NV, Vassiouk I, Puzyrev YS, Sreenivas VP, Pantelides ST, Bolotin KI (2015) The effect of intrinsic crumpling on the mechanics of free-standing graphene. Nat Commun 6:8789

[147] Zhang Y, Pan C (2012) Measurement of mechanical properties and number of layers of graphene from nano-indentation. Diam Relat Mater 24:1-5

[148] Lee C, Li QY, Kalb W, Liu XZ, Berger H, Carpick RW, Hone J (2010) Frictional characteristics of atomically thin sheets. Science 328:76-80

[149] Ahmad SNAS, Hashim J, Ghazali MI (2007) Effect of porosity on tensile properties of cast particle reinforced MMC. J Compos Mater 41:575-589

[150] Oliver WC, Pharr GM (1992) An improved technique for determining hardness and elastic modulus using load and displacement sensing indentation experiments. J Mater Res 7:1564-1583

[151] Oliver WC, Pharr GM (2004) Measurement of hardness and elastic modulus by instrumented indentation: advances in understanding and refinements to methodology. J Mater Res 19:3-20

[152] Xia X, Su Y, Zhong Z, Geng GJ (2017) A unified theory of plasticity, progressive damage and failure in graphenemetal nanocomposites. Int J Plast 99:58-80

[153] Chang SW, Nair AK, Buehler MJ (2012) Geometry and temperature effects of the interfacial thermal conductance in copper-and-nickel-graphene nanocomposites. J Phys Condens Mater 24:245301(6 pp)

[154] Chen L, Huang Z, Kumar S (2013) Phonon transmission and thermal conductance across graphene $/ \mathrm{Cu}$ interface. Appl Phys Lett 103:123110

[155] Schey JA (1984) Tribology in metalworking: friction, lubrication and wear. ASM, Metals Park

[156] Chmielewski M, Michalczewski R, Piekoszewski W, Kalbarczyk M (2016) Tribological behaviour of copper-graphene composite materials. Key Eng Mater 674:219-224

[157] Archard F (1953) Contact and rubbing of flat surfaces. J Appl Phys 24:981-988

[158] Maharana HS, Jena S, Basu A, Mondal K (2018) High temperature oxidation resistance of electrodeposited Reduced Graphene Oxide (RGO) reinforced copper coating. Surf Coat Technol 345:140-151

[159] Kinloch IA, Suhr J-W, Lou J, Young RJ, Ajayan PM (2018) Composites with carbon nanotubes and graphene: an outlook. Science 362:547-553

Publisher's Note Springer Nature remains neutral with regard to jurisdictional claims in published maps and institutional affiliations. 